Aus der Arbeitsgruppe Entwicklungsbiologie in der Abteilung Molekulare Zellbiologie

(Prof. Dr. rer. nat. P. Gruss)

des Max-Planck-Instituts für biophysikalische Chemie in Göttingen

und

aus der Abteilung Entwicklungsbiochemie

(Prof. Dr. rer. nat. T. Pieler)

im Zentrum Biochemie und Molekulare Zellbiologie

der Medizinischen Fakultät der Universität Göttingen

\title{
Molekulare Analyse eines Homöobox-Gen-Promotors in der Gehirnanlage von Wirbeltierembryonen
}

\author{
INAUGURAL-DISSERTATION \\ zur Erlangung des Doktorgrades \\ der Medizinischen Fakultät \\ der Georg-August-Universität zu Göttingen
}

vorgelegt von

Derek Spieler

aus Bremen

Göttingen 2002 
Dekan:

Prof. Dr. med. M. Droese

1. Berichterstatter: Prof. Dr. rer. nat. T. Pieler

2. Berichterstatter/in:

3. Berichterstatter/in:

Tag der mündlichen Prüfung: 


\section{Inhaltsverzeichnis}

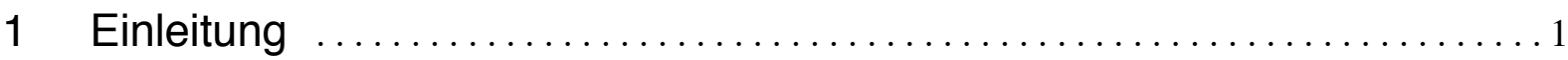

1.1 Die Familie der Transkriptionsfaktoren mit einer Homöodomäne $\ldots \ldots \ldots \ldots 3$

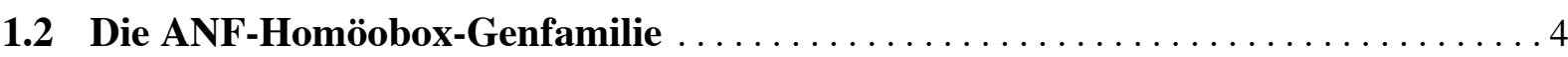

1.3 GANF im Kontext der neuralen Induktion, der Entstehung anteriorer neuraler Strukturen und der Entstehung der Adenohypophyse $\ldots \ldots \ldots \ldots \ldots \ldots \ldots$

1.3.1 Die frühe Entwicklung des Hühnerembryos und die neurale Induktion $\ldots \ldots \ldots \ldots \ldots \ldots$

1.3.2 Gastrulation und die Ausbildung der definitiven Körperstruktur und Körperachse . . . . . . .7

1.3.3 Ein zusätzliches Signalzentrum bei Säugetierembryonen $\ldots \ldots \ldots \ldots \ldots \ldots \ldots \ldots$

1.3.4 Der Transkriptionsfaktor GANF als Teil der molekularen Faktoren, die zu anteriorer

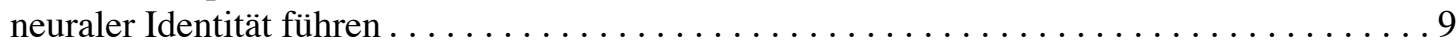

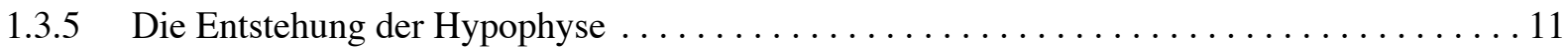

1.4 Mutationen in Entwicklungsgenen als ätiologische Ursache von Erkrankungen . 13

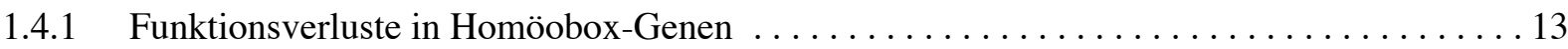

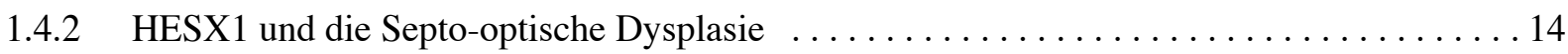

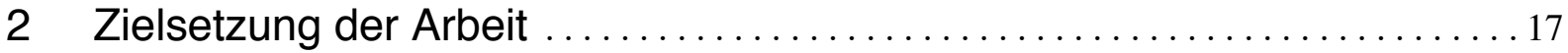

3 Material und Methoden ..................................... 18

3.1 Plasmide, Antikörper, Bakteriophagen und Organismen $\ldots \ldots \ldots \ldots \ldots \ldots$

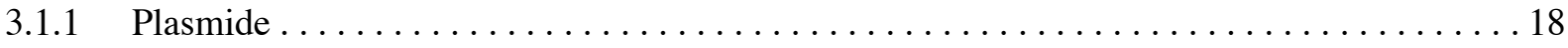

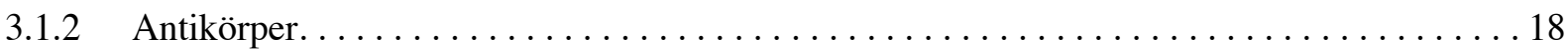

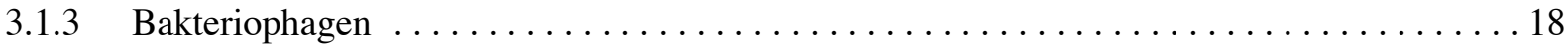

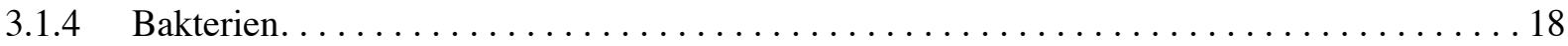

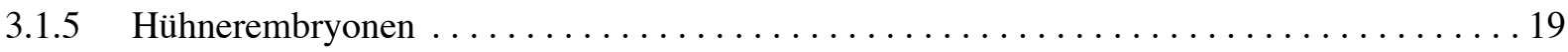

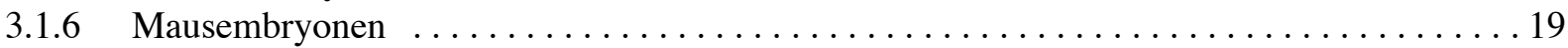

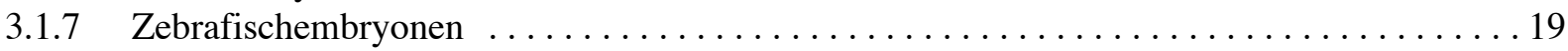

3.2 Computerprogramme, Datenbanken und Fotomaterialien $\ldots \ldots \ldots \ldots \ldots \ldots \ldots$

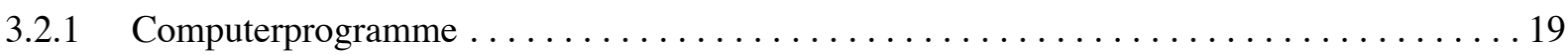

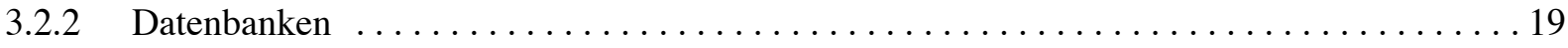

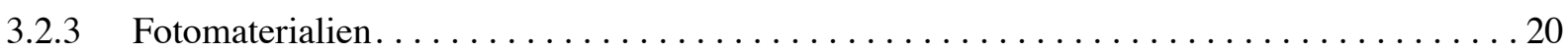

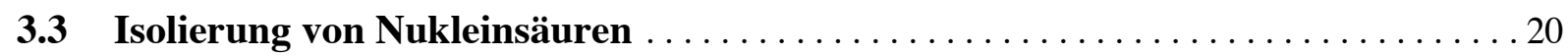

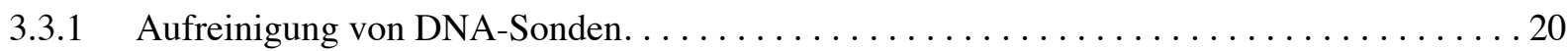

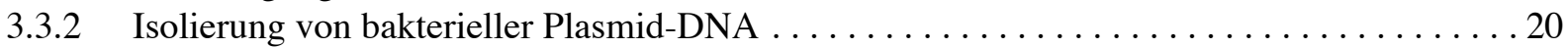

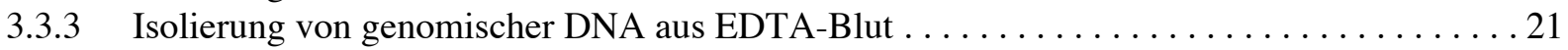

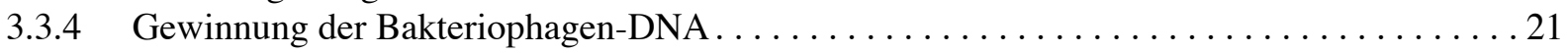

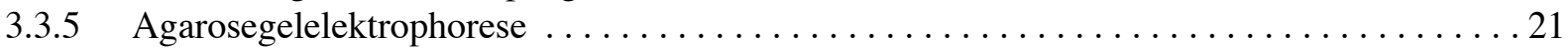

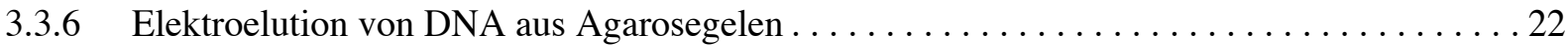

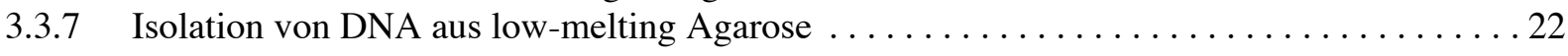

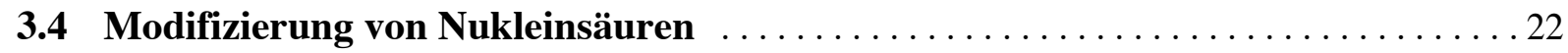

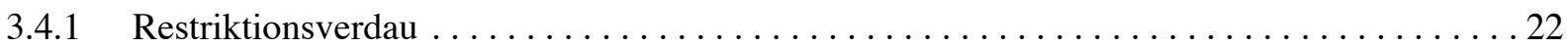

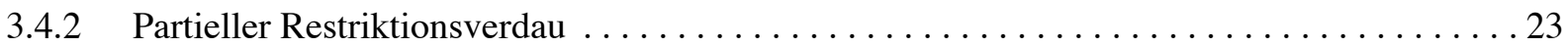

3.4.3 Dephosphorylierung der 5' -Enden von DNA-Fragmenten $\ldots \ldots \ldots \ldots \ldots \ldots \ldots \ldots \ldots \ldots \ldots$

3.4.4 Erzeugung von glatten Enden bei geschnittenen DNA-Fragmenten mit 5'-überhängenden

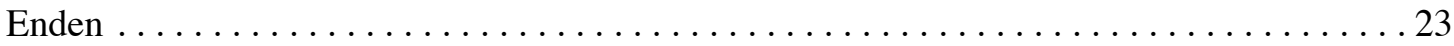


3.4.5 Erzeugung von glatten Enden bei geschnittenen DNA-Fragmenten mit 3'-überhängenden

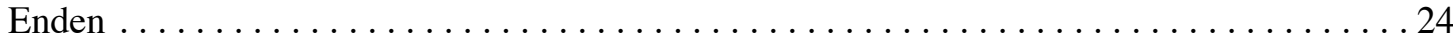

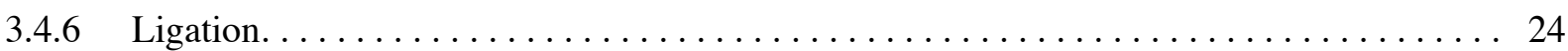

3.4.7 Herstellung von mit Digoxygenin und Fluoreszein markierten Sonden . . . . . . . . . . 24

3.4.8 Herstellung von radioaktiv markierten DNA-Molekülen mittels ${ }^{32}$ Phosphor- $\alpha$-dCTP . . . . 25

3.4.9 Radioaktive Markierung der für den EMSA benötigten Oligonukleotide . . . . . . . . . 25

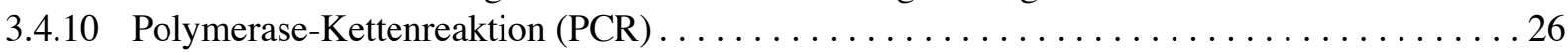

3.4.11 Vorbereitung der DNA zur Injektion in einen Zebrafischembryo $\ldots \ldots \ldots \ldots \ldots \ldots .27$

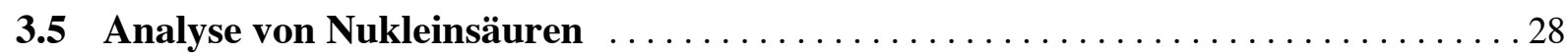

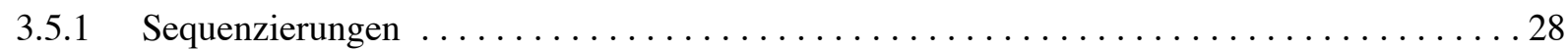

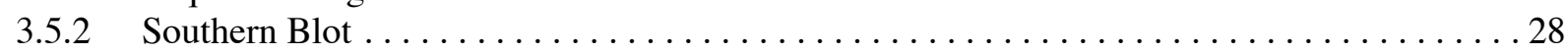

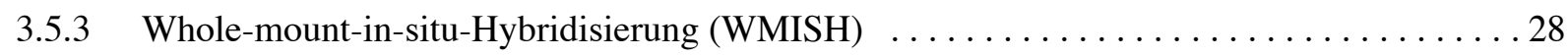

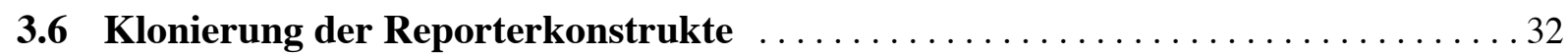

3.6.1 Erzeugung einer NcoI-Schnittstelle im Startkodon des lacZ-Gens im pßgal-BASIC . . . . . 32

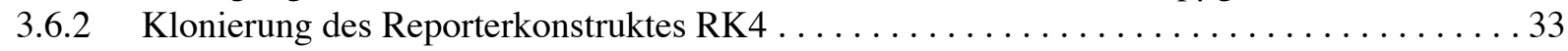

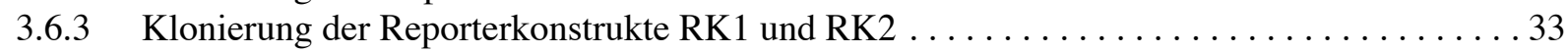

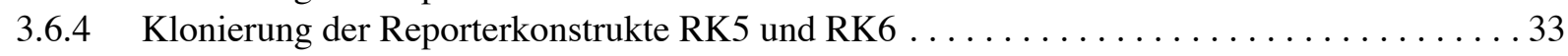

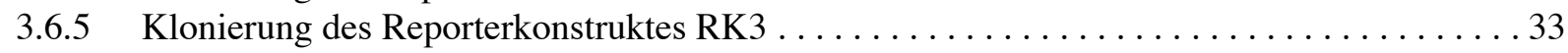

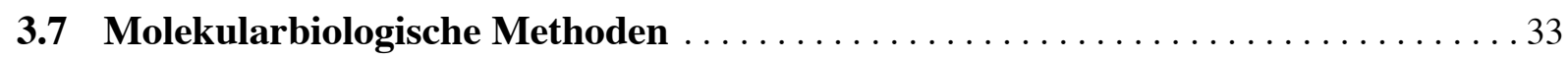

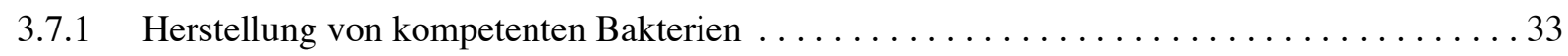

3.7.2 Transformation von Bakterien durch Elektroporation $\ldots \ldots \ldots \ldots \ldots \ldots \ldots \ldots \ldots \ldots \ldots \ldots$

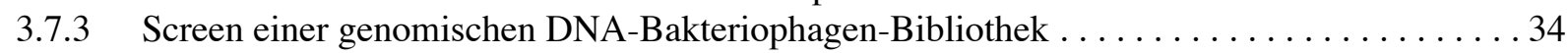

3.7.4 Elektrophoretische Gelretardationsexperimente mit radioaktiv markierten Oligonukleotiden

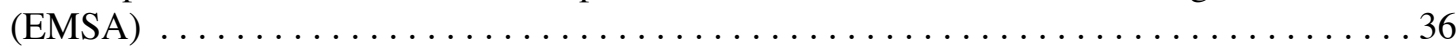

3.7.4.1 In-vitro-Translation zur Überexpression von Proteinen (TNT-system, Promega) . . . . . . . 36

3.7.4.2 SDS-Polyacrylamidgelelektrophorese zur Auftrennung von ${ }^{35} \mathrm{~S}-$ Methionin-markierten

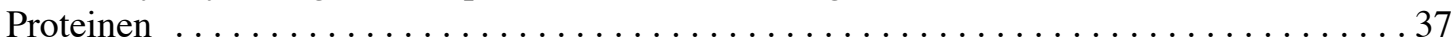

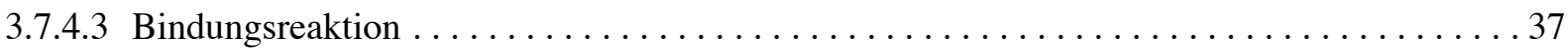

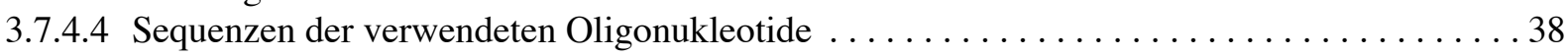

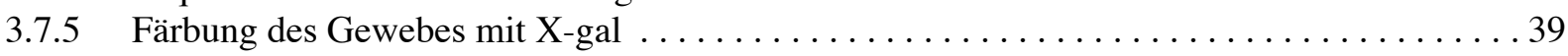

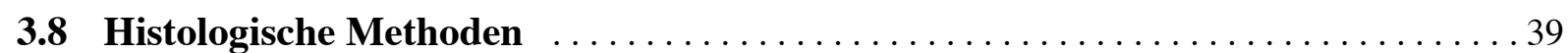

3.8.1 Anfertigung von Paraffinschnitten ..................................... 39

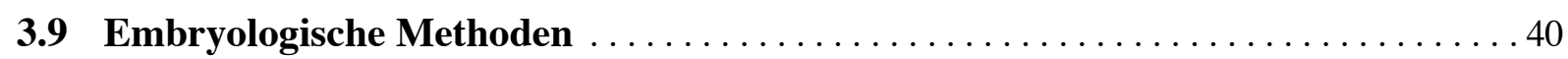

3.9.1 In-vitro-Kultivierung von Hühnerembryonen: die ec-Kultur $\ldots \ldots \ldots \ldots \ldots \ldots \ldots \ldots$

3.9.2 Gen-Transfer in kultivierte Hühnerembryonen mit Hilfe einer im Rahmen dieser Arbeit neu

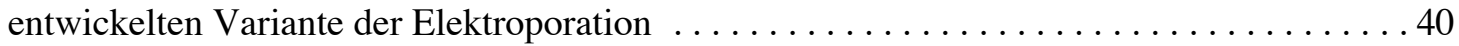

3.9.3 Erzeugung von transgenen Mäusen mittels Mikroinjektion $\ldots \ldots \ldots \ldots \ldots \ldots \ldots \ldots 42$

3.9.4 Mikroinjektion von DNA in die Pronuklei von fertilisierten Oozyten des Zebrafisches . . . 42

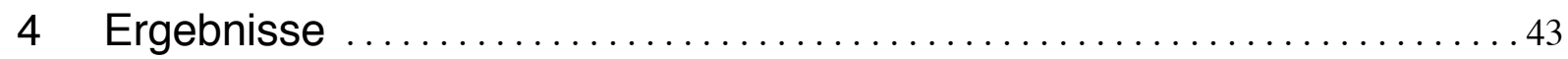

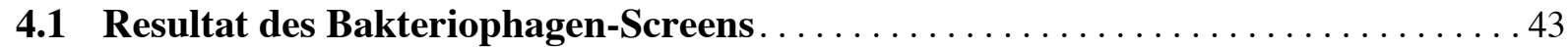

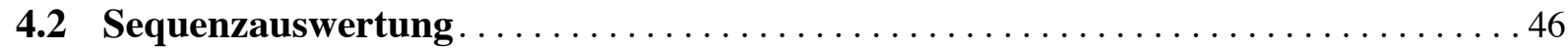

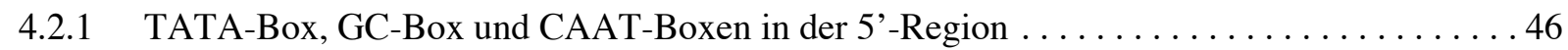

4.2.2 In der 5'-Region von GANF befindet sich eine CpG-Insel . . . . . . . . . . . . . . . . . . 46

4.2.3 Die Region um das Startkodon von GANF stimmt zu $80 \%$ mit der Kozak-Sequenz überein 46

4.2.4 Ca. 600 Nukleotide sind direkt vor dem Startkodon der Orthologen der ANF-Homöobox-

Genfamilie von Mensch, Maus, Frosch und Huhn konserviert . . . . . . . . . . . . . . . . . 46

4.3 Übersicht über die klonierten Reporterkonstrukte $\ldots \ldots \ldots \ldots \ldots \ldots \ldots \ldots \ldots$ 


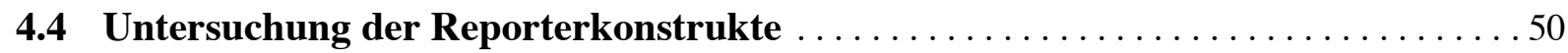

4.4.1 Reporterkonstrukte RK2 und RK4 zeigen anteriore Expression im Huhn. . . . . . . . . . 50

4.4.2 Reporterkonstrukt RK2 und Reporterkonstrukt RK6 zeigen X-gal-Färbung im prospektiven Prosenzephalon des Zebrafisches, während Reporterkonstrukt RK3 gar keine X-gal-Färbung

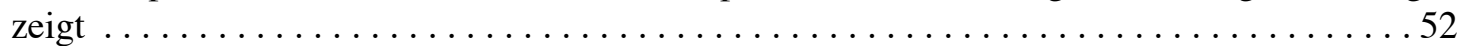

4.4.3 Die Reporterkonstrukte RK2 und RK4 zeigen keine X-gal-Färbung in der Maus . . . . . . 55

4.5 Potenzielle Bindungspartner des GANF-Promotors $\ldots \ldots \ldots \ldots \ldots \ldots \ldots \ldots \ldots \ldots$

4.5.1 Das Homöobox-Gen Otx2 bindet an zwei Stellen des GANF-Promotors . . . . . . . . . . . . . . 56

4.5.2 Eine nahe liegende Bindungssequenz für GANF wird von GANF nicht spezifisch gebunden 56

4.5.3 Das Paired-Homöobox-Gen Pax6 bindet an den GANF-Promotor . . . . . . . . . . . . . . . . . . 57

4.6 Molekulare Untersuchung von Patienten mit der Septo-optischen Dysplasie . . . . 58

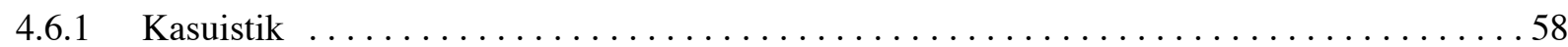

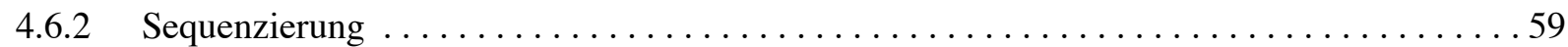

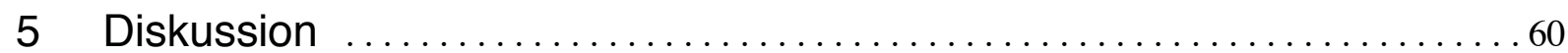

5.1 TATA-Box, CpG-Insel und Kozak-Sequenz $\ldots \ldots \ldots \ldots \ldots \ldots \ldots \ldots \ldots \ldots \ldots \ldots \ldots \ldots \ldots \ldots$

5.2 Die Untersuchung der Reporterkonstrukte $\ldots \ldots \ldots \ldots \ldots \ldots \ldots \ldots \ldots \ldots \ldots \ldots$

5.2.1 Untersuchung der Reporterkonstrukte im Huhn mittels Elektroporation . . . . . . . . . . 61

5.2.1.1 Anwendungsbereich der neu entwickelten Variante der Elektroporation . . . . . . . . . . 61

5.2.1.2 Der konservierte Bereich und die Untersuchung der Reporterkonstrukte RK2 und RK4 legen die Begrenzung der Promotorregion von GANF auf ca. 600 bp nahe . . . . . . . . 62

5.2.2 Die Injektionen der Reporterkonstrukte RK2, RK3 und RK6 in den Zebrafisch belegen in-vivo die Konservierung der Promotorregion der ANF-Homöobox-Genfamilie . . . . . . . 62

5.2.3 Reporterkonstrukte RK2 und RK4 zeigen keine Färbung in der Maus . . . . . . . . . . 63

5.3 Interaktionspartner mit dem GANF-Promotor: Otx2, GANF und Pax6 . . . . . . 64

5.3.1 Das Homöobox-Gen Otx2 als für die Expression von GANF notwendiger Aktivator? . . . . 64

5.3.2 Kein Hinweis auf eine autoregulative Kontrolle von GANF $\ldots \ldots \ldots \ldots \ldots \ldots \ldots \ldots$

5.3.3 Das Homöobox-Gen Pax6 als möglicher Repressor von GANF? . . . . . . . . . . . . . . 65

5.4 Diskussion des Ergebnisses der Sequenzierung der Patienten-DNA $\ldots \ldots \ldots \ldots 6$

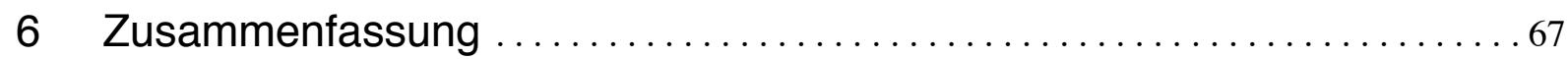

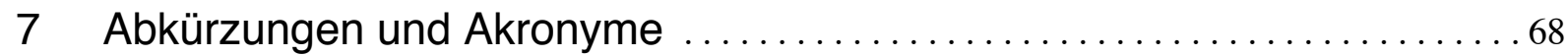

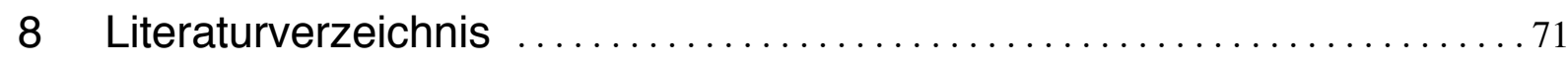




\section{Einleitung}

Nahezu alle Zellen eines adulten Organismus verfügen über die gleiche Ausstattung an Genen, unterscheiden sich aber in Bezug auf Form und Funktion sehr stark voneinander. Der Grund hierfür liegt in der unterschiedlichen Genexpression: Jede Zelle exprimiert nur eine begrenzte Anzahl ihrer Gene zu einem bestimmten Zeitpunkt. Nur diese Gene tragen zu der spezifischen Identität der jeweiligen Zelle bei.

Für die Entwicklung eines Organismus ist diese differentielle Genexpression ebenfalls grundlegend. Die befruchtete Eizelle verfügt über eine ganz andere Zusammenstellung von exprimierten Genen als eine ihrer differenzierteren Nachkommen. die Entwicklung eines Organismus kann demnach als Folge von nacheinander bzw. parallel verlaufenden unterschiedlichen Genexpressionsmustern verstanden werden, die in ihrer Gesamtheit Grundlage für Vorgänge wie zum Beispiel Proliferation, Differenzierung, Migration oder Apoptose sind, welche man während der Entwicklung eines Organismus beobachtet (Abbildung 1). Die differentielle Expression ermöglicht außerdem, auf Umwelteinflüsse - wie zum Beispiel eine Verletzung - zu reagieren. Defekte in der Genexpression können zu einer Vielzahl von unterschiedlichen Erkrankungen führen (siehe dazu 1.4).

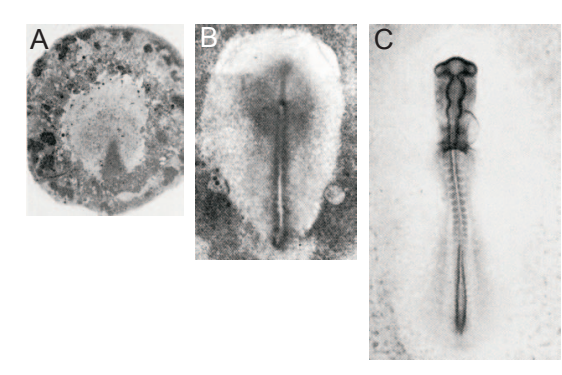

Abb.1: Die Entwicklung des Huhns
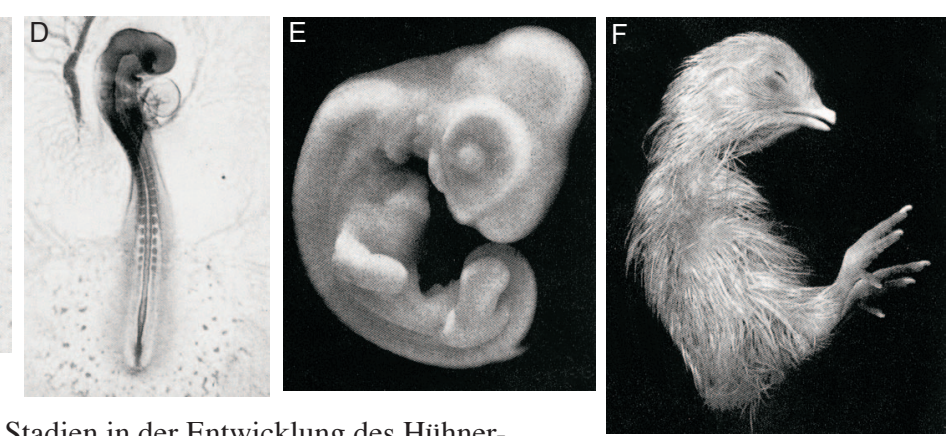

(Gallus gallus). (A-F) zeigen verschiedene Stadien in der Entwicklung des Hühner-

embryos. Die Einteilung folgt der von Hamburger und Hamilton (1951), daher die Abkürzung HH. A) HH2 (Entwicklung nach 6-7 h Inkubation), (B) HH5 (nach 22 h), (C) HH11 (nach 45 h), (D) HH14 (nach 55 h), (E) HH25 (nach 4,5 d), (F) HH41 (nach 15 d). Das Küken schlüpft am 20 d. Abbildungen (A)-(F) sind entnommen aus Hamburger und Hamilton (1951, A, Seite 251; B, Seite 252; C, D, Seite 255; E, Seite 261; F, Seite 262). Alle sechs verschiedenen Stadien sind in unterschiedlichem Maßstab abgebildet.

Drei unterschiedliche Arten von Molekülen spielen im Rahmen der Genexpression eine grundlegende Rolle: die DNA, die RNA und Proteine. DNA speichert die genetische Information. Sie ist ein stabiles polymeres Molekül, das im Zellkern einer eukaryontischen Zelle vorliegt. Dort ist sie - je nach Organismus in unterschiedlicher Anzahl - als Chromosom organisiert (Abbildung 2, Seite 2). Der erste Schritt der Expression eines Genes ist die Übersetzung der DNA in RNA, die Transkription. Die Struktur eines RNA-Moleküls wird dabei genau durch das Gen festgelegt, das eine Matrize für die Synthese der RNA darstellt. Die RNA dient im Anschluss selbst als Matrize für die Synthese eines Proteins, ein Prozess, den man Translation nennt. Die Auswahl der Proteine, die produziert werden, das Proteom einer Zelle, ist somit abhängig von den anwesenden RNA-Molekülen, dem Transkriptom. Dies basiert 
darauf, welche Gene - als Teile des Genoms - exprimiert werden. Genexpression ist somit grundlegend für die Natur, die Identität eines Organismus.

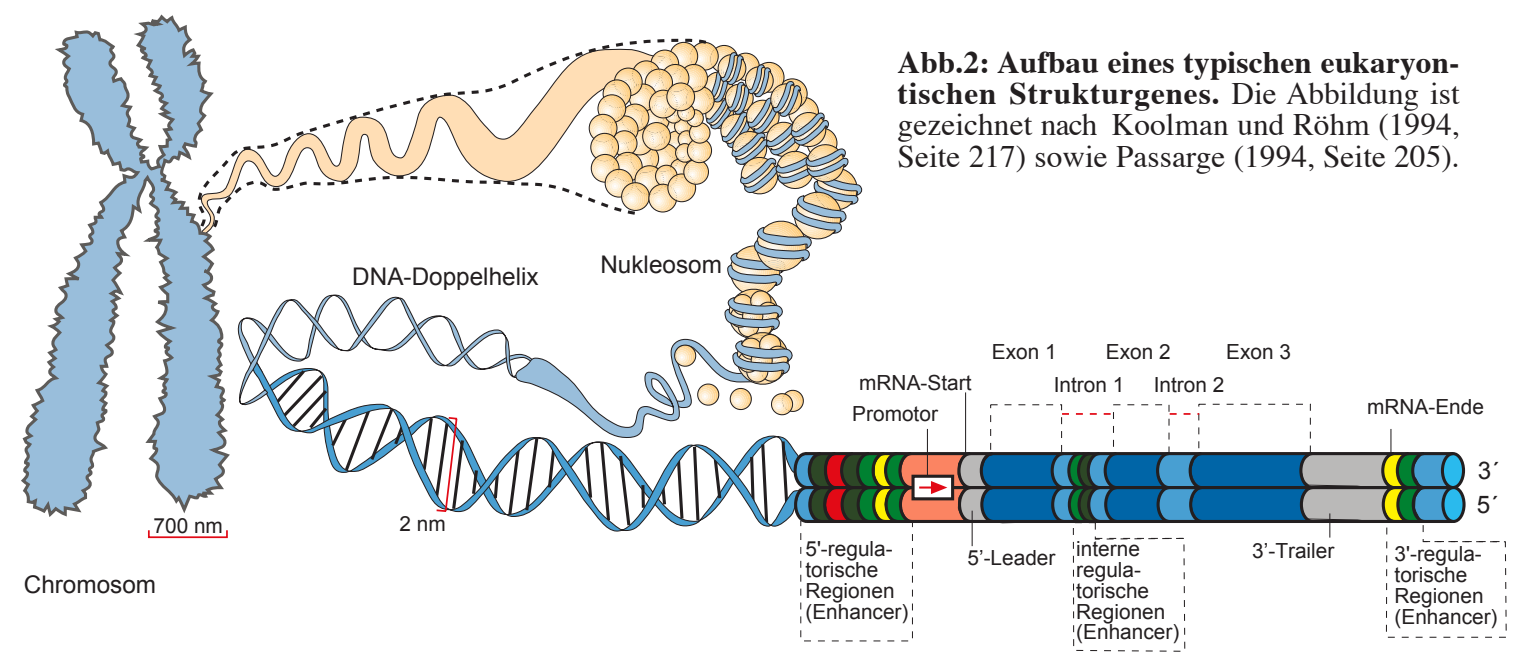

Im Mittelpunkt der Regulation der Genexpression steht die Kontrolle der Transkription (Emerson 2002; White 2001). Im Rahmen dieser Kontrollebene sind DNA bindende Proteine, sogenannte Transkriptionsfaktoren, von grundlegender Bedeutung, da sie - stark vereinfacht - spezifisch die RNAPolymerase II so aktivieren können, dass diese die mRNA eines bestimmten Genes synthetisiert. Die Spezifität dieser Transkriptionsfaktoren liegt in bestimmten Domänen begründet, die es ihnen erlauben, für sie typische Sequenzabschnitte spezifisch zu binden. Diese Regionen werden Enhancer genannt. Enhancer können sehr weit, d. h. mehrere Kilobasen, von den Exons entfernt sein, sie können $3^{6}$-wärts, in einem Intron oder mehreren Introns oder 5'-wärts liegen. Letzteres ist am häufigsten beschrieben (siehe Abbildung 2). Es kommt zu einer Aktivierung der in der basalen Transkriptionseinheit eingebundenen RNA-Polymerase II. Die Region, an die die basale Transkriptionseinheit bindet, bezeichnet man als Promotor (siehe Abbildung 2). Oft wird jedoch auch vereinfachend die gesamte Region, die die Transkription eines Genes steuert, Promotor genannt.

Transkriptionsfaktoren lassen sich in verschiedene Familien einordnen. Zur Illustration einiger bis jetzt beschriebener DNA bindender Polypeptidstrukturen sind in Abbildung 3 (Seite 3) Vertreter der Familie mit einer Homöodomäne, einer bHLHzip-Domäne und einem $\mathrm{C}_{2} \mathrm{H}_{2}$-Zinkfinger-Motiv sowie das TATA-bindende Protein als Teil der basalen Transkriptionseinheit gezeigt. Nicht gezeigt sind Beispiele weiterer Familien, die mit einer bzip-Domäne, einer bHLH-Domäne, einem $\mathrm{C}_{2} \mathrm{C}_{2}$-Zinkfinger-Motiv, sowie singuläre Varianten. Ihre Namen beschreiben meistens strukturelle Besonderheiten.

Die vorliegende Arbeit beschäftigt sich mit der Kontrolle der Transkription eines die Transkription kontrollierenden Proteins, dem Homöobox-Gen GANF. GANF ist das Ortholog des Huhns (Gallus gallus) der ANF-Homöobox-Genfamilie, die im anterioren Teil von Vertebraten früh in der Entwicklung 
exprimiert ist. Im Mittelpunkt dieser Einleitung stehen daher die Beschreibung der morphologischen Prozesse, insofern sie für GANF von Bedeutung sind, sowie die besondere Betrachtung der Faktoren, die für die Kontrolle der Transkription von GANF in Frage kommen. Am Ende der Einleitung folgt die Vorstellung des Krankheitsbildes der Septo-optischen Dysplasie, eines Syndroms, das u. a. auf Mutationen im menschlichen ANF-Orthologen HESX1 zurückgeführt wurde. Zunächst beginnt die Einleitung mit einer Vorstellung der Homöobox-Transkriptionsfaktoren im Allgemeinen und einer Einführung in die ANF-Homöobox-Genfamilie im Speziellen.

A

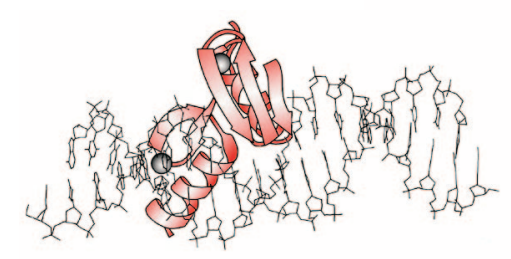

B

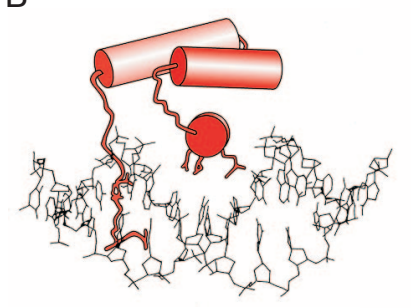

C

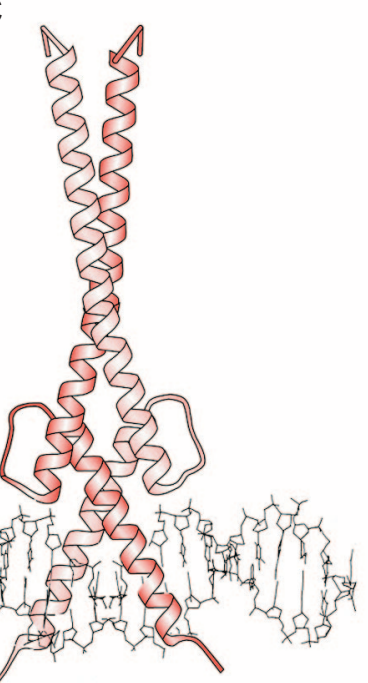

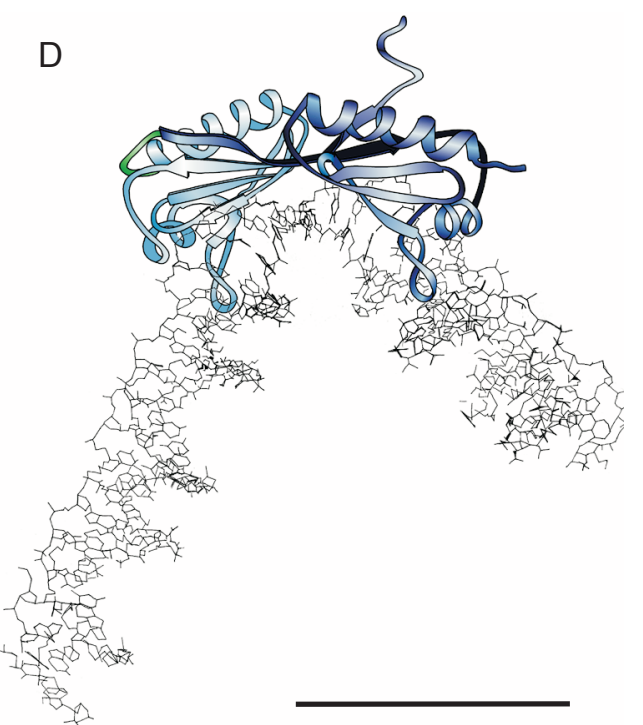

Abb. 3: Strukturen von vier DNA bindenden Proteinen. Blau ist das TBP als Teil der basalen Transkriptionsmaschine dargestellt, rot die übrigen spezifischen Transkriptionsfaktoren. Alle Darstellungen basieren auf röntgenkristallographischen Untersuchungen. Die DNA ist als atomares Stabmodell, die Proteine sind als Bandmodelle nach Richardson dargestellt; $\alpha$-Helix=Spirale/Zylinder, $\beta$-Faltblatt=Pfeil. Der Balken entspricht ungefähr der Distanz von 3,5 nm. (A) Struktur der zwei $\mathrm{C}_{2} \mathrm{H}_{2}$-Zinkfinger des Proteins Tramtrack (Drosophila melanogaster). Es kontrolliert die Transkription des ftzGenes. Zinkionen sind als graue Kugeln dargestellt. (B) Struktur des Homöoboxgenes engrailed. Dunkelrot ist das HelixSchleife-Helix-Motiv abgebildet, welches Kontakt zur großen Furche hat. Hellrot ist der übrige N-terminale Teil gezeigt, dessen Arm Kontakt zur kleinen Furche hat. (C) Struktur der bHLH-ZIP-Domäne eines Homodimers des Onkogenes Max; jeweils in hellrot und dunkelrot. (D) Struktur des TATA bindenden Proteins (TBP) der Hefe, gebunden an DNA. Die sattelähnliche Struktur besteht aus zwei ähnlich aufgebauten Domänen (hellblau und dunkelblau), verbunden durch eine Schleife (grün).Die Unterseite des Sattels und beide Steigbügel biegen die DNA im Winkel von circa $80^{\circ}$. Abbildungen modifiziert nach White (2001, A, Seite 41), Kissinger et al. (1990, B, Seite 582), Ferre-D'Amare et al. (1993, C, Seite 43) und Nikolov und Burley (1994, D, Seite 623).

\subsection{Die Familie der Transkriptionsfaktoren mit einer Homöodomäne}

Bei der Familie der Transkriptionsfaktoren mit einer Homöodomäne ist nicht eine strukturelle Besonderheit für die Namensgebung verantwortlich. Grundlage für den Namen sind Mutationen, die in einigen Genen dieser Familie zu homöotischen Variationen führen (Bateson 1894). Darunter versteht man die Umformung eines Körperteils nach der Form und Funktion eines anderen: die Zellen werden falsch über ihre Lokalisation im Organismus unterrichtet und bilden eine Struktur, die für eine andere Stelle im Körper angemessen wäre (Kessel und Gruss 1991). Zum Beispiel führt die bei Drosophila melano- 
gaster beobachtete Mutation Antennapedia zur Bildung von Beinen anstelle der Antennen (Regulski et al. 1985).

Die Homöobox kodiert die DNA bindende Domäne dieser Transkriptionsfaktorfamilie; sie ist in den meisten Fällen 61 Aminosäuren lang, also kodiert von 183 bp, und weist ein Helix-Schleife-HelixMotiv auf (siehe Abbildung 3 (B), Seite 3). Dies ist eine stark konservierte Polypeptidstruktur, die man auch in prokaryontischen sowie viralen, mit der DNA interagierenden Proteinen findet (Gehring et al. 1994a; Gehring et al. 1994b; Steitz 1990). Die Homöodomäne bindet sehr häufig DNA-Sequenzen, deren Kern aus den Basenpaaren TAAT (bzw. ATTA) besteht. Zuerst wurden Homöodomänen bei Genen gefunden, die die Entwicklung von Drosophila melanogaster steuern. Mittlerweile sind sie auch bei vielen anderen metazoischen und pflanzlichen Transkriptionsfaktoren gefunden worden, die außerdem nicht nur Entwicklungsschritte kontrollieren. Ungefähr $1 \%$ aller Gene des Menschen, aber auch des Nematoden Caenorhabditis elegans enthalten eine Homöobox. $\mathrm{Zu}$ einer Untergliederung der Homöobox-Gene in die Genfamilien der Hox-Homöobox- (Gilbert 2000; Keynes und Krumlauf 1994), Paired-Homöobox- (Galliot et al. 1999; Mansouri et al. 1999), Lim-Homöobox- (Dawid und Chitnis 2001) und POU-Homöobox-Gene (Andersen und Rosenfeld 2001) führen zusätzliche Domänen, die Anordnung im Genom und/oder charakteristische Variationen der Homöobox.

\subsection{Die ANF-Homöobox-Genfamilie}

Die ANF-Homöobox-Gene gehören zu den paired-like Homöobox-Genen, welche durch Variationen der Homöodomäne des prd-Genes in Drosophila melanogaster gekennzeichnet sind. Die drei existierenden Unterfamilien der Paired-Homöobox-Gene sind u. a. nach der Aminosäure an Position 50 definiert, der eine Schlüsselrolle in der DNA-Bindung zukommt (Galliot et al. 1999). Bei der ANFHomöobox-Familie findet man dort ein Glutamin, sie gehört somit zu den $\mathrm{Q}_{50}$-Prd-ähnlichen Genen. Orthologe dieser Familie besitzen N-terminal eine zweite konservierte Region, die sogenannte Oktapeptid-Sequenz (FSIXXILX), die verwandt mit der sogenannten eh-1-Sequenz (FSIDNILS) ist. Dieser wird eine Rolle in der transkriptionellen Repression zugeschrieben (Smith und Jaynes 1996) und sie findet sich $u$. a. ebenfalls in dem Homöobox-Gen goosecoid und der $R X$-Homöobox-Genfamilie.

Die Expression von GANF wurde mittels Whole-mount-in-situ-Hybridisierung und RT-PCR untersucht (Kazanskaya et al. 1997; Knoetgen et al. 1999b). Bei der Beschreibung der Expression wird im Folgenden auf die Stadieneinteilung von Hamburger und Hamilton Bezug genommen. Sie wird mit den Buchstaben HH abgekürzt und orientiert sich an morphologischen Gesichtspunkten (Hamburger und Hamilton 1951). Im Stadium HH2 sind keine Transkripte zu finden. Sehr schwach ist die Expression in den folgenden Stadien (HH3-HH4), bis sie im Stadium HH5 äußerst stark zunimmt. Mit der Bildung der Kopffalte (engl.: head fold) im Stadium HH6 ist eine starke Expression im vorderen Bereich der 
Neuralplatte nachweisbar, während sie weiter posterior in der Mittellinie abnimmt. Wenn die Neuralfalten beginnen sich zu schließen (HH7), ist GANF sowohl am vorderen Teil der beiden Neuralfalten zu finden als auch in dem kleinen, diese beiden Domänen verbindenden Teil. Im Stadium HH9 findet man es im anterioren dorsalen Teil des Neuralrohres und im ventralen Oberflächenektoderm. Nach dem 10-Somiten-Stadium ist die Expression nur noch im oralen Ektoderm zu finden, welches im Stadium HH14 (22 Somiten) mit der Invagination beginnt und die Anlage der Adenohypophyse darstellt (Rathkes Tasche, siehe weiter unten). Zu diesem Zeitpunkt hört die Expression auf. Im adulten Organismus ist kein Transkript nachgewiesen worden. Bei den anderen entwicklungsbiologischen Modellorganismen (Frosch, Maus, Fisch und Kaninchen) verhält sich die Expression im neuralen Ektoderm gleich. Hinzu kommt bei den Säugern (Maus, Kaninchen) eine zweite Expressionsdomäne, das anteriore viszerale Endoderm (AVE), auf das im Kapitel 1.3.3 (Seite 8) genauer eingegangen wird.

Aus der englischen kurz gefassten Bezeichnung der Expressionsdomäne leitet sich der Name der ANFHomöobox-Genfamilie ab: anterior neural fold (dt.: vordere Neuralfalte). Je nach Spezies wurde jeweils der erste Buchstabe der lateinischen Gattungsbezeichung dem jeweiligen Ortholog vorangestellt: DANF (Danio rerio), XANF (Xenopus laevis), GANF (Gallus gallus) und HANF (Homo sapiens) (Kazanskaya et al. 1997). Sowohl für das menschliche als auch für das murine Ortholog sind jeweils die folgenden weiteren Bezeichnungen gebräuchlich: HESX1 (Homeobox expressed in Embryonic Stem cells, Homo sapiens) bzw. Hesx1 oder Rpx (Rpx, engl.: Rathke's Pouch Homeobox Gene, Mus musculus; Dattani et al. 1998; Hermesz et al. 1996; Thomas et al. 1995). Im Falle des menschlichen Orthologes spricht man allerdings ausschließlich von HESX1 (in Großbuchstaben zur Abgrenzung vom murinen, entsprechend den nomenklatorischen Regeln).

\subsection{GANF im Kontext der neuralen Induktion, der Entstehung anteri- orer neuraler Strukturen und der Entstehung der Adenohypophyse}

Zwei wesentliche morphogenetische Vorgänge fallen in den Zeitraum und den Ort der Expression von GANF: die Bildung anteriorer Strukturen des Embryos (die Induktion des prospektiven Kopfes) und der Beginn der Entstehung der Adenohypophyse. Beide sollen deshalb im Folgenden unter Berücksichtigung der möglichen direkten molekularen Interaktionspartner von GANF bzw. Hesx 1 dargestellt werden.

\subsubsection{Die frühe Entwicklung des Hühnerembryos und die neurale Induktion}

Die diskoidalen, telolezithalen und meroblastischen Zellteilungen der befruchteten Hühneroozyte führen zu einem Embryo, der noch im Eileiter (ca. 20 h nach der Befruchtung) die Form einer Zellscheibe 
annimmt, die Keimscheibe bzw. Blastoderm genannt wird, und dem Dotter oben aufsitzt (Gilbert 2000; Wolpert et al. 1998; siehe Abbildung 4). Diese Lage bestimmt insofern die dorso-ventrale Achse des späteren Embryos, als die Dorsalseite des späteren Embryos vom Dotter weg weist und die spätere Ventralseite dem Dotter aufliegt. Die zu diesem Zeitpunkt dorsal bzw. ventral liegenden Zellen werden allerdings nicht diese Teile des Embryos formen, da sie dort nicht liegen bleiben, sondern im Rahmen von Proliferation, Faltung und Wanderung an einen jeweils anderen Ort gelangen werden. Die anfänglich bestehende Radiärsymmetrie des Hühnerblastoderms (siehe Abbildung 4) wird durch die Festlegung des Hinterendes des Embryos unterbrochen. Dies geschieht bei Erscheinen eines dichteren Zellbereichs auf einer Seite der Marginalzone des Blastoderms. Aus dem Bereich dieser sogenannten posterioren Marginalzone wird sich der Primitivstreifen entwickeln, der die Lage der anterior-posterioren Achse im Blastoderm definiert. Durch die Transplantation eines Stückes der posterioren Marginalzone in einen anderen Bereich der Marginalzone kann dort die Bildung eines neuen Primitivstreifens induziert werden (siehe Abbildung 4; Wolpert et al. 1998). Die Rechts-Links-Achse ist somit zu diesem Zeitpunkt auch bereits definiert.

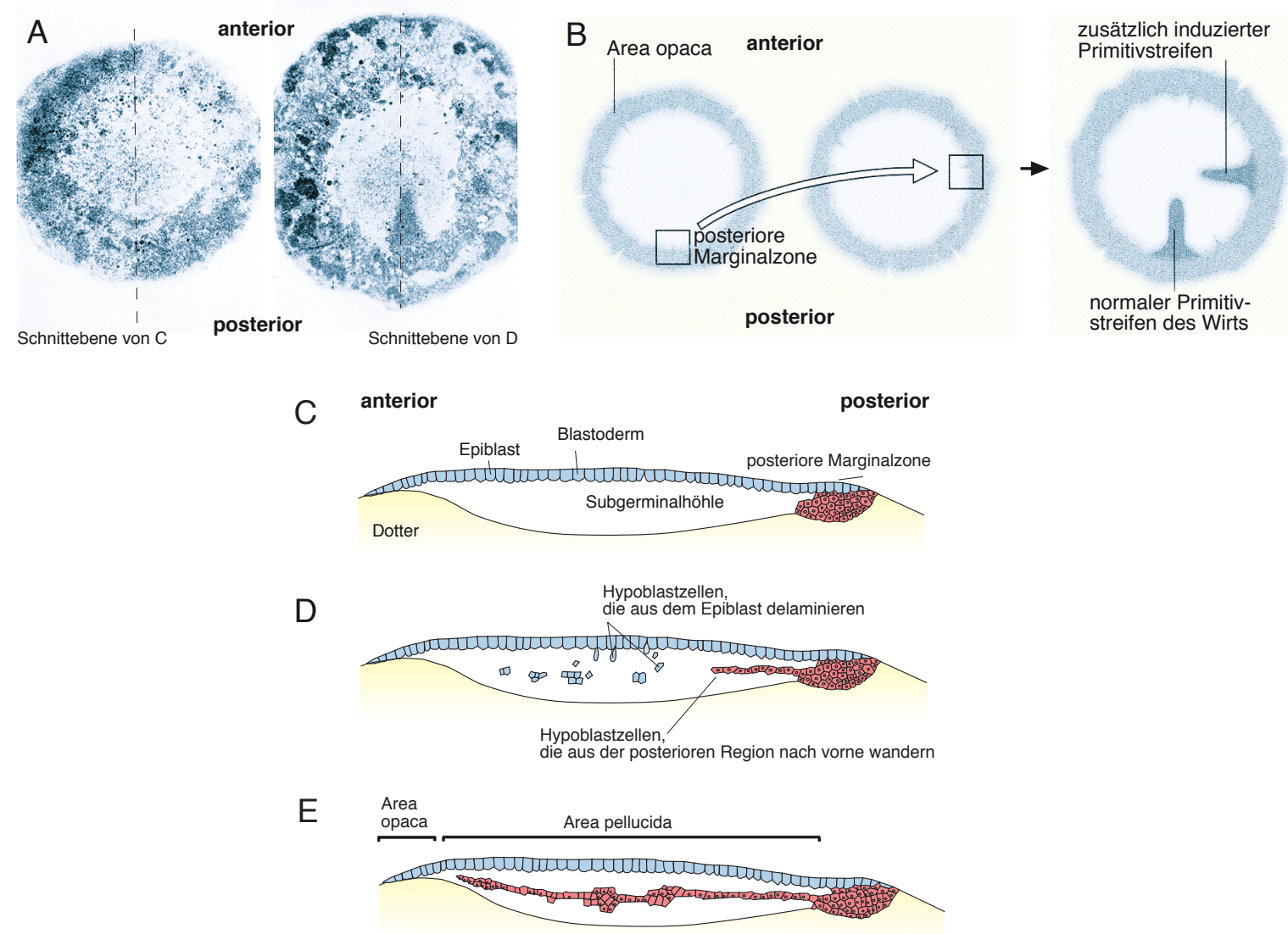

\footnotetext{
Abb. 4: Frühe Entwicklung des Hühnerembryos und neurale Induktion. (A) Aufsicht auf einen Hühnerembryo des Stadiums HH1(Pre-Streak) und Aufsicht auf einen Hühnerembryo des Stadiums HH2 (Initial Streak). Beidesmal zeigen die Linien den sagittalen Verlauf der Schnitte von jeweils (C) und (D) an. (B) Induktion eines ektopischen Primitivstreifens durch Transplantation der posterioren Marginalzone. (C-E) Ansicht eines sagittalen Querschnittes durch einen Hühnerembryo während der Entstehung des Hypoblasten. (A) aus Hamburger und Hamilton (1951, Seite 251) bzw. gezeichnet nach: (B) Wolpert et al. (1999, Seite 81), (C-E) Gilbert (2000, Seite 346).
} 
Im Folgenden differenzieren Zellen durch Proliferation aus der posterioren Marginalzone in Richtung anteriores Ende sowie durch Delamination aus dem Blastoderm zu einer zweiten Zellschicht, die man als Hypoblast von der ursprünglich einzelnen oberen Zellschicht, dem Epiblast, unterscheidet (Gilbert 2000; siehe Abbildung 4, Seite 6). Aus Zellen des Epiblasten werden sich im Weiteren das Mesoderm und das definitive Endoderm durch Einwanderung und Proliferation bilden (siehe 1.3.2), während die in der Epiblast-Zellschicht verbleibenden Zellen zum Ektoderm differenzieren werden - dem Keimblatt, aus dem Epidermis, Neuralleistenderivate und das zentrale Nervensystem entstehen.

In amniotischen Embryonen haben Experimente gezeigt, dass die Entscheidung, welchen dieser Wege die ektodermalen Zellen einschlagen werden, schon im Blastulastadium, im einschichtigen Embryo stattfindet (Spezifikation). In diesem Stadium ist im Huhn eine Differenz zwischen dem lateralen und medialen Epiblasten sowohl in Bezug auf die Expression der Signalmoleküle FGF, Wnt und BMP beobachtet als auch in Bezug auf Transkriptionsfaktoren festgestellt worden: die Zellen des medialen Epiblasten (des Huhnes) zeigen in dieser Periode die Expression von Transkriptionsfaktoren (Sox2, Sox3, Otx2), die typisch sind für allgemein neurales Ektoderm bzw. anteriores Vorderhirn und nicht für weiter kaudal liegende Strukturen, wie zum Beispiel das Mittelhirn (Wilson und Rubenstein 2001). Vor dem folgenden Schritt, der Gastrulation, haben sie also bereits einen neuralen anterioren Charakter.

\subsubsection{Gastrulation und die Ausbildung der definitiven Körperstruktur und Körperachse}

Unter Gastrulation (von gr.: $\gamma \alpha \sigma \tau \eta \dot{ } \rho=$ Magen) versteht man einen bei vielzelligen Tierembryonen beschriebenen Vorgang, bei dem das Keimblatt Endoderm der Blastula in das Innere des Embryos wandert und sich zwischen Ekto- und Endoderm das Mesoderm bildet. Endo- und Mesoderm kommen im weiteren Verlauf der Entwicklung im Embryo zu liegen, wo sie Ursprung aller im Innern liegenden

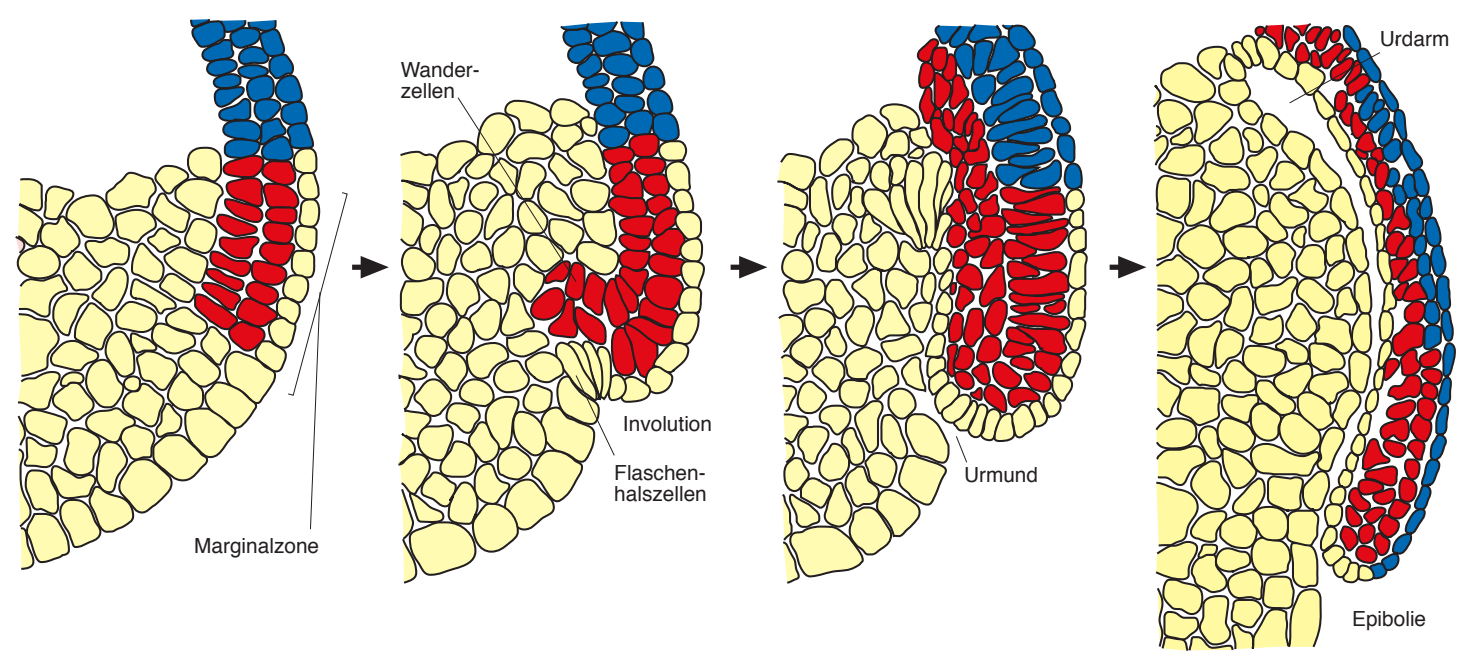

\footnotetext{
Abb.5: Schematische Darstellung des Vorgangs der Gastrulation am Beispiel von Xenopus laevis. Ausschnitte aus sagittalen Querschnitten in Höhe des Äquators zu verschiedenen Entwicklungsstufen. (Da die dargestellte Bilderfolge den Vorgang der Gastrulation besonders anschaulich verdeutlicht, wurde sie Abbildungen der Gastrulation der im Text dargestellten Tiere (Maus, Huhn) vorgezogen.) Abbildungen gezeichnet nach Wolpert et al. (1999, Seite 287).
} 
Gewebe des Embryos sein werden (Langman 1989). Dieser Prozess stellt insofern einen sehr grundlegenden Schritt in der Entwicklung dar, als sich zu diesem Zeitpunkt die drei Keimblätter Ekto-, Mesound Endoderm zum ersten Mal im Lauf der Entwicklung relativ zueinander in der Lage befinden, in der sie später einmal im Fetus und dann im ausgewachsenen Organismus angeordnet sind (siehe Abbildung 5, Seite 7).

Auf der im letzten Abschnitt von 1.3.1 beschriebenen "Vormusterung" des Ektoderms vor der Gastrulation bauen im Rahmen der Gastrulation die Zellen des sogenannten Organisators bzw. dessen Derivate (das prächordale Mesoderm bzw. das Mesendoderm) mit ihren induktiven Signalen auf(Gilbert 2000). Bei dem Organisator handelt es sich um eine kleine Gruppe von Zellen, deren organisatorische Fähigkeit durch Transplantationen in naives, kompetentes Ektoderm entdeckt wurde. Dort rufen diese Zellen zusätzlich zu der Entwicklung der Achse des Empfängerembryos eine weitere Achse hervor, die nur zu einem kleinen Teil aus den Zellen des Organisators besteht, aber zu einem großen Anteil Zellen des Empfängerembryos rekrutiert. Abhängig vom Alter, von der Region und der Größe des Transplantates sowie des Zielgewebes kann eine solche Achse die Anlage des Kopfes bis zu den am weitesten kaudalen Strukturen umfassen (Beddington 1994; Knoetgen et al. 2000). Zuerst wurde dies beim Frosch gefunden, dessen Zellgruppe deskriptiv dorsale Blastoporenlippe genannt wurde (Harland und Gerhart 1997; Spemann und Mangold 1924). Später wurden vergleichbare Strukturen und Funktionen auch beim Zebrafisch (Embryonales Schild; Shih und Fraser 1996) und den Amnioten Huhn (Waddington 1932; Boettger et al. 2001) und Maus (Beddington 1994; Knoetgen et al. 2000) gefunden. Dort bezeichnet man die Zellgruppe als Knoten oder als Hensenschen Knoten (Hensen 1876).

\subsubsection{Ein zusätzliches Signalzentrum bei Säugetierembryonen}

Bei den Säugetieren Maus und Kaninchen wurde neben dem Knoten bzw. dessen Derivaten eine weitere Zellpopulation identifiziert, die zur Organisation des Kopfes beiträgt: das anteriore viszerale Endoderm (AVE, siehe Abbildung 6, Seite 9). Es wurde gezeigt, dass das Gewebe des AVE anteriore Markergene in kompetentem Ektoderm induzieren kann, während eine in Bezug auf die Lage vergleichbare Struktur des Huhns, der Hypoblast, dieselben Gene nicht induzieren kann, wenngleich diese für die regelgerechte Formation des Mesendoderms notwendig ist (Knoetgen et al. 1999b; Withington et al. 2001).

Im Gegensatz zu GANF, welches nur im Epiblasten bzw. prospektiven anterioren Neuroektoderm exprimiert ist, ist sein murines Ortholog, Hesx1/Rpx, zuerst im AVE exprimiert und schließlich im darüberliegenden Neuroektoderm. Im AVE haben eine Reihe weiterer Gene eine unabhängige Expressionsdomäne, die vor oder zu Beginn der Primitivstreifenformation dort zu finden ist, also bevor die jeweiligen Gene im Knoten oder im Mesendoderm exprimiert sind. Funktionelle Inaktivierung dieser Transkriptionsfaktoren führte zu unterschiedlichen Fehlbildungen des Kopfes. Zuerst ließen diese 

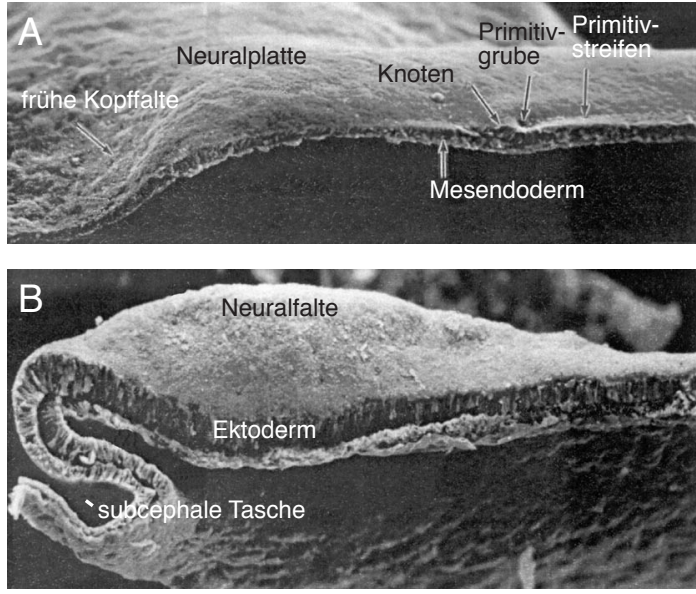

C

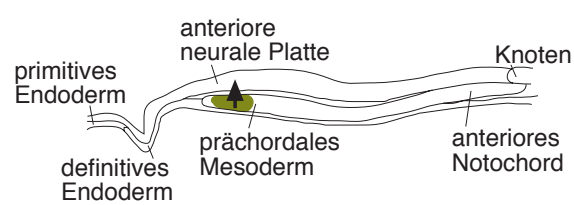

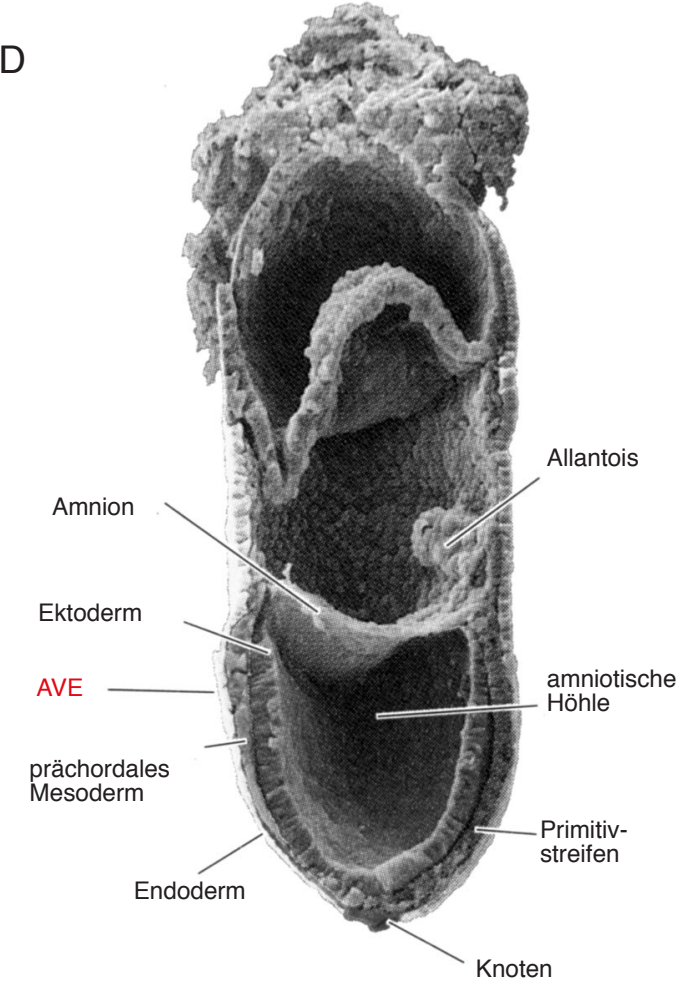

Abb.6: Gastrulation und die Ausbildung der definitiven Körperstruktur beim Huhn und bei der Maus. (A) und (B) Elektronenmikroskopische Aufnahmen von zwei Hühnerembryonen. (A) Parasagittaler Schnitt durch einen Embryo im Stadium HH4+. (B) Parasagittaler Schnitt durch einen Embryo im Stadium HH6. (C) Schematische Darstellung der induktiven Wirkung des Mesendoderms (grün) auf das neurale Ektoderm (Induktion von GANF: Pfeil). (D) Elektronenmikroskopische Aufnahme des Mausembryos im Stadium e7. Anteriores Ende aller Embryonen immer auf der linken Seite. Abbildungen sind übernommen aus bzw. gezeichnet nach: (A und B): Schoenwolf und Watterson (1979, Seite 143 und 145); (C) Knoetgen et al. (1999a, Seite 485); (D) Gilbert (2001, Seite 365).

Versuche allerdings offen, welche Struktur (AVE oder Knoten und dessen Derivate) für die Phänotypen verantwortlich ist. Dies wurde später mittels Chimären untersucht, die jeweils den Funktionsverlust in nur einem der in Frage kommenden Gewebe besaßen. Dabei wurde gefunden, dass das Fehlen von Hesx 1 bei den chimären Verlustmutanten nur im Neuroektoderm zu einem Phänotyp beitrug.

In Bezug auf den Ort und den Zeitpunkt des "Kopf-Organisators" unterscheiden sich demnach die Säugetiere (Maus, Kaninchen) von zum Beispiel dem Huhn bzw. dem Zebrafisch. In Säugetierembryonen sind die Signale, die zu anteriorer neuraler Identität führen, in das primitive Endoderm verlegt und sind dort bereits exprimiert, bevor das Mesendoderm als Derivat des Knotens zwischen Ektoderm und Endoderm einwandert und seinerseits zu anterioren Strukturen führt (siehe 1.3.2; Knoetgen et al. 1999a).

\subsubsection{Der Transkriptionsfaktor GANF als Teil der molekularen Faktoren, die zu anteri- orer neuraler Identität führen}

Im Rahmen der molekularen Analyse der Faktoren, die zu anteriorer neuraler Identität führen, sind neben den Transkriptionsfaktoren sekretierte Proteine untersucht worden. 
Als spezifisch im Organisator exprimierte Moleküle wurden Noggin und Chordin identifiziert. Beide sind Antagonisten der BMP-Signalmoleküle. Die Doppelverlustmutante von Noggin und Chordin der Maus zeigte deren Notwendigkeit für die korrekte Ausbildung des Vorderhirns (Bachiller et al. 2000). Experimente im Huhn zeigten, dass Noggin direkt die GANF-Domäne erweitert, BMP4 aber diese verkleinert (Knoetgen et al. 1999b).

Genauso wurden Antagonisten der Wingless/Wnt-Signalmoleküle, die ebenfalls vom Organisator sekretiert werden, als notwendig für die Induktion des Kopfes identifiziert. Deren ektopische Expression bewirkt die Induktion des Kopfes, während ektopische Expression von Wnt-Signalen im Laufe der Gastrulation die Bildung von Strukturen des Kopfes inhibiert. Viele Moleküle, die Teil des intrazellulären Wnt-Transduktionsweges sind, wurden im Rahmen von Verlustmutanten der Maus sowie von Mutationen des Zebrafisches untersucht. So sind bei der masterblind-(mbl)-Mutante (betroffenes Gen: Axin) und bei der headless-Mutante des Zebrafisches die regionale Spezifizierung aufgehoben und das
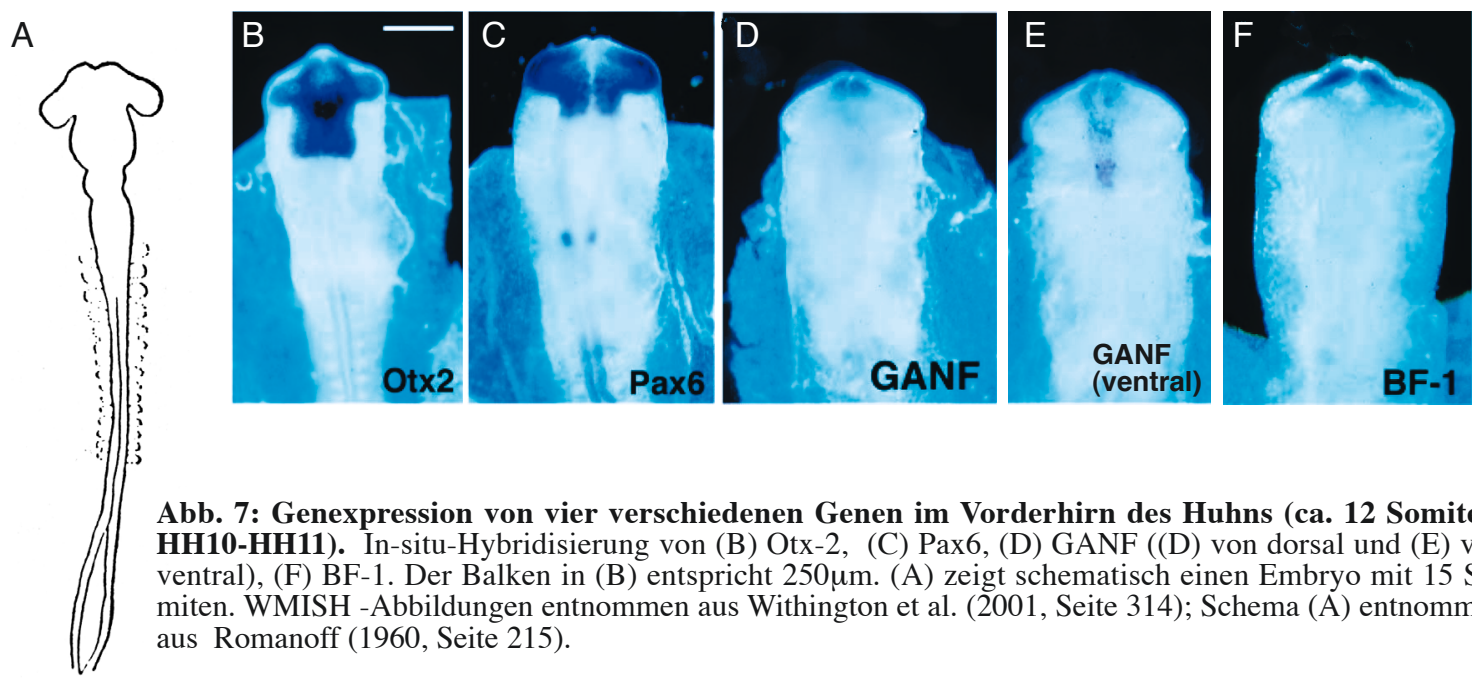

Abb. 7: Genexpression von vier verschiedenen Genen im Vorderhirn des Huhns (ca. 12 Somiten, HH10-HH11). In-situ-Hybridisierung von (B) Otx-2, (C) Pax6, (D) GANF ((D) von dorsal und (E) von ventral), (F) BF-1. Der Balken in (B) entspricht 250um. (A) zeigt schematisch einen Embryo mit 15 Somiten. WMISH -Abbildungen entnommen aus Withington et al. (2001, Seite 314); Schema (A) entnommen aus Romanoff (1960, Seite 215).

Telenzephalon und die Augen zugunsten posteriorer dienzephaler Strukturen nicht ausgebildet (Heisenberg et al. 1996; Heisenberg et al. 2001; Masai et al. 1997). Als eine Grundlage für die Spezifizierung der telenzephalen, also am weitesten anterior liegenden Identität legt dies eine Suppression von posterioren dienzephalen Identitäten nahe, was mit dem Nieuwkoop-Modell übereinstimmen würde. Dieses Aktivierungs-Transformierungs-Modell von Nieuwkoop und dessen Kollegen postuliert für das initial induzierte neurale Gewebe anterioren Charakter im Sinne der Entwicklung des Telenzephalons. Weiter posterior liegende Strukturen sollen im Rahmen eines Gradienten eines transformierenden (posteriosierenden) Signals schließlich graduell jeweils durch $\mathrm{Zu}$ - oder Abnahme geschaffen werden (Foley et al. 2000; Kiecker und Niehrs 2001; Nieuwkoop 1997; Nieuwkoop et al. 1952). Als mögliche posteriosierende Signalmoleküle dafür kommen Wnts, Retinsäure und Mitglieder der FGF-Proteine in Frage (Wilson und Rubenstein 2000).

Als letztes wichtiges Signalmolekül soll FGF8 hervorgehoben werden. In der Hesx1-Verlustmutante 
(Dattani et al. 1998) ist die FGF8-Expression im frühen Somitenstadium deutlich reduziert. Dies ist insofern von Bedeutung, als dies mit der Bildung des Signalzentrums des vorderen neuralen Kammes (engl.: anterior neural ridge, ANR) zusammenfällt (Couly und Le Douarin 1988; siehe Abbildung 7, Seite 10), der in der Ausbildung des Telenzephalons eine entscheidende Rolle spielt (Wilson und Rubenstein 2000). Dem dort exprimierten FGF8 wird eine Induktion des BF1 zugeschrieben, eines Markers für das Telenzephalon (siehe Abbildung 7, Seite 10). Ebenso zeigt eine FGF8-Verlustmutante einen dem Phänotyp der Hesx ${ }^{-/}$-Verlustmutante ähnlichen Phänotyp (Meyers et al. 1998).

In der Gruppe der Transkriptionsfaktoren wurden neben Hesx1 für weitere Homöobox-Gene und andere Transkriptionsfaktoren Funktionen in der regionalen Spezifizierung des Telenzephalons, Dienzephalons und der Augenanlagen gezeigt: u. a. Otx2 (Boncinelli und Morgan 2001; Matsuo et al. 1995), Six3 (Kobayashi et al. 1998; Loosli et al. 1999), Rx (Andreazzoli et al. 1999), Vax (Hallonet et al. 1998; Hallonet et al. 1999), Irx3 (Kobayashi et al. 2002) und Pax6 (Chow et al. 1999; siehe Abbildung 7, Seite 10). Es ist anzunehmen, dass sie u. a. durch gegenseitige Beeinflussung ihrer Transkription gemeinsam eine Rolle in der frühen regionalen Unterteilung des prospektiven Vorderhirns in Richtung Telenzephalon, Dienzephalon und Auge spielen.

In Bezug auf das Nieuwkoop-Modell, das weiter oben bereits vorgestellt wurde, handelt es sich interessanterweise bei Hesx1/GANF, Rx und Six3 um transkriptionelle Repressoren, die somit als aktivierte Transkriptionsfaktoren interessante Kandidaten für die Repression von Genen sind, die zu posterioren Strukturen führen.

Im Hinblick auf die mittige Expression der ANF-Homöobox-Genfamilie kommt der folgende weitere Interaktionspartner in Frage. Die Mutation you-too des Zebrafisches (Karlstrom et al. 1999) zeigt zusätzlich zu Defekten der Muskeldifferenzierung und der retinalen Axonführung eine gestörte Differenzierung der Adenohypophyse des ventralen Vorderhirns und eine gestörte Mittellinienentwicklung. Unter Berücksichtigung von Syntenien zwischen Fisch und Mensch wurde das der Mutation zugrunde liegende Gen, gli2, gefunden. gli2 ist das Homolog zu cubitus interruptus (ci), dem DNA bindenden Zielprotein des sonic hedgehog-(SHH)-Signaltransduktionsweges. Da SHH typisch in der Mittellinie exprimiert ist, kommt gli2 als möglicher Interaktionspartner für das gegen Ende seiner Expression mittig exprimierte GANF in Frage. Ein Einfluss auf die Strukturen der Mittellinie und die Hypophyse von gli2 wurde auch bei der Maus gefunden (Park et al. 2000).

\subsubsection{Die Entstehung der Hypophyse}

Weil GANF zum Schluss seiner Expression nur noch in der prospektiven Adenohypophyse exprimiert wird, werden im Folgenden die morphologischen und molekularen Umstände der Entstehung der Hypophyse dargestellt. Aus dem am weitesten anterior liegenden Teil des vorderen neuralen Kammes (engl. kurz: ANR) entsteht das orale Ektoderm (siehe Abbildung 8, Seite 12). In diesem anfänglich 
uniformen Gewebe entwickelt sich mittig eine Invagination, die man als Rathkes Tasche bezeichnet (nach Martin Heinrich Rathke (1793-1860), engl.: Rathke's pouch). Dies geschieht beim Huhn im Stadium HH14, bei der Maus im Stadium e9, beim Menschen in der dritten Woche der Embryonalentwicklung. Wachstum und Differenzierung führen zur vollständigen Herauslösung aus dem oralen Ektoderm und schließlich zur vollständig ausgebildeten Adenohypophyse (Jacobsen et al. 1979; Pikalow et al. 1994). Die Neurohypophyse bildet sich parallel zu der beschriebenen Entwicklung als Auswachsung aus dem ventralen Dienzephalon (Infundibulum; siehe Abbildung 8; Shimamura und Rubenstein 1997). Zusammen bilden beide Teile eine strukturelle Einheit, die auf der Basis der Integration von Signalen aus dem Hypothalamus und der peripheren Zielorgane eine entscheidende Funktion in der Homöostase von Vertebraten durch die Regulation von Prozessen des Metabolismus, der Reproduktion, des Wachstums und der Fortpflanzung mittels der Produktion ihrer Hormone erfüllt (Silbernagl und Despopolus 1991).

A

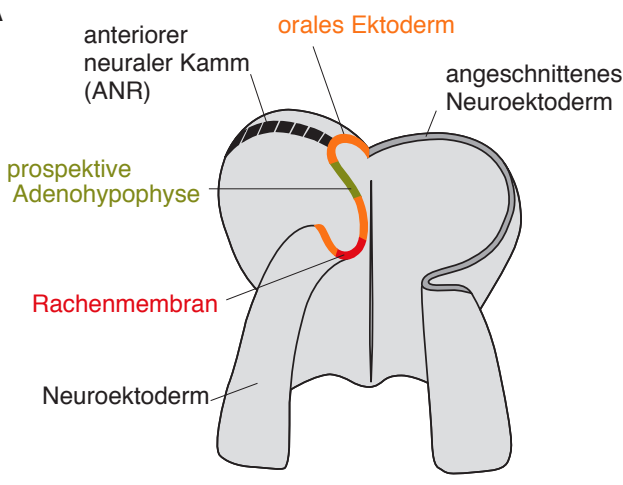

Abb. 8: Stadien der Entwicklung der Нypophyse. (A) Neurales Ektoderm im Stadium der Neuralfalten, von ventral gesehen. Die Abbildung verdeutlicht, wie das orale Ektoderm (das Gebiet der prospektiven Adenohypophyse) in die Nähe des ventralen Dienzephalons (der späteren Neurohypophyse) gelangt.(B) Sagittalschnitt durch den Kopfteil eines 6 Wochen alten Embryos, der die Rathke-Tasche als dorsale Aussackung der Mundhöhle und das Infundibulum als Verdickung am Boden des Dienzephalons zeigt. (C und D) zeigen Sagittalschnitte durch die Anlage der Hypophyse in der 11. und 16. Entwicklungswoche.

(A) Maus, (B-D) Mensch.Dunkelgrau=angeschnittenes neurales Ektoderm; grau=neurales Ektoderm. Abbildungen gezeichnet nach Shimamura und Rubenstein (1997, Seite 2711) und Langman (1989, Seite 330).
$\mathrm{B}$

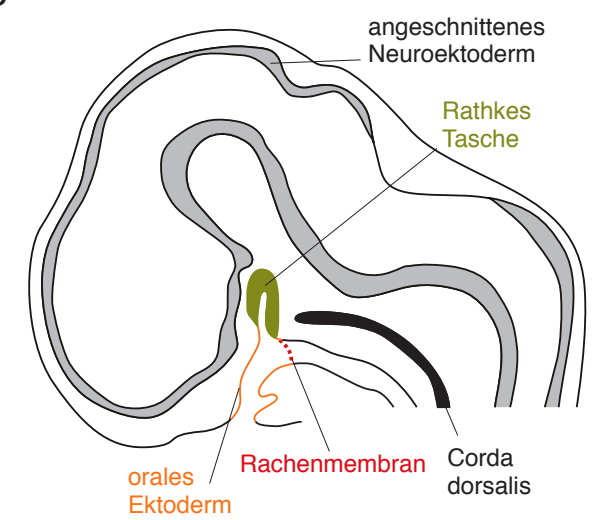

C

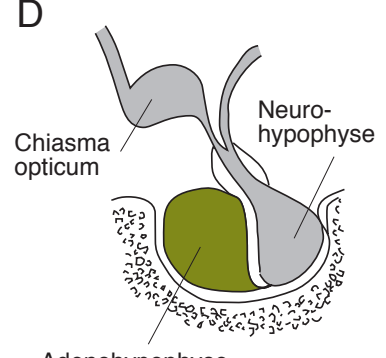

Adenohypophyse

Im Stadium e13.5 beginnt die Differenzierung der ventralen Zellen der Adenohypophyse. Dies belegt die Expression des POU-Transkriptionsfaktors Pit-1, dessen Verlustmutante die laktotropen, ventralen thyreotropen und somatotropen Zellen fehlen (Li et al. 1990). Zu diesem Zeitpunkt ist Hesxl nur noch im dorsalen Teil zu finden. Dies deutet also auf eine direkte Regulation von Hesx1 durch Pit1 hin (Hermesz et al. 1996). 
In den Verlustmutanten von PROP und Lhx3 sind weitere Beobachtungen in Bezug auf die Expression von Hesx 1 in der Hypophyse gemacht worden. In der Lhx $3^{--}$-Maus war Hesx 1 nur bis zum Stadium e12.5 zu finden. Für den Zeitraum von Stadium e12.5 bis zu dem physiologischen Ende scheint deshalb Lhx3 für die Transkription von Hesx1 notwendig zu sein (Sheng et al. 1996). In der PROP $^{-/-}$-Maus ist die Expression bis zum Stadium e15.5 verlängert, was mit einer negativen Wirkung von PROP auf Hesx 1 erklärt werden könnte (Sornson et al. 1996).

Zusammenfassend ist also eine negative, $d$. h. die Transkription von GANF beendende Funktion von Pit-1 und PROP denkbar. Das Homöobox-Gen Lhx3 scheint hingegen für die Expression von GANF notwendig zu sein.

\subsection{Mutationen in Entwicklungsgenen als ätiologische Ursache von Er- krankungen}

Neben Erkrankungen, die durch bestimmte Ernährung, Lebensgewohnheiten oder mikrobiologische Organismen verursacht sind, stellen "genetisch bedingte Erkrankungen [...] in ihrer Gesamtheit einen wesentlichen Anteil aller Krankheitsprozesse in der Medizin" dar (Passarge 1994, Seite 12). Für kongenitale Fehlbildungen spielen dabei Mutationen in Genen, die im Wesentlichen während der Entwicklung des Organismus ihre Funktion erfüllen, eine grundlegende Rolle. Dies soll im Folgenden am Beispiel des humanen Orthologs der ANF-Genfamilie HESX1 erläutert werden.

Genauso sind Mutationen in Entwicklungsgenen für die Ätiologie von Tumorerkrankungen wichtig. In dem einen Fall führt eine Inaktivierung (ein Funktionsverlust), in dem anderen Fall eine ektopische Expression zu einem nicht-physiologischen Zeitpunkt zur Erkrankung. Diese kann sowohl lebensbedrohlich als auch relativ benigne sein (Gilbert 2000).

\subsubsection{Funktionsverluste in Homöobox-Genen}

Für eine Reihe der Homöobox-Gene sind Mutationen bekannt, die mit einer Krankheit des Menschen assoziiert sind. Beispiele hierfür sind die Aniridie (PAX 6; Malandrini et al. 2001), Vorhofseptumdefekte mit atrioventrikulären Überleitungsstörungen (Nkx 2.5; Schott et al. 1998) und die akute lymphoblastische T-Zell-Leukämie (T-ALL, HOX11; Lu et al. 1991).

Eine umfassende und ständig aktualisierte Übersicht findet man im Internet auf der Seite des National Center for Biotechnology Information unter der Sparte OMIM (NCBI; http://www.ncbi.nlm.nih.gov; Online Mendelian Inheritance in Man, Johns Hopkins University). 


\subsubsection{HESX1 und die Septo-optische Dysplasie}

Die Septo-optische Dysplasie (SOD, auch: de Morsier-Syndrom) ist ein seltenes Syndrom. In variabler Zusammensetzung der Entwicklungsstörungen und in variabler Häufigkeit sowie Schwere betrifft sie eine Trias, die die verschiedenen Mittellinienstrukturen Septum pellucidum und/oder das Corpus callosum (Agenesie), die optischen Nerven (Hypoplasie) und/oder die Hypophyse zusammen mit dem Hypothalamus (Hypoplasie) umfasst. Die gemeinsame entwicklungsgeschichtliche Herkunft dieser Strukturen illustriert Abbildung 9.

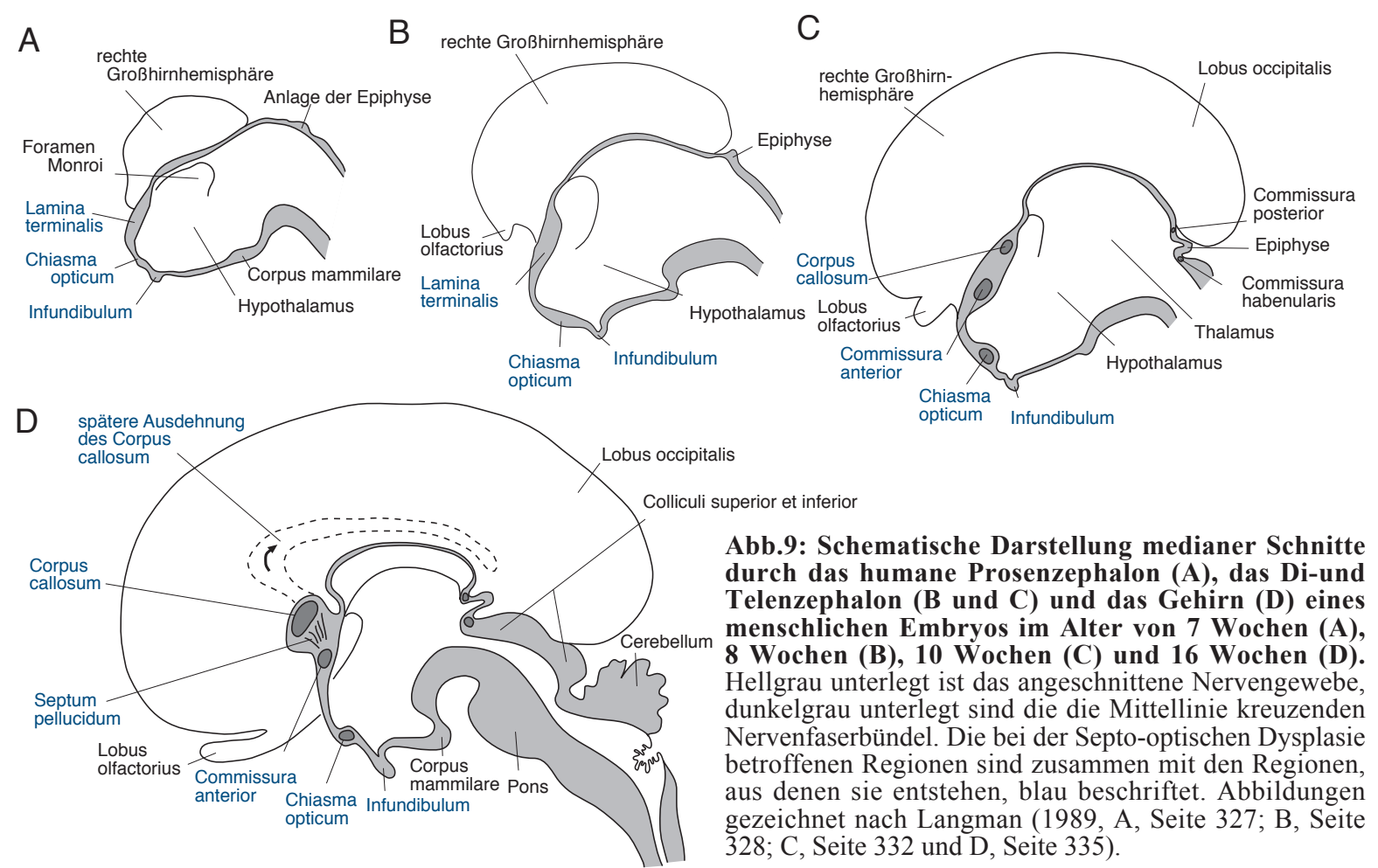

Das Vorkommen einer Agenesie des Septum pellucidum zusammen mit einer Mikropapille wurde erstmalig 1941 von Reeves bei einem sieben Monate alten Kind beschrieben (Reeves 1941). Als zusammenhängenden Komplex erkannte dies 1956 der Schweizer Neurologe de Morsier (de Morsier 1956), der 36 Patientengeschichten aus der Literatur zusammentrug. Zusätzlich zu diesen Entwicklungsfehlbildungen beobachteten Hoyt et al. 1970 bei neun Kindern proportionierten Kleinwuchs aufgrund eines Wachstumshormonmangels $(\mathrm{GH})$. Auch bemerkten sie in einigen Fällen kongenitale Amblyopie, den Mangel anderer tropischer Hormone und einen Nystagmus (Hoyt et al. 1970), so dass das Konzept von de Morsier (Defekt des Septums, Hypoplasie der optischen Nerven) um diese Beobachtungen ergänzt wurde (daher weiteres, aber nicht oft benutztes Synonym: Hoyt-Kaplan-Grumbach-Syndrom). Anfang der 80er Jahre wurde mit den neuen radiologischen Techniken in der Diagnostik ein weiterer Fortschritt erzielt (Blethen und Waldon 1985; Roessmann 1989; Zaias und Becker 1978). 
Im Rahmen der Septo-optischen Dysplasie findet man ein großes Spektrum von klinischen Manifestationen. Die Hypoplasie der Hypophyse kann sich als isolierter Mangel des Wachstumshormons (GH) bis hin zu einem kompletten Ausfall aller Hypophysenhormone (Panhypopituitarismus) manifestieren. Am häufigsten fehlt das GH (Wachstumsverzögerung, Minderwuchs), gefolgt von dem ACTH (sekundäre Nebenniereninsuffizienz), dann dem TSH (Hypothyreose) (Dattani und Robinson 2000). Die Endokrinopathie entwickelt sich oft über einen längeren Zeitraum. Neugeborene können durch eine Hypoglykämie, Hyponatriämie, eine konjugierte Hyperbilirubinämie bzw. einen Kryptorchidismus auffallen (Dattani et al. 1999). Die Ursache eines Diabetes insipidus kann ebenfalls auf die Septo-optische Dysplasie zurückzuführen sein (Masera et al. 1994). Am häufigsten fällt zuerst eine ophthalmologische Problematik auf (Pendel-, Down-Beat- oder Up-Beat-Nystagmus; Amblyopie bis hin zur starken Visuseinschränkung, Kolobome, Strabismus) (Izenberg et al. 1984), die schließlich zu der Diagnose führt. Gewöhnlich wird die Diagnose beim Vorliegen von mindestens zwei Aspekten der oben genannten Trias gestellt.

Bei isoliertem GH-Mangel ist der Beginn der Pubertät oft verzögert. Bei einem GH-Mangel im Rahmen der SOD wurden allerdings Fälle mit vorzeitiger Pubertät beschrieben (Huseman et al. 1978). Eine spätere Entwicklung der GnRH produzierenden Neurone, die somit nicht von der früher entstandenen Fehlbildung betroffen sind, sowie ein nicht normaler Aufbau der Hypothalamus-Hypophysen-Achse können als Erklärung für dieses Phänomen dienen. Analog ist das Vorkommen einer vorzeitigen Pubertät nach der Bestrahlung des Kopfes von Kindern, die an akuter lymphoblastischer Leukämie erkrankt waren (Leiper et al. 1988). Neben der Kontrolle der Wachstumsgeschwindigkeit muss deswegen auch die Pubertätsentwicklung sowie das Knochenalter im Auge behalten werden, um ein vermeintlich normales Wachstum mit aber vorzeitigem Schluss der Epiphysenfugen und schließlich resultierendem Kleinwuchs trotz GH-Substitution zu erkennen und diesem angemessen begegnen zu können (Nanduri und Stanhope 1999). Das Wissen um die Zusammenhänge der SOD kann zu weitreichenden diagnostischen Schritten und therapeutischen Konsequenzen führen. Eine Funduskopie oder eine NMR/CT können neuroanatomische/ophthalmoskopische Aspekte der SOD aufdecken und so zu einer endokrinologischen Untersuchung führen, die rechtzeitig einen noch nicht ins Auge fallenden GHMangel aufdeckt. Im Rahmen von Wachstumsstörungen ist die SOD immer als Differentialdiagnose zu berücksichtigen.

Verschiedene Ätiologien (virale Infektionen, vaskuläre Degeneration, teratogene Umwelteinflüsse) wurden als mögliche Ursachen für die SOD erwogen, die in der Mehrzahl der Fälle sporadisch auftritt. Es liegen aber auch Beschreibungen vor, die mit einem autosomal-rezessiven Vererbungsmodus bzw. einem autosomal-dominanten Vererbungsmodus mit unterschiedlicher Penetranz vereinbar sind (Dattani et al. 1999).

Aufgrund der erstaunlichen Ähnlichkeit zwischen dem menschlichen Phänotyp bei SOD und dem Phänotyp der Hesx1/Rpx-Verlustmutante der Maus schlugen Dattani et al. als ätiologische Ursache für die 
familiäre Form den Funktionsverlust in diesem Gen vor (Dattani et al. 1998; Wales und Quarrell 1996). Sie fanden eine homozygote Punktmutation im HESX1 (C478T; R160C) von zwei Geschwistern. Bei diesen lag eine Agenesie des Corpus callosum, eine Hypoplasie der optischen Nerven und ein Panhypopituitarismus vor. In neun weiteren Familienmitgliedern, einschließlich der Eltern, lag die Mutation heterozygot vor. Das in Folge der Mutation ausgetauschte Arginin stellt eine für die DNA-Bindung wichtige Aminosäure dar, so dass das Protein durch die Mutation seine Funktion verloren hat (Dattani et al. 1998; siehe Abbildung 10).

A

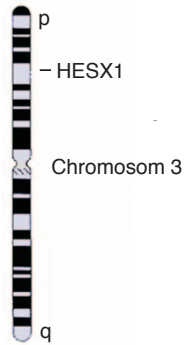

B

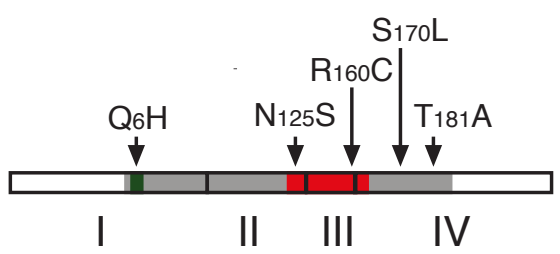

Abb. 10: (A) Lokalisation von HESX1 auf Chromosom 3. Lokus 3p 21.2- 21.1. Abbildung modifiziert nach http://www.ncbi.nlm.nih.gov/disease/. (B) Die bekannten Mutationen in HESX1. (Quellen siehe Text.) Aminosäuren sind nach dem Ein-Buchstaben-Code abgekürzt. Zur besseren Übersicht sind die Mutationen nur auf der Aminosäurenebene eingezeichnet. Der Balken entspricht 100bp. Die römischen Zahlen bezeichnen die Exons. Grau unterlegt ist die kodierende Region markiert, rot die Homöobox und grün die eh-1-Repressorsequenz.

Auch heterozygot vorliegende Mutationen in HESX1 sind als Ursache für eine kongenitale Hypoplasie der Adenohypophyse gefunden worden. Thomas et al. fanden in zwei Brüdern eine Mutation ( $A 541 G$;T181A) in HESX1. Bei einem von diesen lag ein isolierter GH-Mangel vor (Thomas et al. 2001). Es wurden mittlerweile insgesamt fünf Mutationen in HESX1 gefunden, die alle mit einer Erkrankung der Hypophyse bzw. neuroanatomischen Veränderungen in der Mittellinie assoziiert waren (Brickman et al. 2001; Thomas et al. 2001; siehe Abbildungen 9 und 10, Seite 14 bzw. 16). Offensichtlich beruht aber eine große Gruppe von Fällen der SOD nicht auf einer HESX1-Mutation, da bei dem größten Teil der untersuchten Patienten keine Mutation gefunden wurde. Insofern nur der kodierende Bereich untersucht wurde, kann eine Beteiligung der Promotor-Enhancer-Bereiche von HESX1 in diesen Fällen allerdings nicht ausgeschlossen werden.

Eine multigenetische Basis ist eine plausible Erklärungsmöglichkeit für das sehr große Spektrum der Symptome, die unter dem Begriff Septo-optische Dysplasie zusammengefasst werden. Eine wesentliche Beteiligung von HESX1 ist dabei nicht nur für die seltene familiäre Form der SOD, sondern auch für die häufigeren sporadischen Formen der SOD gezeigt worden (Dattani und Robinson 2000). 


\section{Zielsetzung der Arbeit}

Die vorliegende Arbeit beschäftigt sich mit Aspekten der Funktion und der Transkription der ANFHomöobox-Gene. Im Mittelpunkt steht die Untersuchung des Promotors des orthologen Genes des Huhnes, GANF. Während der Entwicklung eines Individuums steht die Transkription bestimmter Gene jeweils am Ende einer Signalkaskade oder eines Zusammenspiels mehrerer Signalkaskaden, so dass mit der näheren Charakterisierung eines Reporterkonstrukts des Homöobox-Genes GANF Aspekte der molekularen Kontrolle der Entwicklung vor allem der Induktion von anteriorem ZNS, der Induktion der Mittellinienstrukturen des Gehirns und der Hypophyse näher verstanden werden können.

Um die Regionen zu identifizieren, die für die spezifische zeitliche und örtliche Expression von GANF verantwortlich sind, war die Isolierung eines genomischen Klones des Homöobox-Genes GANF das erste Ziel dieser Arbeit. Da die Mehrzahl solcher Regionen in 5'-Richtung vom Gen liegen, wurde ein genomischer Klon mit besonders großem 5'-Bereich gesucht, um mit dieser DNA und dem Reportergen $\beta$-Galactosidase Reporterkonstrukte zu klonieren.

Mit dem Ziel, in der endogenen Expressionsdomäne des Genes eine Promotoraktivität zu erreichen, sollte schließlich mittels der neuartigen Methode der Elektroporation von Embryonen die Funktionsfähigkeit der Reporterkonstrukte im Embryo untersucht werden. Darüber hinaus sollte durch Injektionen in Mäuse- sowie Zebrafischembryonen eine mögliche Konservierung innerhalb der Spezien überprüft werden.

Das schließliche Ziel dieser Arbeit war die nähere Charakterisierung von Bindungsstellen und die Identifikation von direkten Interaktionspartnern des GANF-Promotors, um Aspekte der Regulation von GANF molekular darzustellen.

Da bei vielen Patienten, die an dem Syndrom der Septo-optischen Dysplasie (SOD) erkrankt sind, Mutationen im GANF-Orthologen HESX1 gefunden wurden und ein Vergleich mit dem Phänotyp der murinen Verlustmutante von Hesx1 die Vermutung nahelegt, das Zustandekommen dieser Erkrankung in diesem Gen begründet zu sehen, war eine Patientenuntersuchung auf eine Mutation in diesem Gen der zweite Schwerpunkt dieser Arbeit. 


\section{Material und Methoden}

\subsection{Plasmide, Bakteriophagen und Organismen}

\subsubsection{Plasmide}

Zur Klonierung wurden die Plasmide Bluescript II KS + (Stratagene), der low-copy Vektor plcBS (Dieter Treichel, Max-Planck-Institut für biophysikalische Chemie, Göttingen) und pSL1180 (Stratagene) verwendet. Zur Klonierung der Reporterkonstrukte wurde pßgal-Basic (pßgal-BASIC, http:// www.clontech.com/techinfo/vectors/vectorsA-B/pbetagal-Basic.shtml, Genbanknummer: U13184, Clontech) verwendet sowie der pßgal-Promotor (Genbanknummer: U13187, Clontech). Als Kontrollvektor wurden CMV-lacZ, CMV-GFP und CMV-EGFP benutzt. Zur Erstellung der mit Digoxygenin markierten RNA wurden folgende Plasmide benutzt: Krox20 (Oxtoby und Jowett 1993), GANF (Knoetgen et al. 1999b) und Otx2 (Bally-Cuif et al. 1995). Der für die Pax6-in-vitro-Produktion benutzte Vektor wurde von Dr. Nicole Bäumer (Max-Planck-Institut für biophysikalische Chemie, Göttingen) zur Verfügung gestellt (Andrejewski 2002). Alle Plasmide ermöglichen Wachstum unter selektiven Bedingungen durch Ampicillin (Endkonzentration: $75 \mu \mathrm{g} / \mathrm{ml}$ bzw. $20 \mu \mathrm{g} / \mathrm{ml}$ beim low-copy Vektor plcBS).

\subsubsection{Antikörper}

Die Antikörper gegen Otx2 (Baas et al. 2000) und Pax6 (Ericson et al. 1997) wurden von Dr. Nicole Bäumer zur Verfügung gestellt (Andrejewski 2002).

\subsubsection{Bakteriophagen}

Es wurde eine genomische DNA-Bibliothek verwendet, für die als Vektor der $\lambda$-Phage EMBL SP3/T7 (Genbank Nummer: U02427 (rechter Arm), U02426 (linker Arm)) benutzt worden war.

\subsubsection{Bakterien}

Für die Klonierung von Plasmiden wurden der E.coli-Stamm DH5 $\alpha$ (Hanahan 1985) und der Stamm ElectroTen-Blue TM electroporation competent cells (Stratagene, Bestellnummer: 200159) benutzt. Für die Vervielfältigung der Bakteriophagen der genomischen DNA-Bibliothek vom Huhn wurde der E.coli-Stamm K802 (Raleigh und Wilson 1986; Wood 1966) benutzt. 


\subsubsection{Hühnerembryonen}

Die befruchteten Hühnereier der Rasse White Leghorn wurden von der Firma Lohmann Tierzucht (Cuxhaven) bezogen und in einem Brutschrank (Kleinmotorbrüter, W. Ehret, Emmendingen) bei $38{ }^{\circ} \mathrm{C}$ und einer Luftfeuchtigkeit von 60 \% bis zu dem gewünschten Entwicklungsstadium entsprechend der Stadieneinteilung von Hamburger und Hamilton (1951) inkubiert.

\subsubsection{Mausembryonen}

Alle Angaben hierzu finden sich in dem Absatz Erzeugung von transgenen Mäusen mittels Mikroinjektion (3.9.3).

\subsubsection{Zebrafischembryonen}

Es wurden Zebrafischembryonen (Danio rerio) mit dem genetischen Hintergrund AB verwendet. Die Versuche wurden in den Räumen der Arbeitsgruppe 165 des Max-Planck-Instituts für biophysikalische Chemie, Göttingen (Entwicklung der Keimbahnzellen des Zebrafisches, Leiter: Dr. Erez Raz) durchgeführt. Nach der Injektion wurden sie in HEPES $(10 \mathrm{mM}, \mathrm{pH} 7,4)$ bei $28{ }^{\circ} \mathrm{C}$ inkubiert, bis sie das entsprechende Stadium erreicht hatten. In der Beurteilung der Entwicklung wurde der Klassifikation von Kimmel (1995) gefolgt.

\subsection{Computerprogramme, Datenbanken und Fotomaterialien}

\subsubsection{Computerprogramme}

Folgende Computerprogramme wurden im Rahmen dieser Arbeit benutzt: Textverarbeitung: FrameMaker 5.5 (Adobe), Word 98 (Microsoft); Bildverarbeitung: Photoshop 5.5 (Adobe) und Freehand 8.0.1 (macromedia); Literaturverwaltung (Erstellung des Literaturverzeichnisses): EndNote 3.1 (Niles Software Inc.); Bilderstellung: analySIS PRO (Soft Imaging System GmbH), KAPPA Image Base 2.2 (KAPPA opto-electronics GmbH); Sequenzauswertung: sequencher 3.1.1 (Gene Codes Corporation); Sequenzdarstellung: MacBoxshade 2.15 (von Michael Baron); Internetrecherche: Netscape Communicator 4.61 (Netscape Communications Corporation).

\subsubsection{Datenbanken}

Auf folgende Datenbanken wurde im Rahmen dieser Arbeit zugegriffen: Transfac (http://trans- 
fac.gbf.de/ (Wingender et al. 2000)), Genbank (http://www.ncbi.nlm.nih.gov/), EPD-Eukaryontic Promotor Base (http://www.epd.isb.sib.ch/) und Celera (http://www.celera.com).

\subsubsection{Fotomaterialien}

Zusätzlich zu den digitalen Fotoarbeiten mit den in 3.2.1 erwähnten Programmen wurden Embryonen auf Kodak Ektachrome 64T (E.EPY 135-36) Filmen fotografiert. Die Entwicklung wurde von Ralf Altschäffel (Max-Planck-Institut für biophysikalische Chemie, Göttingen) übernommen. Im Rahmen des Bakteriophagen-Screens sowie der EMSA-Experimente wurden Kodak BioMax MR Filme benutzt.

\subsection{Isolierung von Nukleinsäuren}

\subsubsection{Aufreinigung von DNA-Sonden}

Die radioaktiv markierten DNA-Moleküle, die als Sonden für die Hybridisierung der Southern Blots sowie der Bakteriophagen-Banken dienten, wurden mit Hilfe von Sephadex-Gelfiltrationssäulen (ProbeQuant G-50, Amersham-Pharmacia, im folgenden Text: G-50-Säule) von freien Nukleotiden gereinigt.

\subsubsection{Isolierung von bakterieller Plasmid-DNA}

Die Präparation von bakterieller Plasmid-DNA erfolgte nach dem Qiagen Plasmid-Aufreinigungsprotokoll. Alle verwendeten Plasmide verliehen den transformierten Bakterien eine Resistenz gegen das Antibiotikum Ampicillin, so dass zum selektiven Kultivieren der Plasmid tragenden Bakterien stets LB-Medium (10 g Bacto-Trypton, $5 \mathrm{~g}$ Bacto-Hefe Extrakt, $10 \mathrm{~g} \mathrm{NaCl}$, ad 11 (Millipore)) mit $75 \mu \mathrm{g} / \mathrm{ml}$ Ampicillin verwendet wurde. Zur Aufreinigung der Plasmid-DNA wurden die Kits Plasmid Miniprep (bis $10 \mu \mathrm{g}$ DNA) und Plasmid Maxiprep (bis 1 mg DNA) (beides Qiagen) eingesetzt. Bei der Präparation des low-copy Vektors $p l c B S$ wurden Lysate von insgesamt vier $100 \mathrm{ml}$ Bakteriensuspension über eine Säule (QIAfilter Maxi Cartridges) gegeben, um eine ausreichend große Menge DNA zu erhalten. Die Plasmid-DNA, die bei der Elektroporation der Hühnerembryonen (siehe 3.9.2) verwendet wurde, wurde im Anschluss an das Qiagen Protokoll noch zweimal mit je einem Volumen Phenol/Chloroform/ Isoamylalkohol (25: $24: 1 \mathrm{v} / \mathrm{v} / \mathrm{v}, \mathrm{pH}$ 8) extrahiert. Dann wurde die DNA einmal mit Chloroform/Isoamylalkohol (24:1 v/v) ausgeschüttelt und nach Zugabe von einem Zehntel Volumen Natriumazetatlösung (3 M, pH 5,2) mit 2,5 Volumen Ethanol oder 0,7 Volumen Isopropanol ausgefällt. Das Pellet wurde in $70 \%$ igem Ethanol gewaschen, erneut zentrifugiert, getrocknet und dann in PBS ( $8 \mathrm{~g} \mathrm{NaCl}$, 
0,2 $\mathrm{g} \mathrm{KCl}, 1,44 \mathrm{~g} \mathrm{Na}_{2} \mathrm{HPO}_{4}, 0,24 \mathrm{~g} \mathrm{NaH}_{2} \mathrm{PO}_{4}$ in $800 \mathrm{ml} \mathrm{H}_{2}$, auf $\mathrm{pH} 7,4$ mit $\mathrm{HCl}$ einstellen, ad $11 \mathrm{H}_{2} \mathrm{O}$ ) aufgenommen. Dabei wurde die DNA-Konzentration auf ungefähr $5 \mu \mathrm{g} / \mu 1$ eingestellt.

\subsubsection{Isolierung von genomischer DNA aus EDTA-Blut}

Die Präparation von genomischer DNA erfolgte nach dem Qiagen Plasmid-Aufreinigungsprotokoll DNeasy Tissue Kit. Vor der im Rahmen dieser Versuche durchgeführten PCR (siehe 3.4.10) wurde die isolierte DNA 10 min bei $100{ }^{\circ} \mathrm{C}$ gekocht.

\subsubsection{Gewinnung der Bakteriophagen-DNA}

Zur Gewinnung ausreichender Mengen Bakteriophagen-DNA wurde pro Phagenklon eine Flüssigkultur angesetzt. Dazu wurde eine Bakterienkultur wie für die Ausplattierung der Phagenbank von K802 angesetzt. Von der in $1 / 2$ Volumen (mit $10 \mathrm{mM} \mathrm{MgSO}_{4}$ ) aufgenommenen Bakteriensuspension wurden $50 \mathrm{ml}$ einem $20 \mathrm{ml}$ LB-Kulturmediumansatz sowie ebenfalls $200 \mathrm{ml} 1 \mathrm{M} \mathrm{MgSO}_{4}\left(10 \mathrm{mM} \mathrm{MgSO}_{4}\right)$ hinzugefügt. In Anschluss wurde $1 \mathrm{ml}$ der High-Titer-Stocklösung der Bakteriophagen hinzupipettiert und diese Kultur bei mäßigem Schütteln bei $37^{\circ} \mathrm{C}$ so lange inkubiert, bis die zuerst trüb wachsende Bakterienkultur wieder klar wurde und somit die Bakterien lysiert waren. Sobald dies eingetreten war, wurden jeweils $100 \mathrm{ml}$ Chloroform hinzugefügt. Im Anschluss wurden die zerstörten Bakterien bei $9500 \mathrm{x}$ g und $4{ }^{\circ} \mathrm{C} 5 \mathrm{~min}$ abzentrifugiert und der gewonnene Überstand für $1 \mathrm{~h}$ bei Raumtemperatur mit DNase I (20 $\mu \mathrm{g} / \mathrm{ml})$ und RNase A (40 $\mu \mathrm{g} / \mathrm{ml})$ inkubiert. Das Aufschließen der Bakteriophagen sowie die Inaktivierung der DNasen erfolgte im folgenden Schritt durch die Zugabe von hochkonzentrierter EDTA-Lösung (= $\lambda$-Lysis-Mix: 1,0 M Tris (pH 8,6), 3,0 M NaCl, 0,5 M EDTA) im Verhältnis 9:1 für $30 \mathrm{~min}$ bei $37^{\circ} \mathrm{C}$. Es wurden demzufolge $9 \mathrm{ml}$ Phagenlysat $1 \mathrm{ml} \lambda$-Lysis-Mix hinzugefügt sowie außerdem $90 \mu 1$ Proteinase K einer $10 \mathrm{mg} / \mathrm{ml}$ konzentrierten Lösung. Auch wenn Proteinase K ungefähr $80 \%$ seiner Aktivität verliert, wenn $\mathrm{Ca}^{2+}$ aus der Lösung, hier infolge des EDTA, entfernt wird, reicht die Aktivität noch aus, um DNA degradierende Proteine zu inaktivieren. Die Reinigung und Fällung der DNA erfolgte wie oben beschrieben (siehe Isolierung von bakterieller Plasmid-DNA). Das gefällte Pellet wurde in $300 \mu 1$ Wasser (Millipore) aufgenommen.

\subsubsection{Agarosegelelektrophorese}

Die elektrophoretische Auftrennung von DNA-Fragmenten erfolgte entweder zur Analyse ihrer Größe oder zu ihrer Präparation. Entsprechend der erwarteten Länge der DNA-Fragmente wurden 0,3 \%ige bis 1,5\%ige Agarosegele mit 1 x TBE-Puffer (5 x: 54 g Tris-Base, 27,5 g Borsäure, $20 \mathrm{ml}$ 0,5 M EDTA $(\mathrm{pH} 8,0)$ ad $\left.11 \mathrm{H}_{2} \mathrm{O}\right)$ bei analytischen und mit 0,5 x TBE-Puffer bei präparativen Gelen verwendet. Hinzugegeben wurden etwa $10 \mu \mathrm{g} / \mathrm{ml}$ Ethidiumbromid. 
Zum Auftragen wurden die Proben mit einem Fünftel ihres Volumens an Probenpuffer ( $0,125 \%$ (w/v) Bromphenol Blau, $25 \%$ (w/v) Ficoll, 100 mM EDTA) versetzt und nach dem Anlegen einer konstanten Spannung ( $80 \mathrm{~V}$ bei $20 \mathrm{~cm}$ Elektrodenanstand und $10 \mathrm{~cm}$ Laufstrecke) aufgetrennt.

Die DNA-Fragmente wurden durch Anregung mit UV-Licht (Wellenlänge $258 \mathrm{~nm}$ ) analysiert. Bei präparativen Gelen wurde energieärmeres UV-Licht mit der Wellenlänge $366 \mathrm{~nm}$ verwendet, um die DNA zu schützen.

\subsubsection{Elektroelution von DNA aus Agarosegelen}

Aus präparativen Gelen wurde die DNA elektrophoretisch eluiert. Dazu wurde die DNA im Agarosegel mit UV-Licht sichtbar gemacht, das entsprechende DNA-Fragment mit einem Skalpell ausgeschnitten und in einen Dialyseschlauch überführt. Je nach der Größe des ausgeschnittenen Agarosegelblocks wurden $500 \mu \mathrm{l}$ bis $1000 \mu \mathrm{l}$ in den Dialyseschlauch gefüllt und beide Enden mit Gefrierbeutelklammern verschlossen. Anschließend wurde für 15 min eine Spannung von $150 \mathrm{~V}$ angelegt (Elektrodenabstand und Laufstrecke siehe 3.3.5). Daraufhin wurde die Polung für $30 \mathrm{sec}$ vertauscht und der Puffer in ein Eppendorf-Reaktionsgefäß überführt.

Die DNA wurde nach der Zugabe von einem Zehntel Volumen Natriumazetat (3 M, pH 5,2) und $1 \mu \mathrm{l}$ Glykogenlösung $(20 \mathrm{mg} / \mathrm{ml})$ mit 0,7 Volumen Isopropanol gefällt und bei 10000 x g für 30 min zentrifugiert. Das Pellet wurde mit einem halben Volumen an $70 \%$ igem (v/v) Ethanol gewaschen und nach dem Trocknen in $15 \mathrm{ml}$ bis $30 \mathrm{ml}$ Wasser aufgenommen.

\subsubsection{Isolierung von DNA aus low-melting Agarose}

Die Isolierung von DNA aus präparativen Gelen erfolgte in einigen Fällen ebenfalls mit Hilfe des GelExtraktion Kits bzw. des Kits QIAEX II von Qiagen gemäß dem mitgelieferten Protokoll.

\subsection{Modifizierung von Nukleinsäuren}

Alle im Weiteren beschriebenen Techniken basieren auf Protokollen aus folgenden Labortechnikbüchern: Ausubel et al. (1987), Mülhardt (1999) und Sambrook und Russell (2001).

\subsubsection{Restriktionsverdau}

Für analytische Restriktionsverdaue wurden $500 \mathrm{ng}$ bis $1 \mu \mathrm{g}$ DNA mit $10 \mathrm{U}$ Restriktionsenzym innerhalb $2 \mathrm{~h}$ geschnitten und anschließend auf einem Agarosegel ausgewertet. Für präparative Verdaue wurden $10 \mu \mathrm{g}$ DNA mit $100 \mathrm{U}$ Restriktionsenzym für $4 \mathrm{~h}$ inkubiert. Die Inkubationstemperatur sowie 
die Pufferbedingungen richteten sich nach den vom Hersteller angegebenen optimalen Werten. $\mathrm{Zu}$ jedem Verdau wurde 1x BSA hinzugefügt.

\subsubsection{Partieller Restriktionsverdau}

Für die Klonierung der Reporterkonstrukte RK1 und RK2 war ein partieller Restriktionsverdau notwendig. Zunächst wurden die Reaktionsbedingungen (siehe Abbildung 12) ausgetestet. Als beste Variation der Bedingungen wurden schließlich $10 \mu \mathrm{g}$ DNA des bereits klonierten Reporterkonstruktes RK4 in einem $200 \mu \mathrm{l}$ Ansatz bei $37^{\circ} \mathrm{C}$ in einem Tisch-Thermoblock (Thermomixer 5436, Eppendorf) für genau 10 min inkubiert. Es wurden dabei $10 \mathrm{U}$ Enzym NcoI benutzt. Direkt im Anschluss wurde das Reaktionsgefäß für $20 \mathrm{~min}$ bei $65^{\circ} \mathrm{C}$ inkubiert, um die Reaktion abzustoppen. Es folgte die Auftrennung mittels Agarosegel wie beschrieben (siehe 3.3.5 und 3.3.6).

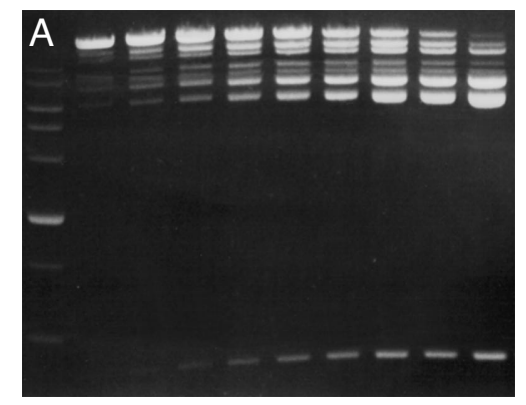

\section{B 5 ... C'CATGG...3-}

3'...GGTACC ...5'

Abb. 12: (A) Agarosegel, welches im Rahmen der Austestung der Bedingungen für den Partialverdau angefertigt wurde. In jeder Bahn sind jeweils $5 \mu$ ldes Verdaus nach jeweils 5 min aufgetragen worden. (B) Erkennungssequenz der Restriktionsendonuklease $N c o I$ und das darin enthaltene Startkodon. Die beiden Dreiecke zeigen die zwei Phosphatverbindungen zwischen den Basen an, die NcoI aufschneidet.

\subsubsection{Dephosphorylierung der 5'-Enden von DNA-Fragmenten}

Um eine Religation der mit Restriktionsenzymen geschnittenen Vektoren zu verhindern, wurden diese vorher dephosphoryliert. Zunächst wurden die geschnittenen Vektoren von DNA-Fragmenten (kleiner als 10 Basen), Restriktionsenzymen und Salzen gereinigt (QIAquick Nucleotide Removal Kit, Qiagen) und im Anschluss mittels der Alkalischen Phosphatase bei $37^{\circ} \mathrm{C}$ genau 30 min lang dephosphoryliert (1 U Intestinale Phosphatase für 20 pmol Vektor, Roche).

\subsubsection{Erzeugung von glatten Enden bei geschnittenen DNA-Fragmenten mit 5'-über- hängenden Enden}

DNA-Fragmente mit 5'-überhängenden Enden wurden mit Hilfe des Klenow-Enzyms in Gegenwart von dNTPs (20 mM) im Puffer B (Roche) für $30 \mathrm{~min}$ bei $37^{\circ} \mathrm{C}$ zu glatten Enden aufgefüllt ( $50 \mu \mathrm{l}$ DNA - Ausgangsvolumnen nach Verwendung des QIAquick Nucleotide Removal Kit, Qiagen - $10 \mu$ l Puffer B, 2,5 $\mu$ l Klenow-Fragment, $3 \mu 1$ dNTPs $(20 \mathrm{mM})$, ad $\left.100 \mu 1 \mathrm{H}_{2} \mathrm{O}\right)$. 


\subsubsection{Erzeugung von glatten Enden bei geschnittenen DNA-Fragmenten mit 3'-über- hängenden Enden}

DNA-Fragmente mit 3'-überhängenden Enden wurden mit Hilfe der T4-DNA-Polymerase (1U) in Gegenwart von einer sehr hohen Konzentration dNTPs im T4-DNA-Polymerase-Puffer für genau 15 min bei Raumtemperatur zu glatten Enden abgebaut (50 $\mu$ l DNA, $20 \mu 1$ T4-Polymerase-Puffer, 2,5 $\mu 1$ T4-DNA-Polymerase, $5 \mu \mathrm{l}$ dNTPs $(20 \mathrm{mM})$, ad $\left.100 \mu 1 \mathrm{H}_{2} \mathrm{O}\right)$.

\subsubsection{Ligation}

Die Ligation von DNA-Fragmenten erfolgte mit Hilfe der T4-DNA-Ligase (1 U; Promega, Roche oder $\mathrm{MBI}$ ), in einem Volumen von $10 \mu \mathrm{l}$ (Ligationspuffer: $30 \mathrm{mM}$ TrisHCl (pH 7,8), $10 \mathrm{mM} \mathrm{MgCl}_{2}, 10 \mathrm{mM}$ DTT, 0,5 mM ATP). In einzelnen Fällen wurde das Gesamtvolumen bis maximal $13 \mu$ überschritten. Es wurden ca. $25 \mathrm{ng}$ des desphosphorylierten Vektors genommen. Die Menge des zu klonierenden phosphorylierten DNA-Fragmentes variierte zwischen einem dreifachen bis fünffachen Überschuss und einem Einsatz zu gleichen Teilen im Verhältnis zu dem desphosphorylierten Vektor (Mülhardt 1999). Die Ligation erfolgte bei ca. $15^{\circ} \mathrm{C}$ über Nacht.

\subsubsection{Herstellung von mit Digoxygenin und Fluoreszein markierten Sonden}

Gegenstrang-RNA wurde, mit Digoxygenin oder Fluoreszein markiert, zur In-situ-Hybridisierung verwendet. Zuerst wurde das die cDNA enthaltende Plasmid mit einem Restriktionsenzym am 5'-Ende geschnitten. Hierfür wurden nur Restriktionsenzyme benutzt, die ein 5'-überhängendes Ende erzeugten. Es wurden $10 \mu \mathrm{g}$ des Plasmids mit dem entsprechenden Restriktionsenyzm (100 U) in einem Ansatz von $100 \mu l$ linearisiert (2,5 - 3 h). Für die Herstellung von Proben, die zur Färbung von elektroporierten Embryonen hergestellt wurden, wurden mittels PCR amplifizierte DNA-Moleküle benutzt. Primer für GANF waren: Reverse primer, 5'-AACAGCTATGACCATG-3', M13-20 Primer (universal), 5'-GTAAAACGACGGCCAGT-3'); diese Primer sind für die Amplifikation von jedem Konstrukt, welches in Bluescript kloniert ist, geeignet.

Dieser Ansatz wurde mit dem PCR-Purification Kit (Qiagen) gereinigt und in $30 \mu 1$ DEPC- $\mathrm{H}_{2} \mathrm{O}$ aufgenommen, davon wurde $1 \mu \mathrm{l}$ mit einem Agarosegel überprüft.

Unter Verwendung von $1 \mu l$ dieses Eluates wurde nach folgendem Muster eine Transkriptionsreaktion angesetzt: $13 \mu \mathrm{l}$ DEPC- $\mathrm{H}_{2} \mathrm{O}, 2 \mu 110 \mathrm{x}$ Transkriptions-Puffer (Roche), $2 \mu 110 \mathrm{x}$ DIG-labelling-mix, 2 $\mu 1$ RNasin (40 U/ $\mu$ l), $1 \mu 1$ RNA Polymerase (SP6, T3 oder T7) (Gesamtvolumen: $20 \mu$ l). Sie wurde bei $37^{\circ} \mathrm{C}$ für $2 \mathrm{~h}$ inkubiert.

Diese $20 \mu \mathrm{l}$ wurden schließlich auf $50 \mu \mathrm{l}$ mit Wasser (Millipore) aufgefüllt und mit Hilfe von G-50Säulen von dem Überschuss an nicht eingebauten Nukleotiden gereinigt. 
Ein Zehntel des Ansatzes (5 $\mu$ l) wurde auf ein Agarosegel aufgetragen, um die Qualität der Synthese zu überprüfen. Die geprüfte Sonde wurde bei $-20^{\circ} \mathrm{C}$ gelagert.

\subsubsection{Herstellung von radioaktiv markierten DNA-Molekülen mittels ${ }^{32}$ Phosphor- $\alpha$ - dCTP}

Zur Herstellung von radioaktiv markierten DNA-Molekülen wurden zwischen 50 ng und 100 ng aufgereinigte DNA bei $95^{\circ} \mathrm{C}$ für 10 min denaturiert und anschließend sofort auf Eis gekühlt. Hexamernukleotide mit jeder möglichen Sequenz $\left(\mathrm{N}_{6}\right)$ dienten als Primer für das Klenow-Fragment, das diese unter Einbau von radioaktivem dCTP innerhalb von $1 \mathrm{~h}$ bei $37^{\circ} \mathrm{C}$ verlängerte (Tabelle 1, Multiprime DNA-labelling-System RPN1601, Amersham Pharmacia Biotech Inc). Die markierten DNA-Sonden wurden mit der G-50-Säule von dem Überschuss an nicht eingebauten Nukleotiden befreit. Der Einbau der radioaktiven Nukleotide wurde in dem L1701 Liquid Scintillation System (Beckman) gemessen. Es wurden spezifische Aktivitäten von $1 * 10^{8}$ bis $3 * 10^{8} \mathrm{cpm} / \mu \mathrm{g}$ DNA erreicht.

\begin{tabular}{l|l}
\hline \multicolumn{1}{c|}{ Komponente } & \multicolumn{1}{c}{ Menge/Volumen } \\
\hline zu markierende DNA & $50 \mathrm{ng}-100 \mathrm{ng}$ in $28 \mu \mathrm{l}$ \\
\hline$(\mathrm{N})_{6}$ Primer/BSA-Mix & $5 \mu \mathrm{l}$ \\
\hline $\begin{array}{l}\text { Klenow-Puffer (50 mM TrisHCl, } 10 \mathrm{mM} \mathrm{MgCl}{ }_{2}, 1 \mathrm{mM} \\
\text { DTT) }\end{array}$ & $10 \mu \mathrm{l}$ \\
\hline 32 Phosphor- $\alpha$-dCTP $(50 \mu \mathrm{Ci})$ & $5 \mu \mathrm{l}$ \\
\hline Klenow-Fragment & $1 \mu \mathrm{l}$ \\
\hline Wasser (Millipore) & auf $100 \mu \mathrm{l}$ \\
\hline
\end{tabular}

Tabelle 1: Ansatz zur radioaktiven Markierung von DNA-Fragmenten.

\subsubsection{Radioaktive Markierung der für den EMSA benötigten Oligonukleotide}

Bei den für den EMSA benötigten doppelsträngigen Oligonukleotiden wurde jeweils nur ein Strang wie folgt 60 min bei $37^{\circ} \mathrm{C}$ radioaktiv markiert. 


\begin{tabular}{l|l}
\hline \multicolumn{1}{c|}{ Komponente } & \multicolumn{1}{c}{ Volumen } \\
\hline einzelsträngiges Oligonukleotid $(0,1 \mathrm{nmol})$ & $1 \mu \mathrm{l}$ \\
\hline Kinasepuffer (Roche) & $2 \mu \mathrm{l}$ \\
\hline$\gamma^{3}{ }^{32} \mathrm{P}-\mathrm{dATP}(30 \mathrm{mCi})$ & $3 \mu \mathrm{l}$ \\
\hline Polynukleotidkinase (1 U) (Roche) & $1 \mu \mathrm{l}$ \\
\hline Wasser (Millipore) & auf $20 \mu \mathrm{l}$ \\
\hline
\end{tabular}

Tabelle 2: Ansatz zur radioaktiven Markierung von Oligonukleotiden.

Die $20 \mu$ l Reaktionsansatz wurden mit Wasser (Millipore) auf $50 \mu 1$ aufgefüllt und mittels einer G-50Säule von den nicht eingebauten Isotopen getrennt. $\mathrm{Zu}$ den meistens ca. $60 \mu 1$ (nach diesem Schritt) wurden $1 / 10$ Volumen $1 \mathrm{M} \mathrm{KCl}$ sowie $1 \mu \mathrm{l}$ des komplementären Oligonukleotides hinzugefügt. Der Reaktionsansatz wurde nun in ein PCR-Cup überführt, $50 \mu$ l Mineralöl hinzugefügt und 10 min bei 94 ${ }^{\circ} \mathrm{C}$ in einer PCR-Maschine inkubiert. In den folgenden 45 min kühlte der Reaktionsansatz in der PCRMaschine auf RT ab. $1 \mu \mathrm{l}$ der Reaktion des hybridisierten doppelsträngigen Oligonukleotides wurde zum Schluss auf die Counts pro Minute (cpm) gemessen und entsprechend auf $25000 \mathrm{cpm} / \mu \mathrm{l} \mathrm{mit}$ Wasser (Millipore) verdünnt.

\subsubsection{Polymerase-Kettenreaktion (PCR)}

Die PCR wurde zum Nachweis eines DNA-Fragmentes in einem Vektor zur Überprüfung der Orientierung von klonierten DNA-Fragmenten in Vektoren bzw. zur Synthese von DNA-Molekülen zur weiteren Klonierung mit der Taq-Polymerase (Thermus aquaticus) durchgeführt (Saiki et al. 1988). Dazu wurden 1 bis 10 pg der Plasmid-DNA, 0,4 $\mu \mathrm{M}$ je Primer, $200 \mu \mathrm{M}$ je Desoxynukleotid, $1 \mathrm{U}$ Taq-Polymerase und entsprechender Puffer (10 mM TrisHCl ( $\mathrm{pH} 8,8), 50 \mathrm{mM} \mathrm{KCl}, 1,5 \mathrm{mM} \mathrm{MgCl} 2)$ verwendet. Es wurde das folgende Temperaturprofil in einem Mastercycler (Eppendorf) gefahren:

\begin{tabular}{l|l|l}
\hline \multicolumn{1}{c|}{ Schritt } & \multicolumn{1}{c}{ Temperatur } & \multicolumn{1}{c}{ Dauer } \\
\hline 1. Initiale Denaturierung & $94^{\circ} \mathrm{C}$ & $3 \mathrm{~min}$ \\
\hline 2. Denaturierung & $94^{\circ} \mathrm{C}$ & $30 \mathrm{sec}$ \\
\hline 3. Annealing & $50^{\circ} \mathrm{C}$ bis $65^{\circ} \mathrm{C}$ & $30 \mathrm{sec}$ \\
\hline 4. Synthese & $72^{\circ} \mathrm{C}$ & $\mathbf{1} \mathbf{~ m i n}$ pro kb \\
\hline 5. Endsynthese & $72^{\circ} \mathrm{C}$ & $10 \mathrm{~min}$ \\
\hline
\end{tabular}

Tabelle 3: Protokoll einer Standard-PCR. Schritte 2-4 wurden in der Regel 30 mal wiederholt. 
Für die Amplifikation der Patienten-DNA wurden das Kit Advantage ${ }^{T} c D N A$ Polymerase Mix (\#84171; Clontech) benutzt. Für die Introns und die Exons wurden die Primer aus Dattani (1998) bzw. für die PCR des konservierten Teiles des Promotors folgende Primer verwendet:

\begin{tabular}{l|l}
\hline \multicolumn{1}{c|}{ Primer } & \multicolumn{1}{c}{ Basensequenz (5'-3') } \\
\hline HESX1F & AGCTGTTGCCTGTGCAGACCACGAAGA \\
\hline HESX1R & ACAAAGAATTTGAAACAATTAAGCTGTGGCA \\
\hline HESX2F & TGGAACATAAGATTGACCATCTAAGAC \\
\hline HESX2R & AGCCTTTATATTATCATTATTGGGTGAA \\
\hline HESX3F & AGCTCATTTTTGGAGACATACTTGAATA \\
\hline HESX3R & TAACATTTCAACATCATGAATAACAACT \\
\hline HESX4F & GAATAATAAAATAATGTTTCTGAGACCTAT \\
\hline HESX4R & TCATGCTCTGCAATTAGAAGATAATTTCAC \\
\hline HESXPRO1 & GCAAGTTGAGGGTTTGTTTTCCCCGAGC \\
\hline HESXPRO3 & GAGCTGACGAGAGCATAGAACGCAG \\
\hline HESXPRO4 & GGTCCGTGAACCTTCTGTTAATGTGAGG \\
\hline
\end{tabular}

Tabelle 4: Amplifikation der Introns, Exons und der konservierten Promotorsequenz beim Menschen: Primer und deren Basensequenz.

Für folgende Paare wurden folgende Annealing-Temperaturen verwendet: HESX1F, HESX1R $\left(65^{\circ} \mathrm{C}\right)$; HESX2F, HESX2R $\left(50^{\circ} \mathrm{C}\right), \operatorname{HESX} 3 \mathrm{~F}, \operatorname{HESX} 3 \mathrm{R}\left(60^{\circ} \mathrm{C}\right)$; HESX4F, HESX4R $\left(60^{\circ} \mathrm{C}\right)$; HESX4R, HESX3F $(60$ $\left.{ }^{\circ} \mathrm{C}\right) ; \operatorname{HESX} 1 \mathrm{~F}, \operatorname{HESX} 2 \mathrm{R}\left(55^{\circ} \mathrm{C}\right) ; \operatorname{HESX} 4 \mathrm{R}, \operatorname{HESX} 1 \mathrm{~F}\left(60^{\circ} \mathrm{C}\right) ; \operatorname{HESXPRO} 4, \operatorname{HESX} 1 \mathrm{~F}\left(60^{\circ} \mathrm{C}\right)$.

\subsubsection{Vorbereitung der DNA zur Injektion in einen Zebrafischembryo}

Zuerst wurden $10 \mu \mathrm{g}$ der DNA von der Ampicillin-Resistenz und den verbleibenden Plasmidsequenzen durch die entsprechenden Restriktionsenzyme getrennt und in einem Agarosegel aufgetrennt (Asp 718I (Roche) und SalI für das Reporterkonstrukt RK2). Im Folgenden wurde die DNA elektroeluiert und anschließend mit Phenol und Chloroform extrahiert und mit 0,7 V Isopropanol gefällt. Die DNA wurde mit der Zielmenge $15 \mathrm{ng} / \mu 1$ in HEPES (N-(2-Hydroxyethyl)Piperazin-N'-(2-Ethansulfonsäure); 10 mM, pH 7,4) äquimolar aufgenommen. Referenzwert war das Reporterkonstrukt RK2 (ca. 16500 bp). 


\subsection{Analyse von Nukleinsäuren}

\subsubsection{Sequenzierungen}

DNA-Sequenzierungen erfolgten als Service durch technische Angestellte der Abteilungen Molekulare Zellbiologie und Molekulare Entwicklungsbiologie des Max-Planck-Instituts für biophysikalische Chemie, Göttingen, mittels des Taq-Dye-Desoxy-Terminator-Kits (Perkin Elmer-ABI) auf ABI 377 Sequenziergeräten.

\subsubsection{Southern Blot}

Zur Identifizierung des Phagenklones mit einem möglichst großen 5'-Bereich wurden Restriktionsverdaue mittels der schnellen Variante des Southern Blots (Blot mit alkalischem Puffer) näher charakterisiert.

Nach der Auftrennung der Restriktionsverdaue auf einem $1 \%$ igen Agarosegel wurde dieses Gel für 15 min in 0,25 M HCl und im Anschluss für 10-20 min in 0,4 M NaOH gebadet.

Es folgte dann der Aufbau der Blotvorrichtung in folgender Reihenfolge auf der Tischplatte der Arbeitsfläche; jeder Teil war dabei auf die Größe des Geles zurechtgeschnitten. Ein bis zwei Stapel Papierhandtücher, zehn Stück trockenes Whatman-Papier, vier Stück in $0,4 \mathrm{M} \mathrm{NaOH}$ getauchtes Whatman-Papier, die positiv geladene Nylonmembran, das Agarosegel und vier Stück in 0,4 M NaOH getauchtes Whatman-Papier. Es folgten drei längliche, ebenfalls in $0,4 \mathrm{M} \mathrm{NaOH}$ gebadete Stück Whatman-Papier, die mit ihren beiden Enden jeweils in einem mit $0,4 \mathrm{M} \mathrm{NaOH}$ gefüllten Behältnis lagen und so durch die Kapillarkräfte als Brücke für den Laufpuffer 0,4 M NaOH dienten. Nach dem Abdekken mit einer Lage Frischhaltefolie wurde der ganze Aufbau mit einer gefüllten $500 \mathrm{ml}$ Flasche beschwert, die zur Verteilung des Gewichts auf den für das Gel benutzten, getrockneten Gelschlitten gestellt wurde.

Um einen "Kurzschluss" der Transferlösung zu vermeiden, wurde bei diesem Aufbau zwischen dem Agarosegel und den oberen vier Stücken Whatman-Papier eine Art Rahmen aus $5 \mathrm{~cm}$ breitem Parafilm gelegt.

Die Transferdauer betrug 3,5 h. Danach wurde die Nylonmembran zweimal kurz in 2 x SSC zur Neutralisierung des alkalischen Puffers gebadet, um schließlich mit der Fixierung und der Hybridisierung fortzufahren.

\subsubsection{Whole-mount-in-situ-Hybridisierung (WMISH)}

Sowohl die Zebrafischembryonen als auch die Hühnerembryonen wurden mittels der In-situ-Hybridisierung untersucht. 


\begin{tabular}{|c|c|}
\hline Lösung & Dauer/Temperatur/Vorgang \\
\hline PBT & $2 \times 5 \mathrm{~min}$ \\
\hline $25 \%$ Methanol in PBT & $5 \mathrm{~min}$ \\
\hline $50 \%$ Methanol in PBT & $5 \mathrm{~min}$ \\
\hline $75 \%$ Methanol in PBT & $5 \mathrm{~min}$ \\
\hline $100 \%$ Methanol in PBT & $5 \min$ \\
\hline $75 \%$ Methanol in PBT & $5 \mathrm{~min}$ \\
\hline $50 \%$ Methanol in PBT & $5 \mathrm{~min}$ \\
\hline $25 \%$ Methanol in PBT & $5 \mathrm{~min}$ \\
\hline PBT & $2 \times 5 \mathrm{~min}$ \\
\hline $\begin{array}{l}6 \% \mathrm{H}_{2} \mathrm{O}_{2} / \mathrm{PBT} \\
\quad\left(2 \mathrm{ml} \mathrm{H}_{2} \mathrm{O}_{2}(30 \%) \text { ad } 10 \mathrm{ml} \mathrm{PBT}\right)\end{array}$ & $30 \mathrm{~min}$ \\
\hline PBT & $3 \times 5 \mathrm{~min}$ \\
\hline $\begin{array}{l}10 \mu \mathrm{g} / \mathrm{ml} \text { Proteinase K/PBT } \\
(10 \mu \mathrm{l} \text { in } 10 \mathrm{ml} \text { PBT, Stocklsg. von Proteinase } \mathrm{K}: 10 \mathrm{mg} / \mathrm{ml})\end{array}$ & $1-3 \min$ \\
\hline $\begin{array}{l}2 \mathrm{mg} / \mathrm{ml} \text { Glyzin/PBT } \\
(20 \mathrm{mg} \text { Glycin in } 10 \mathrm{ml} \text { PBT })\end{array}$ & $5 \mathrm{~min}$ \\
\hline PBT & $2 \times 5 \mathrm{~min}$ \\
\hline $\begin{array}{l}0,2 \% \text { Glutaraldehyd } / 0,1 \% \text { Tween } / 4 \% \text { PFA/PBT } \\
(40 \mu 150 \% \text { Stocklsg. Glutaraldehyd, } 100 \mu 110 \% \text { iges } \\
\text { Tween ad } 10 \mathrm{ml} 4 \% \text { PFA/PBT) }\end{array}$ & $20 \min , 4^{\circ} \mathrm{C}$ \\
\hline PBT & $2 \times 5 \mathrm{~min}$ \\
\hline Optional: $50 \%$ Formamid, 5 x SSC pH 4,5 & Lagern bei $-20^{\circ} \mathrm{C}$ \\
\hline Prähybridisierungslösung & $5 \mathrm{~min}$ \\
\hline Prähybridisierungslösung & $\operatorname{mind} .1 \mathrm{~h}, \max .3 \mathrm{~h}, 70^{\circ} \mathrm{C}$ \\
\hline Hybridisierungslösung & über Nacht, $70^{\circ} \mathrm{C}$ \\
\hline
\end{tabular}

Tabelle 5: Übersicht der Waschschritte und Inkubationen am ersten Tag der In-situ-Hybridisierung. (PBT (0,1 \% Tween-20 in PBS); Prähybridisierungslösung (50 \% Formamid, 5 x SSC pH 4,5, 1 \% SDS, $50 \mu \mathrm{g} / \mathrm{ml}$ Hefe tRNA, $50 \mu \mathrm{g} / \mathrm{ml}$ Heparin); Hybridisierungslösung: Prähybridisierungslösung mit $1 \mu \mathrm{g} / \mathrm{ml}$ Gegenstrang RNA je Probe. 


\begin{tabular}{|c|c|}
\hline Lösung & Dauer/Temperatur/Vorgang \\
\hline $\begin{array}{l}\text { Lösung } 1 \text { (50 \% Formamid, } 5 \times \text { SSC, } \mathrm{pH} 4,5,1 \% \text { SDS) } \\
\left(50 \mathrm{ml} \text { Formamid, } 25 \mathrm{ml} 20 \times \mathrm{SSC}, 10 \mathrm{ml} 10 \% \text { SDS, ad } 100 \mathrm{ml} \mathrm{H}_{2} \mathrm{O}\right)\end{array}$ & $2 \times 30 \min , 70^{\circ} \mathrm{C}$ \\
\hline $\begin{array}{l}\text { Lösung } 3 \text { (50 \% Formamid, } 2 \text { x SSC, pH 4,5) } \\
\left(50 \mathrm{ml} \text { Formamid, } 25 \mathrm{ml} 20 \text { x SSC, } 1 \mathrm{ml} 10 \% \text { Tween, ad } 100 \mathrm{ml} \mathrm{H}_{2} \mathrm{O} \text { ) }\right.\end{array}$ & $2 \times 30 \min , 70^{\circ} \mathrm{C}$ \\
\hline MAB & $3 \times 5 \mathrm{~min}$ \\
\hline $\begin{array}{l}2 \% \text { BBR/0,1\% Tween/MAB } \\
(2 \mathrm{ml} \mathrm{BBR}, 100 \mu \mathrm{l} 10 \% \text { Tween, ad } 10 \mathrm{ml} \mathrm{MAB})\end{array}$ & $5 \min$ \\
\hline $2 \%$ BBR/0,1\% Tween/MAB & $30 \mathrm{~min}$ \\
\hline $\begin{array}{l}20 \% \text { FCS } / 2 \% \text { BBR/0,1 \% Tween/MAB } \\
(2 \mathrm{ml} \mathrm{BBR,} 2 \mathrm{ml} \mathrm{FCS,} 100 \mu \mathrm{l} 10 \% \text { Tween, ad } 10 \mathrm{ml} \mathrm{MAB})\end{array}$ & $1 \mathrm{~h}$ \\
\hline $\begin{array}{l}\text { Anti-Fluoreszein-Antikörper (1:2000) in } 20 \% \mathrm{FCS} / 2 \% \mathrm{BBR} / 0,1 \% \\
\text { Tween/MAB }\end{array}$ & über Nacht, $4^{\circ} \mathrm{C}$ \\
\hline
\end{tabular}

Tabelle 6: Übersicht der Waschschritte und Inkubationen am zweiten Tag der In-situ-Hybridisierung. (MAB (100 mM Maleinsäure, $150 \mathrm{mM} \mathrm{NaCl,} \mathrm{pH} \mathrm{7,5,} \mathrm{mit} \mathrm{NaOH}$ eingestellt); BBR (Boehringer Blockierungsreagens in MAB, Roche)).

\begin{tabular}{|c|c|}
\hline Lösung & Dauer/Temperatur/Vorgang \\
\hline $\begin{array}{l}\text { MABT } \\
(10 \mu 110 \% \text { iges Tween in } 10 \mathrm{ml} \mathrm{MAB})\end{array}$ & $3 \times 5 \min$ \\
\hline MABT & 4 x 1 h (oder über Nacht) \\
\hline $\begin{array}{l}\text { NTMT pH 8,0 } \\
\left(1 \mathrm{ml} 5 \mathrm{M} \mathrm{NaCl}, 5 \mathrm{ml} 1 \mathrm{M} \text { TrisHCl (pH 8,0), } 2,5 \mathrm{ml} 1 \mathrm{M} \mathrm{MgCl}_{2}, 5\right. \\
\mathrm{ml} 10 \% \text { iges Tween, } 0,5 \mathrm{ml} 100 \% \text { iges Levamisol, ad } 50 \mathrm{ml} \mathrm{H} 2 \mathrm{O})\end{array}$ & $2 \times 5 \min$ \\
\hline NTMT pH 8,0 & $3 \times 30 \mathrm{~min}$ \\
\hline Fast Red in NTMT pH $\mathbf{8 , 0} *$ & $45 \mathrm{~min}$ bis $5 \mathrm{~h}$ \\
\hline PBT & $2 \times 10 \mathrm{~min}$ \\
\hline 0,1 M Glyzin/HCl (pH 2,2) & $10 \mathrm{~min}$ \\
\hline PBT & $5 \times 10 \mathrm{~min}$ \\
\hline $4 \%$ PFA/PBS & über Nacht, $4^{\circ} \mathrm{C}$ \\
\hline
\end{tabular}

Tabelle 7: Übersicht der Waschschritte und Inkubationen am dritten Tag der In-situ-Hybridisierung. (*Fast Red TR/ Naphtol AS-MX Tabletten (Sigma) in je $1 \mathrm{ml}$ Wasser (Millipore) gelöst (1 mg/ml 4-Chlor-2methylbenzendiazonium, $\quad 0,4 \mathrm{mg} / \mathrm{ml} \quad$ 3-Hydroxy-2-naphtolsäure-2,4-dimethylanilidphosphat, $0,15 \mathrm{mg} / \mathrm{ml}$ Levamisol, $100 \mathrm{mM}$ TrisHCl (pH 8,0)), vor dem Gebrauch durch einen 0,22 $\mu \mathrm{m}$ Spritzenaufsatzfilter (Millipore) von unlöslichen Bestandteilen gereinigt; NTMT pH 8,0 (100 mM NaCl, 100 mM TrisHCl pH 8,0, 50 mM MgCl$_{2}$, $1 \%$ Tween-20, 2 mM Levamisol)). 


\begin{tabular}{l|l}
\multicolumn{1}{c|}{ Lösung } & \multicolumn{1}{c}{ Dauer/Temperatur/Vorgang } \\
\hline PBT & $2 \times 5$ min \\
\hline MAB & $3 \times$ Waschen \\
\hline MAB & $2 \times 30 \mathrm{~min}$ \\
\hline $2 \%$ BBR/MAB & $1 \mathrm{~h}$ \\
\hline $20 \%$ FCS/2 \% BBR/MAB & $1 \mathrm{~h}$ \\
\hline $\begin{array}{l}\text { Anti-Digoxygenin-Antikörper (1:2000) in 20 \% FCS/ } \\
2 \% \text { BBR/MAB } \\
(5 \mu \mathrm{AB} \text { in } 10 \mathrm{ml} 20 \% \mathrm{FCS} / 2 \% \mathrm{BBR} / \mathrm{MAB})\end{array}$ & \\
\hline
\end{tabular}

Tabelle 8: Übersicht der Waschschritte und Inkubationen am vierten Tag der In-situ-Hybridisierung.

\begin{tabular}{l|l}
\hline \multicolumn{1}{c|}{ Lösung } & \multicolumn{1}{c}{ Dauer/Temperatur/Vorgang } \\
\hline $\begin{array}{l}\text { MABT } \\
\text { (siehe Tabelle 7) }\end{array}$ & $3 \times$ Waschen \\
\hline MABT & $5 \times 1 \mathrm{~h}$ \\
\hline NTMT pH 9,5 & Waschen \\
\hline NTMT pH 9,5 & $3 \times 30$ min \\
\hline NBT/BCIP IN NTMT pH 9,5* & $2 \mathrm{~h}-24 \mathrm{~h}$, im Dunkeln, mit mehr- \\
\hline PBT & fachem Lösungswechsel \\
\hline $50 \%$ Glyzerin/PBT & $2 \times 10$ min \\
\hline $80 \%$ Glyzerin/PBT & $1 \mathrm{~h}$ \\
\hline
\end{tabular}

Tabelle 9: Übersicht der Waschschritte und Inkubationen am fünften Tag der In-situ-Hybridisierung. (* $200 \mu \mathrm{l} \mathrm{NBT/BCIP} \mathrm{Stammlösung} \mathrm{(18,75} \mathrm{mg/ml} \mathrm{NBT,} \mathrm{9,4} \mathrm{mg/ml} \mathrm{BCIP} \mathrm{in} 67$ \% DMSO (v/v), Roche) pro $10 \mathrm{ml}$ NTMT (pH 9,5); Reaktion vor Licht schützen und Färbelösung alle 3 h wechseln; NTMT pH 9,5 (100 mM NaCl, $100 \mathrm{mM}$ TrisHCl (pH 9,5), $50 \mathrm{mM} \mathrm{MgCl} 2,1 \%$ Tween-20, 2mM Levamisol)).

Bei den Zebrafischembryonen wurde dem Protokoll von Jowett und Lettice (1994) gefolgt. Bei den Hühnerembryonen wurde die In-situ-Hybridisierung nach Knoetgen (2000) durchgeführt. Sie wurde sowohl für zwei RNAs als auch für eine RNA durchgeführt. Im letzteren Fall wurde das Protokoll für den dritten Tag (siehe oben) durch das Protokoll für den fünften Tag ersetzt. Tag vier fällt entsprechend weg.

Die In-situ-Hybridisierung eines Genes diente zur Lokalisation der X-gal-Färbung nach der Elektroporation bzw. Injektion. Die Embryonen wurden nach der X-gal-Färbung dreimal 10 min in PBS gewa- 
schen und danach für ca. eine halbe Stunde bei Raumtemperatur nochmals fixiert, diesmal in einer 4 \%igen PFA/PBS-Lösung, alternativ über Nacht bei $4{ }^{\circ} \mathrm{C}$. Nach abermals drei Waschschritten, jetzt in PBT, wurden die Embryonen durch die oben tabellarisch aufgeführten Schritte geführt. In 100 \%igem Methanol konnten sie bei $-20{ }^{\circ} \mathrm{C}$ für einen längeren Zeitraum gelagert werden. Bei allen diesen Schritten befanden sich die Embryonen in Netzen, die das Umsetzen in die jeweils neue Flüssigkeit sehr erleichterten. Die Inkubationsdauer mit Proteinase K war abhängig von dem Entwicklungsstadium (< HH7 = 1 min, $>$ HH7 = 3 min). In den Tabellen 5 bis 9 (Seiten 29-31) sind die Waschschritte und Inkubationen tabellarisch aufgeführt (nach Knoetgen 2000).

\subsection{Klonierung der Reporterkonstrukte}

Für die Bezeichnung der Reporterkonstrukte wurde die Abkürzung $R K$ gewählt. Die Nummerierung folgte der Reihenfolge aus Abbildung 18 (Seite 50) und nicht der Reihenfolge der Klonierungsschritte. Die richtige Orientierung aller Konstrukte wurde mittels Restriktionsverdau und Sequenzierung überprüft. Wegen der notwendigen Abwesenheit des Restplasmids bei den Injektionen wurde bei allen Reporterkonstrukten darauf geachtet, dass die untersuchte Promotorregion zusammen mit dem lacZGen mit den Restriktionsenzymen Asp718I und SalI von diesem Restplasmid trennbar ist.

\subsubsection{Erzeugung einer NcoI-Schnittstelle im Startkodon des lacZ-Gens im pßgal-BASIC}

Erstens wurde mittels PCR ein Stück DNA amplifiziert, das im ATG des lacZ-Gens eine NcoI-Schnittstelle enthielt und 3' hinter einer EcoR $V$-Schnittstelle aufhörte. Folgender degenerierter Primer (pBETAgal5-1) und $100 \%$ ig passender Primer wurde dafür verwendet:

\begin{tabular}{l|l}
\hline \multicolumn{1}{c|}{ Primer } & \multicolumn{1}{c}{ Basensequenz $\left(5^{\prime}-3^{\prime}\right)$} \\
\hline pBETAgal3-1 & CCACATACAGGCCGTAGCGGT \\
\hline pBETAgal5-1 & CCATGGCGTTTACTTTGACCA \\
\hline
\end{tabular}

Tabelle 10: Primer für die Erzeugung einer NcoI-Schnittstelle in pßgal-BASIC. In Rot ist die NcoISchnittstelle eingezeichnet.

Die überstehenden Basen der PCR wurden mit dem Klenow-Enzym aufgefüllt und danach phosphoryliert.

Zweitens wurde das Plasmid pßgal-BASIC mit HindIII und EcoRV geschnitten, die überhängenden Enden wurden aufgefüllt, dephosphoryliert und auf einem Gel aufgetrennt. 
Als abschließender Schritt erfolgte die Ligation, deren richtige Orientierung mittels eines Doppelverdaus der Enzyme NdeI und EcoRV überprüft wurde.

\subsubsection{Klonierung des Reporterkonstruktes RK4}

Die Klonierung des Reporterkonstruktes RK4 erfolgte durch direkte Ligation des 1800 bp langen Fragments in die NcoI-Schnittstelle des pßgal-Basic-NCO.

\subsubsection{Klonierung der Reporterkonstrukte RK1 und RK2}

Die Konstruktionen der Reporterkonstrukte RK1 und RK2 basierten auf einer Ligation eines Fragmentes aus einem Partialverdau des bereits klonierten Reporterkonstruktes RK4 mit dem 7200 bp bzw. dem 5600 bp langen Fragment (siehe 3.4.2).

\subsubsection{Klonierung der Reporterkonstrukte RK5 und RK6}

Die Konstruktionen der Reporterkonstrukte RK5 und RK6 basierten auf dem Reporterkonstrukt RK4. Die Restriktionsenzyme NsiI und HindIII schneiden nicht im Vektor pßgal-BASIC und nur einmal in dem 1800 bp langen Fragment, und zwar jeweils 534 und 983 bp von der "ATG- NcoI"- Schnittstelle. Durch einen Doppelverdau mit einem weiteren Enzym der MCS (Xhol) konnten somit die 5'-verbleibenden Fragmente herausgeschnitten werden. Nach der Auffüllung der überstehenden Enden (bei HindIII mit dem Klenow-Enzym, siehe 3.4.4; bei NsiI mit T4-DNA-Polymerase, siehe 3.4.5) wurden beide Plasmide im Anschluss religiert.

\subsubsection{Klonierung des Reporterkonstruktes RK3}

Die NcoI-Schnittstellen des 7200 bp langen Fragmentes sind von um jeweils ca. 100 bp versetzten Schnittstellen der Restriktionsenzyme Asp718 und Nhe1 flankiert (siehe Abbildung 18, Seite 50). Dieses Fragment wurde gerichtet in die MCS des p $\beta$ gal-PROMOTOR kloniert.

\subsection{Molekularbiologische Methoden}

\subsubsection{Herstellung von kompetenten Bakterien}

Zur Präparation von elektrokompetenten Bakterien wurde eine Vorkultur DH5 $\alpha$-Bakterien aus einer 
Einzelkolonie in $5 \mathrm{ml}$ LB-Medium angeimpft und über Nacht bei $37{ }^{\circ} \mathrm{C}$ unter Schütteln (200 bis 250 rpm) inkubiert. 2,5 $\mathrm{ml}$ der Vorkultur wurden in $500 \mathrm{ml} \mathrm{LB}$-Medium inokuliert und bei $37{ }^{\circ} \mathrm{C}$ bis zu einer optischen Dichte bei einer Wellenlänge von $600 \mathrm{~nm}$ von 0,5 bis 0,6 OD inkubiert. Die Kultur wurde 15 min auf Eis gekühlt, dann zentrifugiert (15 min, 2000 x g, Sorvall GS-3 Rotor) und das Pellet in $10 \mathrm{ml}$ eiskaltem Wasser resuspendiert. Anschließend wurden 250 bis $500 \mathrm{ml}$ eiskaltes Wasser zugegeben, gemischt und erneut zentrifugiert. Der Überstand wurde dekantiert und das Bakterienpellet in der übrigen Flüssigkeit resuspendiert. Dieser Vorgang wurde einmal wiederholt.

Dann wurde das Bakterienpellet in $10 \%$ igem Glyzerol resuspendiert und erneut zentrifugiert. Der Überstand wurde abgenommen und etwa ein Pelletvolumen 10 \%iges Glyzerol zugegeben. Die Bakterien wurden resuspendiert, in $50 \mu 1$ Aliquots auf Eppendorf-Reaktionsröhrchen aufgeteilt und auf Trokkeneis eingefroren. Die Bakterien wurden anschließend bei $-80{ }^{\circ} \mathrm{C}$ aufbewahrt.

\subsubsection{Transformation von Bakterien durch Elektroporation}

Zur Transformation der elektrokompetenten Bakterien wurde ein Gene Pulser mit Pulse Controller (beides BioRad) verwendet.

Um die Effizienz der Transformation zu erhöhen, wurde der Ligationsansatz vor der Elektroporation entsalzt. Dazu wurde der gesamte Ligationsansatz für 20 min auf einen auf Wasser (Millipore) schwimmenden Filter mit einer Porengröße von 0,025 $\mu \mathrm{m}$ gegeben (Filter VS 0,025 $\mu \mathrm{m}$, Millipore). AnschlieBend wurde $1 \mu l$ Ligationsansatz $\mathrm{zu} 50 \quad \mu \mathrm{l}$ kompetenten Bakterien gegeben und in eine Elektroporationsküvette (1 mm Elektrodenabstand) überführt. Der Elektroporationsapparat wurde auf eine Spannung von 1,75 kV, eine Kapazität von $25 \mu \mathrm{F}$ und einen Widerstand von $200 \mathrm{Ohm}(600 \mathrm{Ohm}$ bei dem Stamm ElectroTen-Blue ${ }^{\mathrm{TM}}$ ) eingestellt und der Spannungspuls ausgelöst.

Im Anschluss wurden unmittelbar $400 \mu \mathrm{l}$ warmes $\left(30^{\circ} \mathrm{C}\right)$ SOC-Medium $(20 \mathrm{~g}$ Tryptone, $5 \mathrm{~g}$ HefeExtrakt, 0,5g NaCl, $5 \mathrm{ml} 2 \mathrm{M} \mathrm{MgCl}_{2}, 10 \mathrm{ml} 250 \mathrm{mM} \mathrm{KCl}, 20 \mathrm{ml} 1 \mathrm{M}$ Glukoselösung, ad $11 \mathrm{H}_{2} \mathrm{O}$ ) zugegeben und für 45 min bei $37^{\circ} \mathrm{C}$ unter Schütteln inkubiert. Anschließend wurden verschiedene Volumina des Transformationsansatzes auf LB-Ampicillin-Agar-Platten (100 $\mu \mathrm{g} / \mathrm{ml}$ Ampicillin) ausplattiert und bei $37^{\circ} \mathrm{C}$ über Nacht inkubiert.

\subsubsection{Screen einer genomischen DNA-Bakteriophagen-Bibliothek}

Mit dem Ziel, einen genomischen Klon des Genes GANF zu isolieren, wurde eine Phagenbibliothek (Chicken Genomic Library, Cat.\# CL1012j, LOT.\# 9030735, Clontech) mit der cDNA (ca. 800 bp, erhalten von Dr. Hendrik Knötgen, Max-Planck-Institut für biophysikalische Chemie, Göttingen) von GANF durchgemustert.

Die für die Phagenvervielfältigung notwendigen Bakterien wurden am Abend vor dem Versuchstag 
von einer antibiotikafreien Agarplatte angeimpft. Dazu wurde eine $50 \mathrm{ml}$ LB-Kultur unter Zusatz von $\mathrm{MgSO}_{4}$ und Maltose (Endkonzentrationen: $10 \mathrm{mM} \mathrm{MgSO}_{4}, 0,2 \%$ Maltose) vorbereitet. Es wurde eine einzelne Bakterienkolonie inokuliert und die Kultur bei $37{ }^{\circ} \mathrm{C}$ über Nacht mäßig geschüttelt. Der Zusatz des Zuckers erhöht die Effizienz der Phagenadsorption, da Maltose das Maltoseoperon induziert, welches das Gen für den Bakteriophagen- $\lambda$-Rezeptor enthält. Das bei 4000 x g 10 min zentrifugierte Bakterienpellet wurde in $1 / 3$ Volumen $10 \mathrm{mM} \mathrm{MgSO}_{4}$ der ursprünglichen Bakterienkultur aufgenommen und gelöst. Nachdem $600 \mu \mathrm{l}$ dieser Bakteriensuspension mit $1 \mathrm{ml}$ Phagenlösung bei 37 ${ }^{\circ} \mathrm{C} 15$ min inkubiert worden waren, wurde der Plattengröße entsprechend viel $47{ }^{\circ} \mathrm{C}$ warmer Topagar zügig hinzugegeben, zweimal vorsichtig hin und her geschwenkt und der Inhalt direkt im Anschluss gleichmäßig auf der $2 \mathrm{~h}$ vorgewärmten Platte verteilt. Diese Platte wurde über Nacht bei $37^{\circ} \mathrm{C}$ inkubiert.

Bei der Ausplattierung der Phagen wurden folgende Mengen und Verhältnisse berücksichtigt: für $24 \mathrm{x}$ $24 \mathrm{~cm}$ Platten bzw. $15 \mathrm{~cm}$ (Durchmesser) Platten jeweils $2 \mathrm{ml} / 60 \mu \mathrm{l}$ Bakteriensuspension, $40 \mathrm{ml} / 10 \mathrm{ml}$ Top-Agarose entsprechend, $2 \times 10^{5} / 5 \times 10^{4}$ pfu (plaque forming $u$ nits - Kolonie bildende Einheit). Jeder Plaque enthält die Nachkommen von einem einzelnen Bakteriophagenpartikel, so dass es möglich ist, Populationen von Bakteriophagen zu erhalten, die genetisch absolut identisch sind. Im Folgenden wurde von den Platten ein Abdruck gemacht, indem eine passend zurechtgeschnittene Membran (Qiagen und NEN ${ }^{\mathrm{TM}}$ Life Science Products Colony/Plaque Screen Hybridization Transfer Membrane) auf den Bakterienboden sowie die Phagenplaques gelegt wurde. Die Membran blieb genau 1 min lang liegen, während dessen mit einer sterilen Kanüle vorher auf der Rückseite der Platte asymmetrisch angebrachte Punkte durch die Membran gestochen wurden, um diese Position im Nachhinein exakt bestimmen zu können. Um die Abweichung zwischen Markierungspunkt auf der Unterseite der Bakterienplatte und dem Einstichloch der Kanüle zu vermeiden, die durch die punktförmige Lichtquelle des verwendeten Overheadprojektors entstehen kann, wurde vorher der Mittelpunkt der Lampe auf dem Glas mit einem Kreuz markiert und die Membran immer in Übereinstimmung von diesem Kreuz und der Markierung auf der Unterseite der Platte durchstochen. Schließlich wurde mit einem Bleistift die Nicht-DNA-Seite beschriftet. Die Bildung von Luftblasen wurde vermieden; die Reinigung der Handschuhe erfolgte mit 70 \%igem Ethanol.

Nachdem die Membranen mit einer Greifpinzette zügig von dem Agar abgezogen waren, wurden sie mit der DNA-Seite nach oben bei Raumtemperatur getrocknet. Die nächsten Schritte hatten die kovalente Fixierung der Bakteriophagen-DNA zum Ziel. Zum Aufschließen der Phagen wurde die Membran zuerst $5 \mathrm{~min}$ in der Denaturierungslösung gebadet (1,5 $\mathrm{m} \mathrm{NaCl}, 0,4 \mathrm{mM} \mathrm{NaOH})$, danach $5 \mathrm{~min}$ in einer Neutralisierungslösung (1 M Tris/HCl $(\mathrm{pH} 8,0), 1,5 \mathrm{M} \mathrm{NaCl})$ gewaschen und schließlich zweimal jeweils $5 \mathrm{~min}$ in 2 x SSC (20 x SSC: 175,3 $\mathrm{g} \mathrm{NaCl}, 88,2 \mathrm{~g} \mathrm{NaCitrat,} \mathrm{ad} 11$, (pH 7,0$)$ ) äquilibriert und wiederum bei Raumtemperartur luftgetrocknet. Die kovalente Fixierung der DNA auf den Membranen erfolgte mit UV-Licht der Wellenlänge $312 \mathrm{~nm}\left(0,3 \mathrm{~J} / \mathrm{cm}^{2}\right)$ (Fluolink, 28607) sowie durch die 
Inkubation der Membranen bei $80{ }^{\circ} \mathrm{C}$ für $2 \mathrm{~h}$. Nachdem die Membranen mit demineralisiertem Wasser (Millipore) angefeuchtet waren, wurden sie $2 \mathrm{~h}$ bei $65^{\circ} \mathrm{C}$ in der Prähybridisierungslösung (4 x SSC, 0,1 \% SDS, 10 x Denhardt's Lösung, 50 g/ml ssDNA; Denhardt's Lösung (50 x): 5 g BSA, 5 g Ficoll, 5 g Polyvinyl-Pyrollidon, ad $500 \mathrm{ml} \mathrm{H}_{2}$ ) inkubiert. (Die $24 \mathrm{~cm}$ x $24 \mathrm{~cm}-$ Membranen zu dritt in einer Hybridisierungsflasche $(50 \mathrm{ml})$, die $15 \mathrm{~cm}-M e m b r a n e n$ alle in einem Topf $(350 \mathrm{ml})$.)

Die Hybridisierung erfolgte bei $65{ }^{\circ} \mathrm{C}$ über Nacht in $20 \mathrm{ml}$ Hybridisierungslösung (identisch mit der Prähybridisierunglösung), zu der radioaktiv markierte DNA zuvor hinzugegeben worden war. Die Membranen wurden am folgenden Tag mit hoher Stringenz (hohe Temperatur, niedriger Salzgehalt) wie folgt gewaschen: 2 x: $45 \mathrm{~min}, 200 \mathrm{ml}, 2$ x SSC, 0,5 \% SDS - 1 x: $20 \mathrm{~min}, 200 \mathrm{ml}, 0,5$ x SSC, 0,5\% SDS - 1 x: $20 \mathrm{~min}, 200 \mathrm{ml}, 0,5 \mathrm{x}$ SSC, 0,1\% SDS - 2 x: $10 \mathrm{~min}, 200 \mathrm{ml}, 0,1 \mathrm{x}$ SSC, 0,1\% SDS.

Die wiederum getrockneten Membranen wurden in einer Röntgenkassette zusammen mit einem Röntgenfilm und einer Verstärkerfolie bei $-70{ }^{\circ} \mathrm{C}$ entwickelt. Im Anschluss wurden die markierten Einstichstellen von den Filtern auf die entwickelten Filme übertragen und wiederum mit Hilfe des Overheadprojektors mit den Punkten auf den Bakterienplatten in Übereinstimmung gebracht. So konnte schließlich ein Plaque, das ein positives Zeichen ergab, mit einer abgeschnittenen Plastikpasteurpipette unter leichtem Drehen ausgestochen werden und in ein $2 \mathrm{ml}$ Eppendorf-Reaktionsgefäß mit $500 \mu \mathrm{l}$ SM-Puffer (=Solution Medium: 5,8 g NaCl, $2 \mathrm{~g} \mathrm{MgSO}_{4}$ x 7 H $\mathrm{H}_{2} \mathrm{O}, 50 \mathrm{ml} 1 \mathrm{M}$ Tris $\mathrm{HCl}$ (pH 7,5), $5 \mathrm{ml} 2 \%$ Gelatinlösung ad $11 \mathrm{H}_{2} \mathrm{O}$ ) und $50 \mu \mathrm{l}$ Chloroform übertragen werden. Dieses Reaktionsgefäß wurde 1-2 h bei Raumtemperatur stehen gelassen, um es den Bakteriophagen zu ermöglichen, aus dem Agar herauszudiffundieren.

Da aufgrund des sehr dichten Wachstums der Phagenplaques beim ersten Durchlauf des Protokolls nur sehr wenige Plaques sicher einzeln isoliert werden konnten, folgte ein zweiter Durchlauf mit der gewonnenen Phagensuspension. Dieser zweite Durchlauf war ausreichend, um im Anschluss einzelne Plaques mit genügend großem Abstand von nicht positiven Plaques zu isolieren.

\subsubsection{Elektrophoretische Gelretardationsexperimente mit radioaktiv markierten Oli- gonukleotiden (EMSA)}

Die sequenzspezifische Bindung von Proteinen an doppelsträngigen Oligonukleotiden erfolgte mittels elektrophoretischer Mobilitätstests (EMSA, radioaktive Markierung der Oligonukleotide siehe 3.4.9).

\subsubsection{In-vitro-Translation zur Überexpression von Proteinen (TNT-system, Promega)}

Als Ausgangsplasmid für die In-vitro-Translation wurde Bluescript sowie pSP65 benutzt. Als Polymerase wurde im ersten Fall immer die T7-RNA-Polymerase (GANF, Otx2), im letzten Fall SP6-RNAPolymerase (Pax6) benutzt. Da die Aminosäuresequenz des murinen Pax6 zu 99,3 \% mit dem Ortholog des Huhnes identisch ist, wurde mit dem im Labor vorhandenen murinen Vektor gearbeitet (Kawakami 
et al. 1997). Der folgende Ansatz wurde für $2 \mathrm{~h}$ bei $30{ }^{\circ} \mathrm{C}$ inkubiert und direkt danach bei $-80{ }^{\circ} \mathrm{C}$ gelagert:

\begin{tabular}{l|l}
\hline \multicolumn{1}{c|}{ Komponente } & \multicolumn{1}{c}{ Menge/Volumen } \\
\hline Retikulozytenextrakt (Kaninchen) & $25 \mu \mathrm{l}$ \\
\hline Reaktionspuffer & $2 \mu \mathrm{l}$ \\
\hline Aminosäurenmix ohne Methionin (je 1mM) & $1 \mu \mathrm{l}$ \\
\hline Aminosäurenmix ohne Cystein (je 1mM) & $1 \mu \mathrm{l}$ \\
\hline RNasin (40 U) & $1 \mu \mathrm{l}$ \\
\hline Matrizen-DNA & $1-3 \mu \mathrm{l}$ \\
\hline entsprechende Polymerase & $1 \mu \mathrm{l}$ \\
\hline Wasser (Millipore) & auf $50 \mu \mathrm{l}$ \\
\hline
\end{tabular}

Tabelle 11: Übersicht über einen In-vitro-Translation-Reaktionsansatz.

\subsubsection{SDS-Polyacrylamidgelelektrophorese zur Auftrennung von ${ }^{35}$ S-Methionin-mar- kierten Proteinen}

Vor der Durchführung des EMSA wurden Reinheit und Effizienz der In-vitro-Translation getestet. Dafür wurde mit ${ }^{35} \mathrm{~S}-$ Methionin das jeweilige Protein hergestellt und in einer SDS-Polyacrylamidgelelektrophorese (SDS-PAGE) nach ihrem Molekulargewicht aufgetrennt. Die Gele bestanden aus einem Trenn- und einem Sammelgel (ersteres: (10\%), 1,65 ml $30 \%$ Acrylamid/0,8 \% Bisacrylamid, 1,25 ml Tris/HCl, pH 8,8, $50 \mu \mathrm{l} 10 \%$ SDS, 2 ml H $\mathrm{H}_{2} 0,30 \mu \mathrm{l} 10 \%$ APS und 1,7 $\mu$ l TEMED; letzteres: $330 \mu 130$ $\%$ Acrylamid/0,8 \% Bisacrylamid, $622 \mu \mathrm{l}$ Tris/HCl, $\mathrm{pH}$ 8,8, $25 \mu \mathrm{l} 10 \%$ SDS, 1,52 $\mu 1 \mathrm{H}_{2} 0,15 \mu 110 \%$ APS und 1,3 $\mu$ l TEMED). 0,5-2 $\mu 1$ der Proteine wurden für die SDS-PAGE auf ein Volumen von $10 \mu 1$ mit $\mathrm{H}_{2} \mathrm{O}$ aufgefüllt, mit $10 \mathrm{ml}$ Solubilizer gemischt und genauso wie der Prestained-Marker 5 min bei $95{ }^{\circ} \mathrm{C}$ denaturiert. Die Elektrophorese dauerte ca. 1 h (bei 30-100 mA). Die Gele wurden zwischen Whatman-Papier und Frischhaltefolie im Geltrockner getrocknet und für $1 \mathrm{~h}$ bzw. über Nacht auf einem Biomax-Film exponiert.

\subsubsection{Bindungsreaktion}

Am Vortag oder als Vorbereitung am Versuchstag wurde das Polyacrylamidgel (8 \%iges Gel: $20 \mathrm{ml}$ Polyacrylamidlösung (29 \% Acrylamid, 0,8 \% Bisacrylamid), 1,5 ml 10 x TBE- Puffer, 53,1 ml Wasser (Millipore), $400 \mu 110 \%$ APS, $40 \mu 1$ TEMED) gegossen. Polymerisiertes Acrylamid im Glasbecher zeigte mit Gewissheit die erfolgte Polymerisierung des Geles. Bevor die in-vitro translatierten Proteine mit den Oligonukleotiden für $1 \mathrm{~h}$ auf Eis zusammen in folgendem Reaktionsansatz inkubiert wurden, 
begann eine einstündige Equilibrierung des Geles bei $150 \mathrm{~V}$ in 0,2 \%igem TBE-Laufpuffer mit einem Marker zur Kontrolle u. a. der richtigen Polung.

\begin{tabular}{l|l}
\hline \multicolumn{1}{c|}{ Komponente } & \multicolumn{1}{c}{ Menge/Volumen } \\
\hline Retardationspuffer (2x) & $10 \mu \mathrm{l}$ \\
\hline $\begin{array}{l}25000 \mathrm{cpm} / \mu \mathrm{l} \gamma-{ }^{32} \mathrm{P}-\mathrm{dATP} \text { markiertes doppelsträngiges } \\
\text { Oligonukleotid }\end{array}$ & $1 \mu \mathrm{l}$ \\
\hline $\begin{array}{l}\text { in-vitro translatiertes Protein (TNT-system, Promega) } \\
\text { Poly-d-IdC (Poly-Desoxyinositol-Desoxycytosin) }\end{array}$ & $3-10 \mu \mathrm{l}$ \\
\hline Wasser (Millipore) & $1 \mu \mathrm{l}$ \\
\hline
\end{tabular}

Tabelle 12: Bindungsreaktion (RB-Puffer: $40 \mathrm{mM}$ HEPES-NaOH (pH 7,6), $8 \%$ Ficoll, $10 \mathrm{mM} \mathrm{MgCl} 2,80 \mathrm{mM}$ $\mathrm{NaCl}, 0,2 \mathrm{mM}$ EDTA, $1 \mathrm{mM}$ DTT), $1 \mathrm{~h}$ auf Eis.

Nach der einstündigen Inkubation wurden die Proben in die vorher sorgfältig durchgespülten Taschen pipettiert und die Elektrophorese entweder über Nacht (150 V) oder ca. 5-6 h lang durchgeführt (250 V), (RT, 0,2 \%iger TBE-Laufpuffer). Anschließend wurde das Gel in Klarsichtfolie eingepackt und in einer Filmkassette 8 h oder über Nacht zusammen mit einem Film exponiert.

\subsubsection{Sequenzen der verwendeten Oligonukleotide}

Stellvertretend für beide komplementären doppelsträngigen Oligonukleotide sind im Folgenden jeweils ein einzelsträngiges Oligonukleotid angegeben:

\begin{tabular}{l|l|c}
\hline \multicolumn{1}{c|}{ Oligonukleotid } & \multicolumn{1}{|c|}{ Basensequenz (5'-3') } & Basen \\
\hline bs001 (P3) & GATCCTGAGTCTAATTGAATTACTGTACA & 29 \\
\hline bsP3MUT & GATCCTGAGTCTACCCGGGTAACTGTACA & 29 \\
\hline bsP52 & GATCTGAGTCTAATTGATGATTACTGTAC & 29 \\
\hline bsP53 & GATCTGAGTCTAATTGAGAATTACTGTAC & 29 \\
\hline bsGANF & AATAATCTCTTAATGCTATTAGGCTAATCCCAATGAA & 37 \\
\hline bsGANFMUT & AATAATCTCTTAGGGCCCTTAGGCATTTCCCAATGAA & 37 \\
\hline bsotxI & CTGTTACTGCTAAGTAATCCAAGCACTTGGAAGGCAA & 37 \\
\hline bsotxIMUT & CTGTTACTGCTAAGGGGCCCAAGCACTTGGAAGGCAA & 37 \\
\hline
\end{tabular}

Fortsetzung nächste Seite

Tabelle 13: Übersicht über die bei den EMSAs verwendeten Oligonukleotide. In roter Farbe sind bei den mutierten Oligonukleotiden die veränderten Basen kenntlich gemacht; unterstrichen sind die untersuchten Bindungsmotive. Die römischen Ziffern bei den Namen der otx-Oligonukleotide beziehen sich auf jeweils eine mögliche Bindungssequenz von Otx2, nicht auf die Nomenklatur der Proteine (Otx1 und Otx2). 


\begin{tabular}{l|l|c}
\hline \multicolumn{1}{c|}{ Oligonukleotid } & \multicolumn{1}{|c}{ Basensequenz (5'-3') } & Basen \\
\hline bsotxII & TTAATGCTATTAGGCTAATCCCAATGAAAATGCCTCT & 37 \\
\hline bsotxIIMUT & TTAATGCTATTAGGCTGGGCCCAATGAAAATGCCTCT & 37 \\
\hline bsOTS & TGCTGAGACCTAATCCTGGGTTATCT & 26 \\
\hline bsoo5apax6 & $\begin{array}{l}\text { GCACGATAGGAAACCAGTCAAGTAATAAGTAATCTCATTTAAGT- } \\
\text { GAATTTCC }\end{array}$ & 52 \\
\hline bspax6MUTR & $\begin{array}{l}\text { GCACGATAGGAAACTGGGCCCTTTATAAGTATGCTCATTTAAGT- } \\
\text { GAATTTCC }\end{array}$ & 52 \\
\hline
\end{tabular}

Tabelle 13: Übersicht über die bei den EMSAs verwendeten Oligonukleotide. In roter Farbe sind bei den mutierten Oligonukleotiden die veränderten Basen kenntlich gemacht; unterstrichen sind die untersuchten Bindungsmotive. Die römischen Ziffern bei den Namen der otx-Oligonukleotide beziehen sich auf jeweils eine mögliche Bindungssequenz von Otx2, nicht auf die Nomenklatur der Proteine (Otx1 und Otx2).

\subsubsection{Färbung des Gewebes mit X-gal}

Vor der Färbung wurden die Embryonen 30 min auf Eis fixiert (für $100 \mathrm{ml}:$ 2,7 ml 37 \% Formaldehyd, $0,8 \mathrm{ml} 25 \%$ Glutaraldehyd, 0,2 $\mathrm{ml} 10 \% \mathrm{NP} 40,5,0 \mathrm{ml} 20 \times \mathrm{PBS}$ (pH 7,4), 91,3 $\mathrm{H}_{2} 0$ (Millipore)). Nach jeweils drei 10 min dauernden Waschschritten (1x PBS) wurde das Gewebe mindestens $3 \mathrm{~h}$ bei $30{ }^{\circ} \mathrm{C}$ mit der X-gal-Färbelösung (für $50 \mathrm{ml}$ : 46,75 $\mathrm{ml} 1$ x PBS (pH 7,4), 0,5 ml $500 \mathrm{mM} \mathrm{K}_{3} \mathrm{Fe}(\mathrm{CN})_{6}, 0,5 \mathrm{ml}$ $500 \mathrm{mM} \mathrm{K}_{4} \mathrm{Fe}(\mathrm{CN})_{6}, 1 \mathrm{ml} 100 \mathrm{mM} \mathrm{MgCl} 2,1,25 \mathrm{ml} 40 \mathrm{mg} / \mathrm{ml} \mathrm{X}$-gal, gelöst in DMSO) inkubiert. Im Anschluss wurde das Gewebe zweimal mit 1 x PBS gewaschen und über eine 50 \%ige PBT/Glyzerinlösung in eine 80 \%ige PBT/Glyzerinlösung überführt und bei $4{ }^{\circ} \mathrm{C}$ gelagert.

\subsection{Histologische Methoden}

\subsubsection{Anfertigung von Paraffinschnitten}

Sowohl Hühnerembryonen als auch Zebrafischembryonen wurden histologisch untersucht. Sie wurden über eine aufsteigende Ethanolreihe entwässert, anschließend in Paraplast eingebettet und im Mikrotom geschnitten (Schnittbreite: $8 \mu \mathrm{m}$ ). Alle histologischen Arbeiten wurden von Wiebke Behrens (MaxPlanck-Institut für biophysikalische Chemie, Göttingen) ausgeführt. 


\subsection{Embryologische Methoden}

\subsubsection{In-vitro-Kultivierung von Hühnerembryonen: die ec-Kultur}

Die In-vitro-Kultivierung mittels der ec-Kultur von Hühnerembryonen wurde wie von Chapman et al. (2001) beschrieben durchgeführt. Als Vorbereitung wurden Agar-Albumin-Kulturschalen hergestellt. Dazu wurden $120 \mathrm{ml} \mathrm{NaCl-Lösung}\left(7,19 \mathrm{~g} \mathrm{NaCl}\right.$ ad $\left.11 \mathrm{H}_{2} \mathrm{O}\right)$ auf $49^{\circ} \mathrm{C}$ erhitzt und 0,72 $\mathrm{g}$ Bacto-Agar hinzugefügt. Wenn dieser gelöst war, wurden $120 \mathrm{ml}$ Eiweiss (aus ca. 24 Eiern) hinzugefügt. Penicillin/ Streptomycin wurde mit der Endkonzentration $5 \mathrm{U} / \mathrm{ml}$ eingestellt. Alles zusammen wurde gut gemischt und schließlich wurden jeweils $2,5 \mathrm{ml}$ in eine $35 \mathrm{~mm}$-Petrischale gefüllt.

Entsprechend der Stadieneinteilung nach Hamburger und Hamilton wurden die Eier - liegend - inkubiert, bis sie das gewünschte Stadium erreicht hatten. Um Embryonen der Stadien HH5 bis HH6 zu erhalten, wurden die Eier 24 h inkubiert. Nach dieser oder der dem gewünschten Stadium entsprechenden Inkubationsdauer und einer 15-30 minütigen Abkühlungsdauer wurde das Ei in einer Petrischale geöffnet und das Eidotter mit der intakten Vitellinmembran in der Petrischale positioniert. Der Embryo war dabei nach oben ausgerichtet. Mittels klein geschnittener Küchentücher (ca. 2 x $4 \mathrm{~cm}$ ) wurde das Eiweiss vorsichtig entfernt. Auf die Vitellinmembran - direkt über der Stelle, unter der der Embryo wächst - wurden $2 \mathrm{~cm}^{2}$ große Whatman-Papiere gelegt, die in der Mitte kleeblattförmig ausgeschnitten waren. Danach wurde die Vitellinmembran um das Whatman-Papier ausgeschnitten und zusammen mit dem Embryo langsam von dem Eigelb gelöst und so auf die vorbereiteten Kulturschalen gelegt, dass der Embryo auf seiner dorsalen Seite zu liegen kam. Die Kulturschalen wurden jeweils in eine größere Petrischale gestellt, in die für eine angemessene Luftfeuchtigkeit ein feuchtes Papiertuch gelegt wurde, und in einem $38^{\circ} \mathrm{C}$ Brutschrank aufbewahrt.

\subsubsection{Gen-Transfer in kultivierte Hühnerembryonen mit Hilfe einer im Rahmen dieser Arbeit neu entwickelten Variante der Elektroporation}

Zur Analyse der Reporterkonstrukte wurde die Methode der Elektroporation verwendet (Itasaki et al. 1999; Muramatsu et al. 1998). Im Rahmen dieser Arbeit wurde hierfür eine neue Elektroporationsvariante entwickelt und im Labor etabliert, die es anders als die In-ovo-Elektroporation erlaubt, sehr junge Embryonen (HH4-HH5) zu elektroporieren. Dies wird im Folgenden dargestellt. Ausgangspunkte sind die Arbeiten von Endo et al. (2002) und Chapmann et al. (2001).

Die Elektroporationskammer wurde so entworfen, dass der Embryo zwischen den beiden Elektroden liegt. Die in der Kammer eingebaute Kathode besitzt eine Fläche von $2 \mathrm{~mm}^{2}$. Die Anode ist ein leicht gebogener Platinstab (Durchmesser 0,2 mm), der wie ein Stempel mittels Mikromanipulator auf den Embryo von oben geführt wird. Diese Bewegung wird gestoppt, sobald ein Kontakt zu der Vitellinmembran hergestellt ist. Zunächst wurden die Embryonen gemäß dem oben dargestellten Protokoll für 
die ec-Kultur vorbereitet. Bevor der Embryo relativ zügig aus dieser Kulturschale mit einer Pinzette herausgeholt wurde, wurden beide Teile des Beckens um die Kathode (siehe Abbildung 13) mit Puffer (PBS) angefüllt. Um die Spiegel beider Becken auf dieselbe Höhe einzustellen, wurde eine Pipette auf den Rand des Glasringes gesetzt und der überschüssige Puffer abgezogen. Im Anschluss wurde der Embryo auf dem Ring so platziert, dass der zu elektroporierende Teil zentral über der Kathode lag. Durch die entsprechende Beleuchtung (siehe Abbildung 13) ergibt sich ein guter Kontrast zwischen der dann dunkel erscheinenden Kathode und dem Embryo. Mit Hilfe einer Mikropipette wurde danach eine
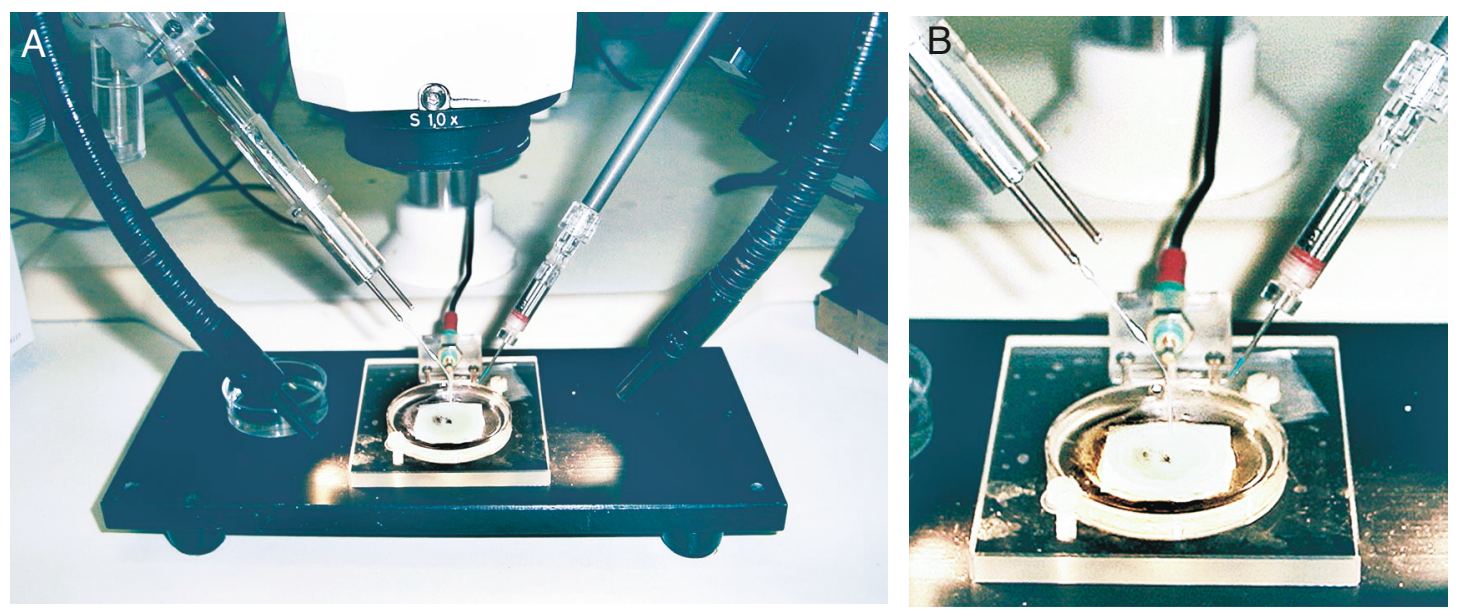

C

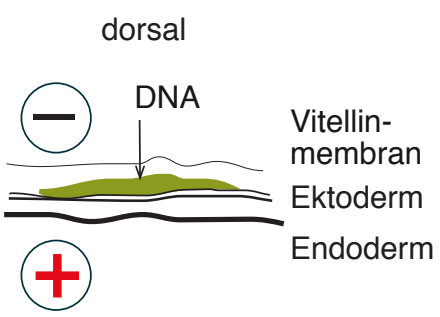

ventral

D

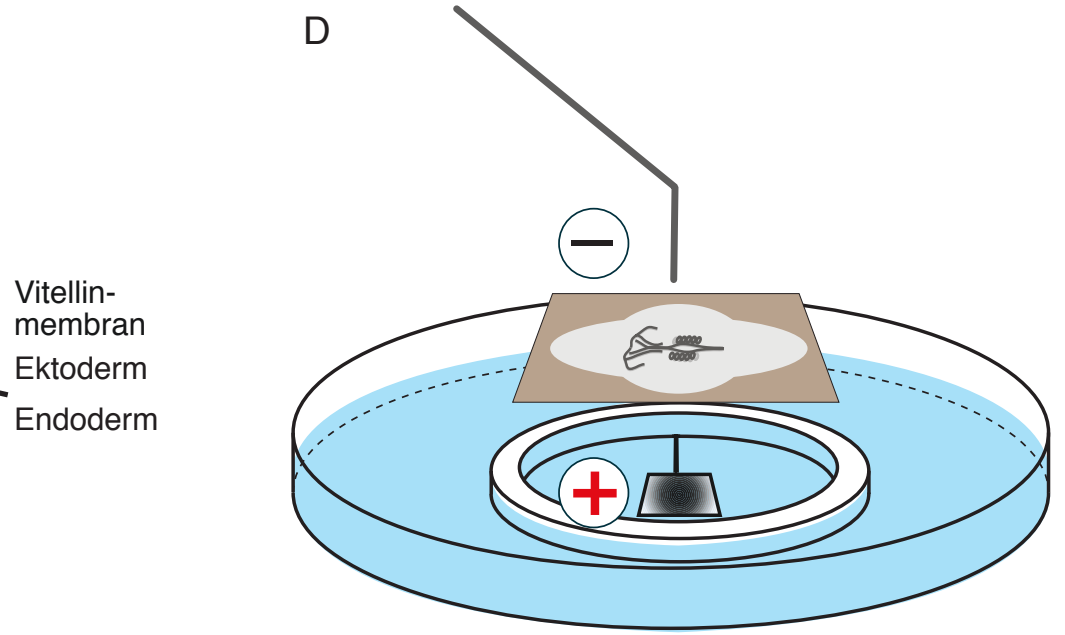

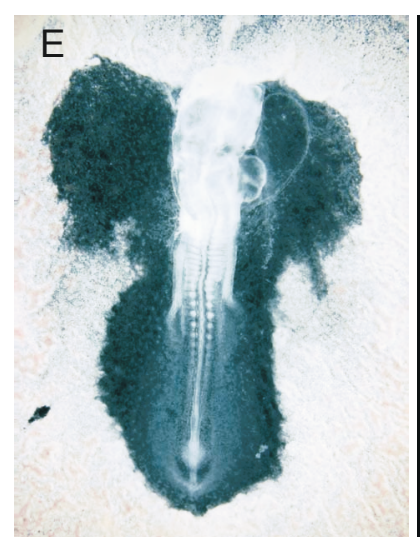

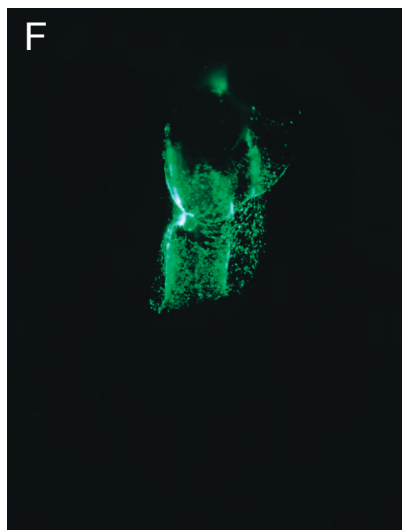

Abb. 13: Darstellung der neu entwickelten Variante der Elektroporation. (A) Übersicht über den Arbeitsplatz. (B) Detailansicht der Elektroporationskammer. Von links ragt die Anode über den Embryo, rechts sieht man die DNA-Injektionsnadel. (C) Schematische Darstellung der Injektion der DNA (grün) zwischen die Vitellinmembran und das Ektoderm. Kathode (+), Anode (-). Membranen und Keimblätter sind so gezeichnet, wie der Embryo elektroporiert wird, mit der dorsalen Seite nach oben, zur Anode. (D) Schematische Darstellung der neu entworfenen Apparatur für die Elektroporation. (E und F) Elektroporation einer ecKultur im Stadium HH10 mit CMV-GFP. Die DNA wurde in Höhe des ersten Somiten injiziert. Elektroporationsbedingungen siehe Kapitel 3.9.2. (E) Dunkelfeldaufnahme, (F) GFP-Fluoreszenzaufnahme. 
konzentrierte Lösung des Vektors und des Kontrollvektors (CMV-GFP) (beides ca. $5 \mu \mathrm{g} / \mu \mathrm{l}$ in PBS, somit ca. 2,5 $\mu \mathrm{g} / \mu \mathrm{l}$ in der Mischung beider Vektoren) injiziert (PV 820 Pneumatic PicoPump der Firma World Precision Instruments), zu der zuvor außerdem steril filtriertes 1 \%iges Fastgreen mit der Endkonzentration $0,025 \%$ hinzugegeben worden war.

Es wurden einige Nanoliter der Lösung zwischen die Vitellinmembran und das Ektoderm gegeben, so dass der gesamte vordere Teil des Embryos von einer großen Menge der grünen Flüssigkeit bedeckt war; während der Injektion konnte man gut verfolgen, wie der Abstand zwischen Vitellinmembran und Ektoderm immer größer wurde. Da bei dem Versuch, in den Injektionsraum zu gelangen, fast immer auch der darunter liegende Embryo durchstochen wurde, musste dieser Injektionsort langsam durch das Herausziehen der Nadel gefunden werden. Die Embryonen wurden im Anschluss einem elektrischen Feld ausgesetzt (7 V, drei Pulse von je 25 ms innerhalb 200 ms: HH4-6; 12 V, drei Pulse von je 25 ms innerhalb 200 ms: HH8-11, BTX Electro Square Porator ECM 820; Endo et al. 2002, siehe Abbildung 13 (E und F), Seite 41). Nach der Injektion wurde der Embryo wieder mit Hilfe einer Pinzette zurück in die Kulturschale gelegt, wieder mit der dorsalen Seite nach unten, und bis zu dem gewünschten Stadium (HH9-11) im Wärmeschrank inkubiert. Sobald der Zeitpunkt gekommen war, an dem die Entwicklung der Embryonen abgestoppt werden sollte, wurden diese mit einer Miniaturschere aus der Kulturschale herausgeschnitten und mit einem kleinen gebogenen Löffel in ein 12-well-Gefäß überführt und dort in PBS gewaschen.

Die Dokumentation der GFP-Elektroporation erfolgte ebenfalls im 12-well-Gefäß, wozu der Puffer herauspipettiert wurde, so dass der Embryo auf dem Boden plan lag. Erst danach schloss sich die Xgal-Färbung an.

\subsubsection{Erzeugung von transgenen Mäusen mittels Mikroinjektion}

Die Mikroinjektion von DNA in die Pronuklei von fertilisierten murinen Oozyten wurde von Ullrich Franke (Max-Planck-Institut für biophysikalische Chemie, Göttingen) durchgeführt. Die DNA wurde wie oben beschrieben (siehe 3.3.2) vorbereitet. Es wurden nur transiente Linien hergestellt. Zur Analyse wurden die Embyonen des entsprechenden Stadiums in kaltem 1 x PBS gesammelt und im Anschluss von den extraembryonalen Membranen befreit.

\subsubsection{Mikroinjektion von DNA in die Pronuklei von fertilisierten Oozyten des Zebra- fisches}

Die DNA wurde wie oben beschrieben (3.3.2 und 3.6.5) vorbereitet. Es wurden mittels einer Glaskapillare 1-2 nl der $15 \mathrm{ng} / \mu 1$ DNA-Lösung in den einzelligen Embryo injiziert. Die Mikroinjektionen, die die Grundlage für die Abbildungen waren, wurden von Dr. Marion Köprunner (Max-Planck-Institut für biophysikalische Chemie, Göttingen) ausgeführt. 


\section{Ergebnisse}

\subsection{Resultat des Bakteriophagen-Screens}

Nach der zweiten Runde des Bakteriophagen-Screens waren die positiven Plaques einzeln gut voneinander getrennt zu isolieren. Es wurden elf Klone isoliert. Von ihnen wurde jeweils ein High-Titer-Stock angelegt. Mit dem Ziel, eine besonders große 5'-Region zu erhalten, wurden die Klone mittels des Southern Blots näher analysiert.

Klon Nummer 6 umfasst ca. 15900 bp, von denen 800 bp den Beginn des GANF-Lokus darstellen. Der Rest, 15100 bp, umfasst somit den 5'-Bereich von GANF. Die 800 bp enthalten die ersten zwei Exons und die ersten zwei Introns. Die Exons stimmen zu $100 \%$ mit der cDNA von GANF überein. Klon Nummer 6 wurde mit SalI aus dem $\lambda$-Bakteriophagen ausgeschnitten, in den low-copy Vektor plcBS kloniert und komplett sequenziert (mindestens zweimal in jeweils eine Richtung; Abb. 14, Seite 43 ff.).

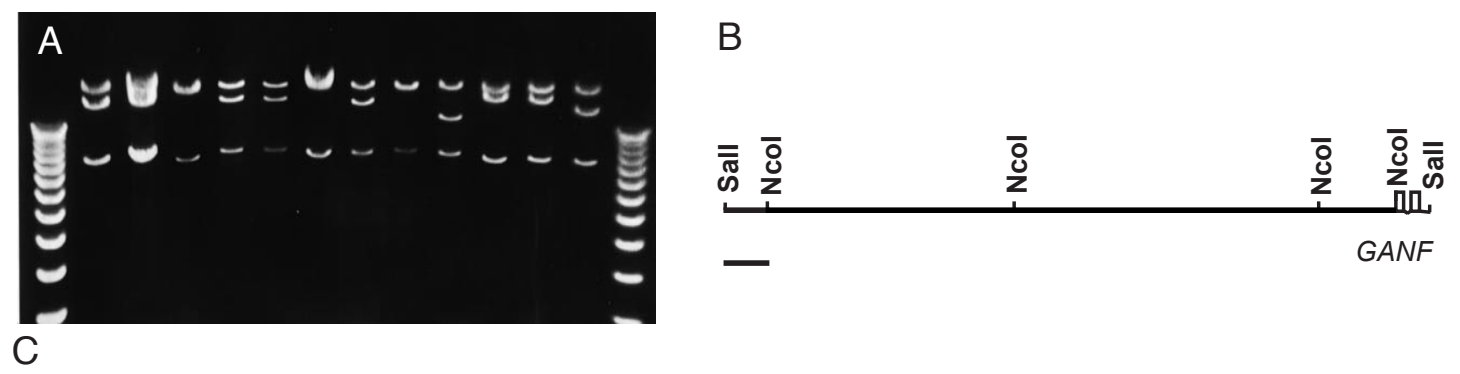

AGGTAAGGGTATCTTGCTGGAGATCCCTGCATACCTGAGGCCTTCCAAGGGTAAGCAGCTTATTTTCCTTTGTTTCTGTGTCTATGG CTTCTGCATTTAGGCTTATCTTTACTTACTCCAGCCTAGAACTTTGTTACCCTGCTATTATTGCTGTATTATTGCTTTCTATTGCAT TATGAGTGCTACAGTAATAAAGGAAATACCACAGTTTTGGCACTTCATCTTTTGAATTTAATTCAGTCAGTATATTTATGTTGTGAT GTTGGTATATACACAATTATTTCCTGAACATGCAAATTATCTGAAAACATTTACAGCAACTCCAAAATTTTCAACTTGGGTAGCTGC TTCTATAACGTAAGTAGTATTTTTGTTGTAACACAGTAATACTTAGTTCTTCAACTCTAGTGCTCTCCTGAGTAGAAACAACTTATA TTAACAACATTCAGAGATGCATACACTCGAGAGCTGAAAAATAAGTGGCAGATCCTATTGTGTACAATAAGAGCTAGAGACAGAATG CTGTGACTTTTGTATTGTTGCATGGCAAAAAGCAGTATTTGTTTGACCATCCTACCTTTTAGATCTCTTTCTTTAAACTGAGTAA TAGGAAACATCATTGCATCTGCAAGTTGAGTTGAAAGTACTGCATGGCAAGAACTGAGCTGTAAAATAAGGGAAAAAAGGGCATTTT TAGGAAAACAGTACTGAGACTAAGGAAAGTAAGAAAGCAAGAGAGGTTTCACTGAAACTTGATGTACAGCTTGAACGTAATTTTGCA AATTCACTTTTGCAGCTATTGTCTCCTTATTTCACCATCATCTTTACATAAAAGACCTTCACAGCATAGTATTTTTCCCTTCTTCCC TCTATCTATACTCCAAATTGCTGAATCATGTCAGAAGATGGCCTCGCACCTTCTGGTGACTCAATTTATTTCCCCAGCTTCTCTCCA GCTACATCACAGTCCCGTCTTTCTCAGGTTACAGAGGATGATCCAAACAAAACGCTCTTTCTTTCAAAAAGTAGTGTTTAAACAGAG GAGAGGGATCATGAGGAAAAATCCTGATTCTCAACGATGCTAAAATATTTCTTTTTCAGAAGAGTTGGTCACTCAGTCTGTCTCTAA TACAGACAGAAAAGGCTCCTTTATCAGTCAGGCATCTGAAACCAGGGGATGCAAATACCCTGATGAGACAAAGGTGTTTTTTATCAC TCTGTAATGTCACTTATCATTCTGTAATGCTTTTAGTTTTGTAGTTAAACTACCTTGATCGTCAGCAATGTGTACTCATTTTGCTGA ATTGATTCTTTACCTTCAGGTTACGCAACCCTAAGCTTATACTGCATCAGAAGTTCAACATCATCAAATGAAAGCCATTTCTGAAAC TCCAATCTTAAGACTATGGTCTAAGAAGTCAAAGCGAATACATGACAAACATTAGCAAAGTAAACGAAATGAATGCAAGTACTTGCC TCGTCGATCACTTTTGCAAATTGCTGTAAAGTAGAACTCATAATTTCATCATCTCCCCCTAGTGGAAAGTGCTGCAAAAAAACAAAA GGAGGTATGCTGTAGTGTTTTCTGCCATTCACGCAAATATAATATTCATGTCTAAGAATACACTAGGTATTTATTTTAAAATGGTGC AGTTGCAGTACACTGTGGGACTATTTTGAGAAGCCCTTTTTTTTTTTTTTACTGTCTCAAATAAAAAAGATTTTTTGGAAAACAGTA AGTAATAAATTCTCCTCACTCACTCTCCCCCTTTTCTCTTTTCTCTGCCCCTTCTCTTCTTGAACAGACGACAGGATGCATGGGAA TGGTACAGTGCTGCATCAGGGGAGGTTCAGATTAGATATTAGGGAAAATCTGTTCGCCATGAGTTGTCAGGAATTGGAACAGGGTTC СTAATGAGGTGGCTGATTGATTCCCTAAGCCTGTCAGTATTCAAAAAGCATTTGGATAATGCCTCATTAATAAGCTTTAACTTTTGG TTCATCTTTGTAGGTTTCTTCCAACTGAACTATTCTAAAACAACAATAGAAATAAAATCTCCAGAACTTATTAACATTCATCATAGT AAGAAGAACTTAATTCTGAAAAATAGTAATAACAGGACACATTTCTCTTCAGCAAACACTTTATGTGCACCATTTTTCCATACAGAA TGGAAAGCACCTGTGTTTTATTGGAAGAACTGATACGAAGATAGGCTGATTCTTTTGGCAACGATTTGAGCCACCAACCTTAATAG TTTGCTTTATCTGAATCAAACCTGAATACATTCTGTACTGTGCTCTGGGAGATAAGACTACAAAAATACAGTCCTGACCACAAAAAC CAACAGTGATTTATACTATACCTGTTTCTCATATTCCTTCAGAAGCTTTGAAGTCAGATGAGTCGCTGCACTTAATTCATTCTAATT TAGAAAAAAAGAAAGAAGTTTATACTTTTTGATTAAATTATTATTTTTTTAAAAATCACGTATTTAAAAAGCAAAATATTGCAGA CGTGGAACTCAGAAGCAGGAATCCTGATTTCTTAGCTTTTCTGAAAACTTGGAATTCTGCCCTTCCATTTCTATAGCAATGATAAAA GTTGCAAATAATCAGTATTTACAAATACTTAGTTCACAGCTTGTACTATGCACAATGACTTCTGTATTTTTGATGGTATACAATACA TATTTGCTTTTAATTATTTCAAATTTGTCCTCCTAAGAATTTGATATTTGTGAAGGCAAGAAAAGACTACAATGGACTTCAGGACTA CTTGGCTACCAACAGCTCTGACTTGTACACACATGGGAGAAAATGCAAAATAGAAAGGCAATAGTAAAGTCAGATTAACAGCAATAA GAAGAGCAAGACTAACAAATCAGTAAGAATGTCCAACAGTACAGGTGTACAGTAATTAAAAATACAGCCATAAACTTAACTGTTCAG AAAAACACACAAAATAAGTTCTGCCTTGGCCTGAAAGTAGAGTTACTGACAGATGAGTAAAACAGTATGAATGTATTTTGGTAAAAT 
ATGTATGTCCCTCTTGGTTCACACTATTATGCACAGTGAGACCTTTGTAGCAAGCAATTTAGAAATATTTGGGGAATACAATAAAATG ACAAGATGATGAGAAAATTCTTATTTAGTCCTCACCATTCCCTAGCATATGGAAAAACAATAATGCTTATTTTATAAACATGAAACAC TTTCACAAAGTTTAAATATATGTATACTTTGCTTATATAAATTTTCCAAAAAAAGCGAGAGAGACAAAATGTGGTTCAAAAGCTTTGT AATGCATTCAGGAATTCTGTAACAGTACCTGTGCATCATATACTCTATGCATTGCTTGAAATAATTGATTGACGTAGTTGGAAATTGC AGCAGCATCTTCTTCAAATACTCCCAGCAAAGAACGGGTCTGTAAGAATGAATCAGACAGAACAATGTGCCAAGGTAGCAAAGAAGAA TTTAAATGCAACAGAATTTCCAAGTTAAGCAGCAGTGCTGCAGTTCTCCTTTCTGAAAAGTTTATAAAGCCTCTGTCACAGCATCCAC AACTGTTTCCAGGAATTCTACGTGCTGCATATCAGAAAACTAGAAAAAAAACAACAAAAAACTGTATTTTAAAATGACATCCAAGCTC AGTCTTGCTGGTACTATTGGCCTCTCTCCAGGTTAAAGGAGTACGTTGTCAGACAGGACCAAGAGATGTGGATAAGTATAAATTATAA GCATTGGAACTGTGAGCTACTACCGGTATATCATTATGGCATATCCCCAAGGAAAACTGACTGGAATTAAATATTGTGCCAGGTACAC ATTTCCTCTGCAGAAAGAACAGCTGTGGCTTTCTAGCACTCTCTCTTCTGCATGAACAGTTCCTGGCTGTGCTGGGATATGTAACTCA CATCTGCAGTAGCAGCCAATTCTGTGTTCAAAAAGCAGAGGAACTGAAAGTAACCAAATCAAACGAAAACCAACTGATAGAATCTACA TCTTCTTGATATGTACACTTCTCCCTTCCCCCCCCCTGCCGCCCACACACACACTTCACAGTGAGAAGATCTGTTCTTTTGTCTGCTG CCCCCAGCCTGTCAGTCAGCTAGCCCTTAGCTGGTGCCACACAAATGCATCTCCTGCATAACTTTAGGAGTGGTCACTCTCTTTATTG CTGTCCACATGTTGGACTTCAAAACTCTGATCACTAGCATTTAGGTCTAACTGTCCCACTGTTTTTTCCACCCAGTTGCAGTCTGTAC CTCCCTACTTTGGTCAGAAGGAAGTTGCTGGAGACAGATCAGAATCCTCGGGTAAGTTGGCATGAATGACATTCACTGCTCTTGATGA GACGACTGACTAGACAAGAAGGCAATCAGGTTGCTTAGGGATAATTTGCCCTTAAGATTAATTAAGATGCTTACTCAGTGCTCTTGCA TCTTTGCATTTGGAAGCAGTATTACTCCTAACCATGAGGTTATGAGGTAGCTTGGCAAAAGGGGGAAGAGCAGAGAATGTAACTGTAA CTCTGCACAAGCTACATTTGCTCTTCCTAAGAAAAAGCTGCGTAGTATTGCACTAAAATATTGGTTGTGATGCTTGGATGCAAGGCCA CTCACTCGCAAAACCCACAAAATAAACCTTTAACTCTTAACTTATTGGCAAGAAGACTGTGCATTTTTAGGTTCATACTAAAATTAAT GTCCAGACAGAAAATGAAGAGAAATGTGACTACATAACAGATTTTTTTTAACCTCTCACAAATTGTCAGTTTTAAGCACTGGAACTTG TTAATTCTCTTTCTTAGCCTTCCTCAAGCTGAATAACTGTAGGTTCCCTGATTAGGAATGGATGGAACTTATGGGGCTTGGGAAGAAA ATGAGAGACCAATGCAGGAGATCGGGAAAATCTCTCTGATGAGATCAGTGAAAAGCACTGGATTGCACTGCATACAAAACATGGTAAT AAAAACTTGAAATGTGCTTAGAATGTAGTTCATCTCCCCTTGTATAAACATTTATCAAGTGTGTTATTTGATCACTTGATTGTGAAA GCCTCTTATTTAATTCAAATTGATGAGTGGTTGTCTCACAGATGTGACCATACCATATAACTCCTACAGGATACCTAAAGGGAAAGAA TATACATAAGCAAACAGCATTACCAACACAGCAAATCACTTTAATGATGGTTCTCATTCATAAAGCAACTGGAAAAAGTGTTGGGGGG TGGGTGGAGGAGGAAAGAGGTGGAGAGCTCAGATGGTTGCCAGGCGTGGCAACATGTTGTGTCATCCTAATAGCCGTGAGTCTTCCAG ACATGAAAGAATGCAGAAACAAAAATTACATAGTACCATAAAAACTGAAGTGTACACTCATGACCTTTAAACCAAGCATTAACAAATC TGACCCTGCCATTTTAAAGTGTTATCATGTTTGACTTCTGGATTATATTTACTCTCTAATACTCTGTAATACAGAACCCTGTGGAATA AAAGCATTTCTGTGGGTTTGGTTAAGATATCAGTTATTGACTTCAAACTGATAATGTTATTATACTGATGGAAAGAAAACAGTTTGAA ATTGAGAAGTTATGACAGACACTGCTTAAAAAAAAAACTGGAGGAACTGTTCGCTCATGTTTCTAGTGAGAAACTGGGGAGCTCTGCA TGCTCTTTACGATGCTTTCATCCCACATATATTAGCAGCTATACTAAAAGCTACCGGTAAAAAACTGCACAAGGAAACCACCTATTTG GAAGTCAGTGAATTGTTAAAAATTGTTAATTGTCATGTCATCACACGTATTGTGTTGTAAGAGACATGAGAGAGTCTGTACCATTGA GTTCTGTGGATTTTTTGTTGTGCAATAGTTTGGAAATAAGAGCGCAGAAACTCTCTAAACACATATATATGCACACTGAATATGTGTA CAACATGTGTACAACACTACCTGAACTGTGCTGCTTTGCTCATCAAAGACAATGTAAAATGTCATTTGGTTTATGTCTGAAAATAGAG TGGTTTGATTTTACCCTGCACCAAAAGGAAATCAATGGTTGATTCACCATTTAAGAGATCTTCCTTCCCTCAGACACAGTAAGTTTG ATTTGAAGTTATATAAGTGAAGTTAGCATCTCAAACATGTCTAATGGTACCAAATTCCAGAGCACAGTCTGGCCCTGAAAAACTGTC TAGATTAATGGTCTTTTTAACATGACAACAGAACAGTACAAACATGTCACCCAGAAAGCCATGGCAACTCCTAAAGAGAGCAGGGTT TCCTCTTTCTTCAAGATGTTGTCATTGTCAAAATGTTGTCATCTTCAATGTACTGATTTCAAAATAAAAGAAATGAACTGATGTGGT AGAAGACTACAGAACTACAGTTGCATTCTTCTAAGGGTGATTACTGAAATCTTAGGTTGGCTGGAAGATAGAAGAATTTTATAGCTCT AATAGAAAAAGTAATAGTTTAAGTATGTCAACAAACAAGCAAAGGGCTGAGTGAGGTTTTGCTTGTCTGCATTTATCACAAACAGCAC CAAACAAAAGATTCTAGAATTGACAATTATGTTCTGAAATGTAACCTTTTAGCCTATGCTTCCCAAGTGACACTTCAGCCTTACGTGC TTGAAAAAAAACACCTCGACATCCCATTCGATAGGGATCCTATCAAACTGACATTGACATTCCCAATAAATACAAACAGTTCTGATTT CCATTAACTGAGAACAGATCTTCAATGGACAATTATGTGAAACTACTATTATTGTAACACTTCCATATTTTTTTCCTCTTTGTGACAG TACATCAGGTCTAGGCTCCAGGCCAGAGACCGTGCAACAAACCAGATCTTGTCTGACATCTGGTACAGAGCTATATGGGACACTGTCT CTTGGAAAGCAATGATACACCTCCTACACAGCCTTCTTTTCCAAGCTGTCCCTCCACTTGATCTAGATTTGTCACAGTAGTTGTCACT GCCATTATAGGGATTAAAATCTCTGTTTAGCAAAGAAAGTTCCTATGGTTGAGGAATCAAAACTATCAATGCATTTGCTATTACAGC ATCGGAACTGGTGCTCATCTGCATAAACAATGCAACAAAACAAGGATCCAATTCAAAAAGAGTGAATAATTTATATGGATATTCATAC AGTAAACTTTTCCATGCCAAAGAAAAGAGGTGGTGCAAAGTAACTGCTGTTGTTGCAGACAGCAAGAGAAACCTGTACTACGGAATGG AGCATTCTGTGCGTGATTGCAGCATGAAATAAACGGCCGTGTAATATCACGGCATCGCTGACAGAGGTCAAGCAGCAGGAATGGAGGC

- GAAGATACCGGAGCAAATGAAGCCATCGCAGCACCGTGCATCTCCCACCTTCTCACAGCAGTAACAAACGCCACGAACGCCTGTCTAT TAAAACGTTCGCGTATTTTGTGCAAGACGAAGATGACCAAAAACCCTCTCGAGAAGCGAGGACAGGCTCTGTCGGCACGAGCGCTCCC AGATACACGCGGACGCGCACCCAGGAGCGGCGGCAGGAGGGGACGCACCGCACCGCCCCACCGCCCGAAGCTGACGCCCGCTCTCCCC CCACGCGCAGCCCGCAGCGCGCAGAGGGGAATGCGCCGCGGGGAGCGGCCGCCACCGCACCGGGACAGCGCCGCGGCTGACAGCCCGC AACGCTCCGAGCGCGCGCCGCACGGGAGGACAGGGGGCCGGGCCGGGCCTCCCGCTCCGCGCCGCGCTTCTGAGACGCTGAGGGAAGC CGCACTAGGCCTGGCGCTCCCGAGTCAAGCCCGATCTGCGCTCCCCTCATCGAGCTGCTCCTCGCCTAACTTACCTGGGGGCTGTCTT CCAGCGTCTCCTCGATGGGCAGCTTGTCGATGCCGGGCATGGCGGCCGCGGGGACTGATCTGCGTCGCTGCTGCTCCCACTCCCCTCG CTTCGCCCAGCTGGCTGGGCCCCCCCGGCAGCGCGACACGCGGCCCCGCCCCGAACCGGATGTCCCTCCCACCTGCCGCCCGCCTGCC CTTGCGATTGGATCCGCCGCCCAGCTGCCCGGCTTGTTATTGGTCAGCGGGCCCTTCTGTCTGCCCACATAGCGTGGGTCCCGTTCCC GCCTCGGTGGCCGCCTGACGGGAGGTGGTTTGTGGTTCGGGTTGCTTTCGCGCGCGATGAGCGGCGGGAGCTGCGCCTCGCGCCTCGG AGCTGGCGCTTACCTGCGCGGCGGAGCGCTGCGGGACTGCCGCCACCGCCGCCACCGCGTCCTGTCAGGGTGGGGACGTCCCTCCCGC TCTTGGTGCAGGAGCTCGTTAGGCTGAGCCAGGTCGGTGCGTGTTGTTAAACGGAGGGGGAAGAAACTGCTCCTGATGCGCCCTTCCT ACAGCTCTGTGACTAGGGTGTTGTGCTTTAAGTTACCCTTCTGGGTTCAGCAATTCGTGTTTTAAGGATAGATCTCTGAGGAGGCATA AGCTACGTACAGGTTGTTAGTAACGTGTATTTAGTTATAAACTTAGTAAAAAGCGTGAGAATGCGCTGTGTCAGACGAGGCTGTGCGC TCATTGTTGCTCTCAAAGCTCTGACAGAACGAAAACCGAACCGTGCTGGGTGTCTGCAGTTGCGTCTGGGTTCGGCTCTGCGGTCCGC TGATGTTTCACTTTTGCACTTCAGAGCAGCCTGCGCTGCTGGAGGTTCCCGTCCCGCTGGGAGCGGCTGTTCTGCTGCCCGTGCCCTC CTGTGCCCGGCTGTATGAGCTGCTGACGGGCCGTGCCGGATGGCCCGGGGAGCCAAGTGTTCGGTGCTGTGCGGACCTGTTAGAAAGG CCTTCCTTTGCGTTGTGTCAGGTCATGTTTTACTTCTAAAGACATACAGGCAAGAGGCATACAGGCATTTTTACGATATTAAAAAGTA TTAAACTGCAAGCAATTGACAATGTAGGTTTTTTTGTTCATTATTTGGTTGGTTTTTGGTTTTTTTTTCCTAGGGAACAGTGAATAAA TGTCACTGCTAGAACTCAGTTCAATGGGTTCTTTTACCAGCTCATCGGTGACTCATGTGGCTGAGGTAAACTGCGCTGCTAACTTCCT TATCTCCCTATCAAATGAGAGAGATATATAGTGTTATCTTACCAGGTTTAAAGACTAAGCCTTATACCTTCTTGTTTGATTTTTTGCT TGCTGAGCTCTAACTGGGTCTGTAAGTACGAGCAGGCAATGCCAGCGTTGGCTCGTGACCCATGTACACGCGCACAGCTTTCTGGTTT TGATATCAGTTCACTTGTGACCAATCTCTTACAGCAGTCTTCTGTGAGAATTGCTCTCTGTTTCGTAATATATATTAGCGTCATTCCT TTAGCAGAACTCAGATAGGTAGTAAGGTACTTTAAGCAGAATTATTTGTAGTTACCTTTGGATTTTTATAGCTGTAAGTGACAGAAAA GACACATTCATTTAGCTCCTATAGAATGAGAGGAACAGCCCTTAAAAAACTGAAACTTTTGTGGATATGGAACAGGTTGCCCAGAGAG GTTGTGAATGCCCCCTAACTGGACGTGTTCAAGGGGCTGTGAGCAACCTGGTCTAGAAGGAGGGGTCCCTGCCTATAGCAGGGAGTTG GGACTAGATGATCTTAAAAATCCCTTCAAACCCAAACCATTCTGTGATGTTATATCAAAACAAAATGGTAACAGACACATTTTTAACA

Fortsetzung nächste Seite 
TGTAAAAATGTGCTTTGGTATCTCAATTGGCACGTAGCATAATGTTTCTTGTTTCTGTTGATCTTAATGTTTCAGTGTAATGAATCAG TTCATTTTAGTAGCAAGAAAGAGCCCTTTCTAGTTGTTCTGTAGTGTACCAGGGCTGCTTCTAGTTTGTTGTTAGGTTTCTAAATAAG TCCCTTACATGGAAACAATCAGTAATGTCTTAGTAGTGTATGTTGAGACATTTGTGACGATGTACACAAGGCATTTATAAGTTTTATT TGGCATATATATTTGGCTGCAACAGAGGAGATTGGATAGCAATGAACTGAGGAATCCATAAGAACCCACTAATGAGTATGCTTTTGTT GTTACGCTTCTATCAGAATGGTAAACTTCCTTTGTGTGTATGACTCTTCCTTTTTCTCTTTGTACAAAATGCTGACTAGGGGATACTG TAAGTGTGAAGAACTAATACCTGGCTCTATATAAACAGGGAGAAGAGCAGCCAACGGCTCTTTTAAGGATTTCAGATGTGTCCCCTAA TGGAGAGAACTTTGGCTCTGCTGAGGAGTGGAATTAGCTGACTGGATCAGGTAGGCTTTATTTGCACGTTACACGTTAACTAGCATTC TGTTTCTTCTGATATCCTTGAATTACCTTGAATTATGTGCGTTCACTTAATTGCCGTAGATCAAAGTAGCTTTCACTTAACTAAGG AGTAGCTAACTGCTTTCAGTAGTGCTTTGAAAAAAATGATGTTGAAAGTATTGAGGCACTCTTGCAAAAAAAAAAAAAAAGAACCAAA AAACAAACAAAAAGAAACACCTTCACTGTTTTGTACTTGGCTTTGAATGTAATCTCTGTAATTAATGTTCAAAACATATTTGAAAGGT TGATATGTGCAGCAAAATGTCTAAGGTGGTGATACACTGCTACACTTGGGTAAAAGAGCTGCGGGAAAGGTGAGATGAAAGGCAATTT TCTGTGTGATAAGTAATCAAGAAAGATTACGTGTGCTGTTCATAGTGTTCCAAAAAGCTGAAAATACTGCTCAGGCTGTTGTGAAAGG TGACCTGATGGCAGAGTTGCAATGGGTGATAGTGGCAATAGGTAGCATCTGCTCAAGAGATGAATGCTGCTGTCCCTGGGCAAAGAAC AGGTGGTATAAGGTCTGCAAGGGATATGAATTTTCTGCTTCATAAAGTGTGAATTCTGCTAGAATTTTGCATATTCAAGGAACAGTG ATTTCTCCCGTGATTGTTTTTTTTTGTCACCCAGGGTTTTCAGTGTAAAGTTTCTTCTGCTGCTCTCATTGTTTCTACAAATGTATTT AGGCAAAACTGTTCATATGGGTTGCAAGGGAAGAGCTGCTCATTTGTGATAGACCTGTATGATAAGATAGAATTTTTGAATGAAGAAT CAAGCTGGAGTTATACTTGCAGTGTGAATTCCTTGAAATGGGATCTGAATCTTTACTATCAAATTCTACTGCTTTAGAATCATAGAAT GCCTTGAGTGAGTGTAAATTTCTTAAGTTTCTGCTCTACTGAGGATATGTTTTTATCCTCATTTCTTGTGTAAAAAGCTTTGTTG ACTTTGTGGTTTTTTTTGTTTGTTTGTTTATAACAAATTGCTTTCTTCTACACTGTAGCAATCTTCTCTCTGAAGAAATGTAACACC ATTTGGTTGTCAGATCTTCAGCCAGACTTTCCAGTAAATTTACCTCTGTTTCATTTTGGTATTAAAACAAACTTGTTACCTTTAGAAT AAATTCTCTTTCACGTGAAATTTTATAAACAGTTATATGGATTTGTCCTAACACTGTAAGGGTTTCTTAGGTGTATGGTGTTTCAT TTTCACTGAATTCCTCAAATTAGAGAGCACTGTGAAAGCTGTTACCCCAGGAGCTTCTGAATTGGTACTTCCAGTTCCTATGTGGAGT TGCAGCCATGCAGAGTTTCAAAACAGTGTTGTGTGTTTCAGTTACTGTGCTGCAGTCTCCAGGTCTGATTCAATTCAACTTTGAGCA AATTAATGTAATTATTTAATAGTAAGTTTCCTATTCAGATAACATTGTTGAACAAAAACGGTAGCTGAGCAAACATAAACACCAGAT GGCAGTATTTGATTAGGTTCTGACTTCTGCCTGTCAAATTCATTCCATGTGTTTTGTCTGATTTTATTAAACCTATTTTTGAGAGCTA CTGAGATCTTTTCCTGGAAAGTCCTTAAGATAAACAAATAAATAAATCCTGAAGGAATGAGAACCTCCAACTGGGAGCTAAAAGCAA ACTACTCTGAAGGGCTTTTGTTGTCCTCCACAATCTCAGAGAGACCAAAACAAGTCACAGCTACTTGTTGGTTTGTTTTGTGGAGGTA TGTGCTTCCTCAGTACTACTTCCACCTCCATGTATCTTTTGTGACAGTCCTTGGTAGCCTCCTGAAGAGATCAGCCTACACCAGTTTG GGACTTGATTGATATGGTAATCTGACTGTGAACCGTGCAGTTTCAGTAAATTTAATTGCTATTCATTATGGTGAAATAAGTATTTTCT GAGATGTTTTTGTGTAAGTTCTTTTATAAAACTTAAAAAAAAAAAAAAAAAAAAAAACCAACCCACACACAGTATGTATACGTAGATA GTGGTCTGTATTTGGAAACCAGCTTCATTTACACTCATTAAGAGGTTTCTTCTATTGTTAAAGTCCACATTTGTTTCCAATTCAAGAC ACTGTCTATCAGTGATTGTGCTTCAAACCTCTTTAGGATAGAGAAATTGATAAGCAGCACCAGATTCATTACAGGAGATGTATTGATT TCTTTTTGACTGTTATGTTTTGGGCATTTTTTTAATAAAGTTGGCATTCCATGTAGAAACTGTAGAGGTAAAAAACTGATTTATC AATTGCATGGGATACAAGAGCCGTAGCTTTATCTCTTCAGTAACCTCTCAACTTGGTGTGTTGTCAAAAGTCTGCAGTCAAGAAAAGG AGCTCTGCTGTTCATCTGGGATCTCAGTTTGTGTTGCATTAGGACCAGCTATACTTAAATATAAAGGGCTGTAAGGCCCTCATTTCCT CCTGACCTCTGATTCATGAAATACACCATCATGAAACCCCTGAAACTTCTGGGCAGATGAGACTTCTCCAGAGGCTACCAATGTGTTA CAGATTCTTGTGAAAACAGTGACGGGTCTGTTACATTTTGATCTTGACACTCTTGAAGTTTCCAGTTAGGAAAAGTTATATCAGCTGC TCTGCAGTTTTCTGAGAGCTGGCACTGGGTTTCCTTCAGAAAGGAACGTTTGAGCATAAAGGAGAACCTGAGGAAAGATTTTGGCAGT TAAGCATGTCTGTCTTCAGGTTCAGACCTTACCCATCTGATACCTAAAAACTGCACATTCTTTTTGCCTCAAGTCTTCATATACATTC ATAAAACATCATTAGCCTAGTACAGAAGATTAAACACTGTCAATACATTCTTGGAATTCTCAGTTTTCATATTCTGCCACGGGTCTTT AAGGGGTTTCTAAGCCAGCTTTCTTAGCAACTGAGTTTGGACAGGCTAGCAGAAGTTGTGTTTTGCTCGGGAAGTTCATGGGAGTGTG GATCATGCATATGAAGACAGCCTTACTGAGAGATGAGTCCCATGGGCCTTGTTACTCTTTCTCAATGCTGACATGATCAGAAGGCATG GCAGTAGCCAGTGAGCTGCTTATACAGGTTTGTATGATTTTTTTTTCCTGTGTTTATACTGTGTAGTTGCTGAGGCTGCCAAATGGTG ATTGGAGCTCAGTTTGCAGGTGGTCACTGCGTTTATTCTGCTGCCACTTCAAAATATATTGACATGTTGATAAGGTGTCTTGGTAAGA TCACTTCTTGAATCACTACTTCTGAGTCAGCCCATAAAGTCAATGTAATGCAGCCGAACATCATTCTGATAGAAAATAATGTATGATT CTATTTTTCACACTAGAATCTCCCTCAACACCCCACTGTCAGTTCCATGCTGTGCCATTTCCCTACAAGTTTTCCTGCTTCTGTTATT CCTAAAGGTTCATCTTGGGCGGTTTACACATGAACATTACCTGTACTTTGATTTTCTGTATTTTCCTTTGTATAACTTGTTAACCAT GAGCATGTGACTGATTACGCAGAATAAACTACTCTGAGTAAATGGTGAAACAAGAAAAAAAGGGTGAGATTTTTCCTCTGAAAGGGTA TGATCCTACATCATGTGCTCCAAAGTTATATTTTAGAGGGGTTTTGCTTTCTGAAAGAAAAATATTCCTTGCATTTTTGCATTTATCA GATAGCTGTATTTAAAATATGAGAAGAGGTTTTCAAAAATGAGAAGTTGTTACTGACTGTGTGTAAATGGCCAATAGTTGAGTTTGAA AATCTTACAGCTGATGCGTTCTCTGTAATTAAAAAAATCAGTGATCTTTTCAAGCTTTGAACATCAAAAGAAATGCTTTAAATCCTTT ATGTCCATTACATGTGATTTTGGTCATTTTAAGTATGTGCTCTGTGGAAAAATTTCTGTTGGTTATAAAGCCACTTACAGGAAAGAA GGAACACCTAACAGGTCAAGGGTATTAAAACCTGTACATTTGAGTGTGTGGCTAATATTAATTCATGTTTTGTTTTATTTTGTATAG TGTGATCAGGAAATTTCACATACGGTATCCTTCAAAAAAGCTGCTACAAAGCTATTTTAATAAGAAAAATGAATGTATGAATTATTTA AAATAGTTGGGGCAACTGTTACTGCTAAGTAATCCAAGCACTTGGAAGGCAATTACACTGAGCTTTGACAACATTGCCAACCCACTGC ACAGTGCCTTATGCCAAAAGCTATTGTTGTTTTATTGACCACGTTCACCATTACATATGCATATGAAAAAACAGAGGCATTTTCATTG GGATTAGCCTAATAGCATTAAGAGATTATTTTTTAAATTTCCTTGGAAGGAAATTCACTTAAATGAGATTACTTATTACTTGACTGGT

TTCCTATCGTGCTGCTATGTTTAGGTAAGTGGAGTCCATTAGAGTATAAAGTTTTTTTAAAAAAACTGATTTTATACATTAATGATTT CAAATAAAAGAGAAGTCCTATATTTGTGCATAGCTTCTTTTGAGAAAGTTAAGTCGATGTTCTGGTTAGGAGAGATAACACTTCTTGT CCCTCTTGGTGGCCCCCCTAGTGTCACCATTAGTTGCTAATTACTTGCAAACAAATAAACAATTAACTCCTCGTGCCTCTTGGTGGGA GAGTTTTCATTGACATGCTAAAACTTTCTAATAAAAGATTTAATTAATGACGTTGCAAATCCAACCCCCTTGTCAACATAGCTATAAG GAGGACTTCTGGAGAAATGCAAGTACAGTGAGTGTATGTGCTGTGCTGTGCTGGCTGAAGGTGAAACCATGGCAAGTACATCGCTGTG TGCAGCTAATCCATCAGCATCTCAGAATCTTCGGAAAGTGTCTGGTTTTGTAGAAAATAAAACCACACAGTGCTCATTTTCCATTGAA AGTATTTTAGGATTGGAACAGAAGAAGGATGGCATTGCAGCTGTGAAACCTCACAGACCGTGGATGGATGCGTGCACCAGCTTGGGTA AGCCAGCGGTCTGTTTTTAACCTCTCAAGCTTTTACTCCTTTTAAAATATATACCTAGTCATGGTTCTACTGAAAATCAGTAACATG AAGTTCACATTTGCTTGCTTTTTCCAGTTTTAGGTGATGACAGTGATCCACATCTGCAAATCCCTGTTGTTTCCTATGAAAATTCATT ATTTCATGCTAACAGTAATCTAATGCAAGAGGAAAAAGTTTTGAACTGTGAAAAATATTTTTCAGTCACTGAAAGGTTATCTTTCAAA CGAGAATTAGCTGGTATAGGGGTAGAAGACCGAGAACTGCTTTCACTAGAAACCAGGTATGGATTTTCTTTCTATCTGATGAATCAG TAACAATGTAGTTTAGAAGCTGGCAGAAGCCTGTAACAGCTAATTAAATACTGTGTGCCTCTCCATAGAAAAATGTAATTATTCACTT GTGTGAATTTGGTACGTTGCTAACTTCAGCAGGCTGGTATTTCTGCATGAAGTCAGAACTGCCCAAGCACAATTCAGAGGTCTCCTA TAAAACAAACTATTTTTAACTCTTATGAAGGTAGTGATGATCCTCGAGCTCCCTATAGTGAGTCGTATTAGGCCAGTGAGGCCTAGAGTCGAC

Abb.14: Phagenklon Nummer 6. (A) zeigt die im Screen isolierten Phagen, die mit SalI verdaut worden sind; 0,3\%iges Agarosegel. Das längste und das kürzeste Fragment sind die beiden Teile des Phagen. Entweder befindet sich die genomische DNA zwischen diesen beiden Stücken oder sie ist als Stück von gleicher Länge zusammen mit einem Stück des Phagen als eine Bande zu vermuten. Längste Bande des Markers 12200 bp. (B) Restriktionskarte von Klon Nummer 6. Der Balken entspricht 1000 bp. Kästen = Exon 1 und 2 von GANF. (C) Nukleotidsequenz von Klon Nummer 6. Eingezeichnet sind folgende Angaben: a) Schnittstellen von NcoI (CCATGG ) und SalI (GTCGAC), markiert durch Kästen, b) CpG-Insel, markiert durch zwei blaue Punkte, c) konservierter Bereich, markiert durch zwei rote Punkte, d) Exons von GANF, grau unterlegt, e) Startkodon von GANF, dick gedruckt, f) potenzielle TATA-Box, GC-Box und CCAAT-Boxen, hellgelb unterlegt. 


\subsection{Sequenzauswertung}

\subsubsection{TATA-Box, GC-Box und CAAT-Boxen in der 5'-Region}

In der Sequenz wurden für eukaryontische Promotoren typische Elemente gefunden: eine TATA-Box, eine GC-Box und vier CAAT-Boxen. Funktionell wurden diese Elemente nicht untersucht. In Abbildung 15 sind die Boxen gesondert dargestellt. In absteigender Häufigkeit sind die häufigsten (rot) bzw. die seltensten (grau) Nukleotide an der jeweiligen Position gekennzeichnet.

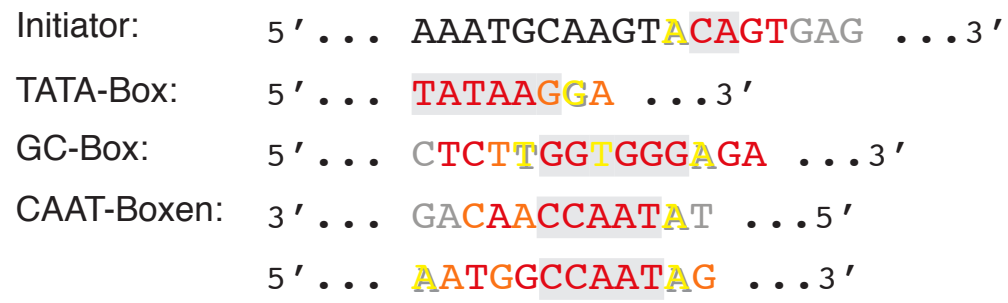

Abb. 15: TATA-Box, Initiator, GC-Box und CAAT-Boxen. Rot: Base, die am häufigsten im Konsensus vertreten ist, dann in absteigender Reihenfolge (orange, gelb) bis grau. Grau unterlegt sind die wichtigsten Basen, d. h. die Positionen, bei denen fast keine anderen Basen zu finden sind.

\subsubsection{In der 5'-Region von GANF befindet sich eine CpG-Insel}

Im Bereich um das Nukleotid -6800 beginnt ein Bereich mit überdurchschnittlich vielen $\mathrm{C}$ und $\mathrm{G}$. Er erstreckt sich bis in den Bereich um das Nukleotid -7400. Es liegt somit eine ca. 600 bp lange CpGInsel vor (siehe Abbildung 14, Seite 43 ff.).

\subsubsection{Die Region um das Startkodon von GANF stimmt zu 80\% mit der Kozak-Sequenz überein}

In Abbildung 16 ist zusammen mit der Sequenz um das Startkodon von GANF die Kozak-Sequenz abgebildet. Sie stimmt zu 80\% mit der Sequenz um das Startkodon von GANF überein.

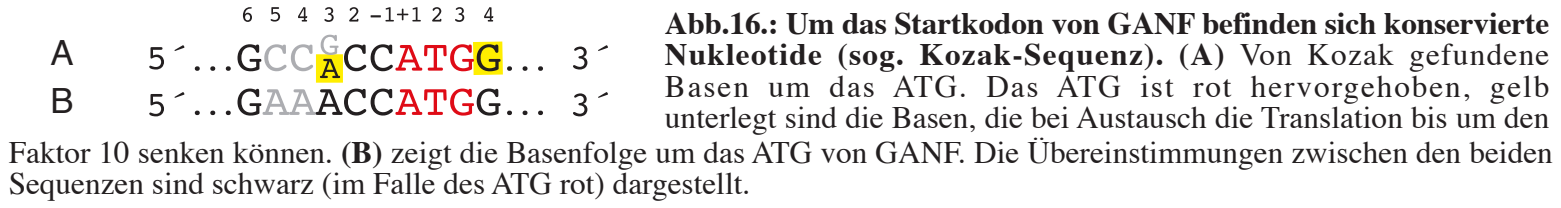
unterlegt sind die Basen, die bei Austausch die Translation bis um den Faktor 10 senken können. (B) zeigt die Basenfolge um das ATG von GANF. Die Übereinstimmungen zwischen den beiden Sequenzen sind schwarz (im Falle des ATG rot) dargestellt.

\subsubsection{Ca. 600 Nukleotide sind direkt vor dem Startkodon der Orthologen der ANF- Homöobox-Genfamilie von Mensch, Maus, Frosch und Huhn konserviert}

Im Rahmen der Untersuchung der Promotorsequenz von GANF wurde diese mit den homologen Sequenzen des Menschen, der Maus und des Frosches verglichen. 
Die Sequenzen des Menschen und der Maus sind der Celera Datenbank entnommen (Datenbanknummern: GA_x54KREACQDQ:1750000 (Maus) und GA_X5J8B7W4DBG:1000001 (Mensch)), die des Frosches der NCBI-Datenbank (X70282, gi:65220; Samakhvalov et al. 1993). Zur Zeit besteht kein Zugriff auf die homologe genomische Sequenz des Zebrafisches.

In dem verglichenen Bereich wurde ein ca. 600 bp langer Bereich gefunden, der in allen vier Organismen erstaunlich stark konserviert ist. Er liegt direkt vor dem Startkodon. Er ist in Abbildung 17 (Seite 47 ff.) dargestellt. In ihr ist jede Sequenz in 5' - 3' -Richtung dargestellt. Die Sequenzen beginnen 3'wärts mit dem entsprechenden Startkodon.
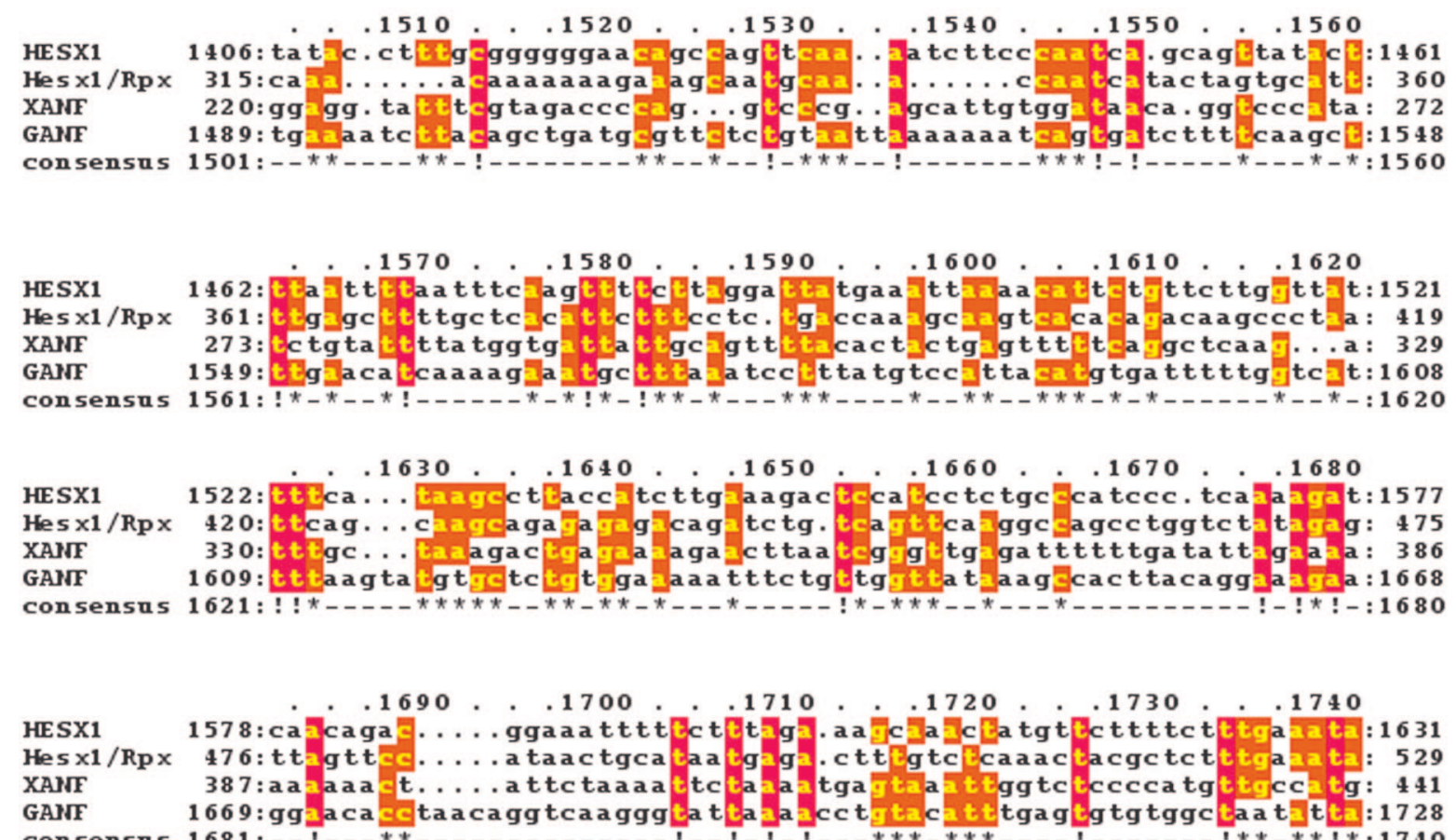

consensns $1681:-1 ! * *$ -
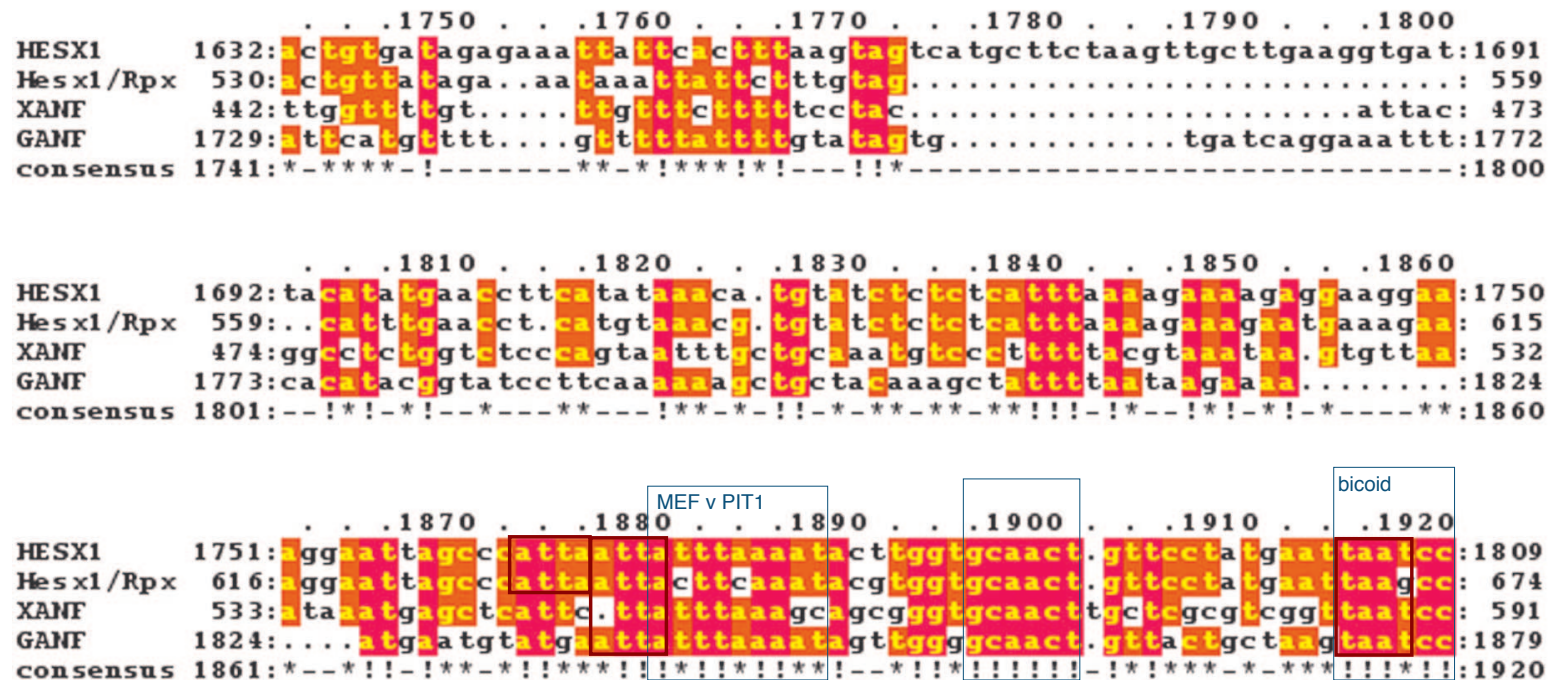
1930.01940 .0 .1950 .0 .1960 .0 .1970 .0 .1980

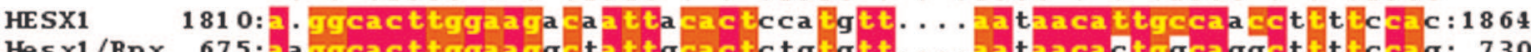

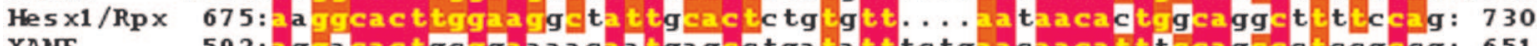

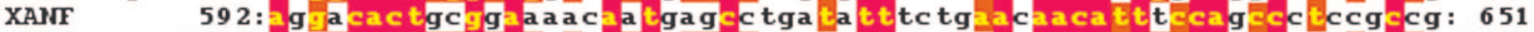

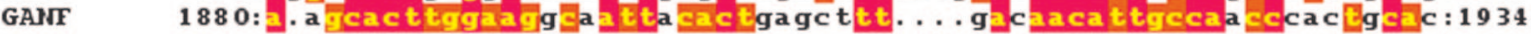
consensus $1921: !-* \star ! ! ! ! * \star ! * ! *-*-! * !-\star \star ! *---\star-! !----* !-! ! ! ! * ! * \star ! !-* !-*-\star-! *-: 1980$

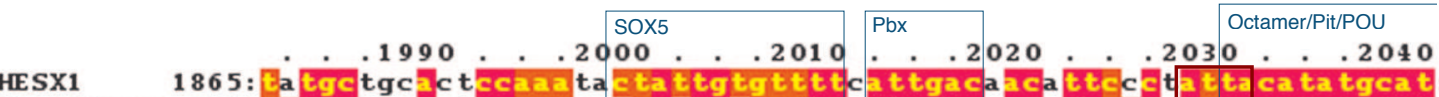
igctgcactccaaatacta tigtgtttcattgacaacattccstattaca ta tgcat: 1924 31: tgtgctgcactccaaagagtactgcgttttcattgacaacgttcacoattacatatgcat: 790 XANF 652:tgtgccttatacctccatccattgtgtcttattgaccacattactactaca ta tgcat: 711 GANF $1935:$ agtgccttatgccaaajgcta ttgttgtttattgaccacgttcacdattaca ta tgcat: 1994 consensus $1981: * \star ! ! !---!--! ! * \star \star--* \star ! * ! ! * \star * \star ! !-! ! ! ! ! !-! !-! ! * * !-! * ! ! ! ! ! ! ! ! ! ! !: 2040$

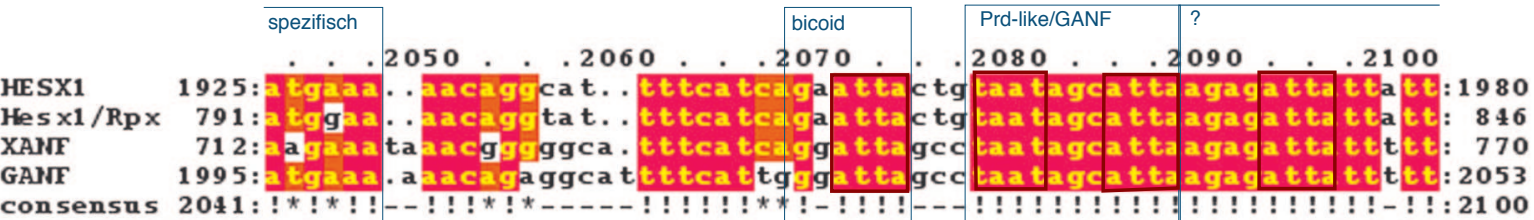

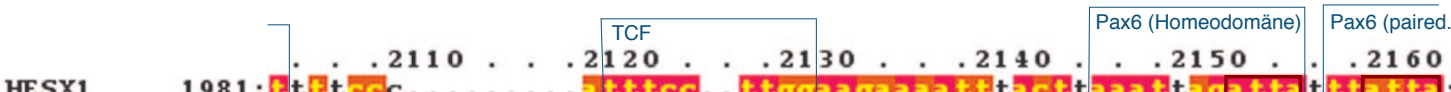

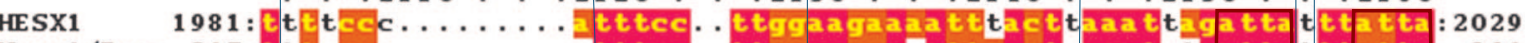

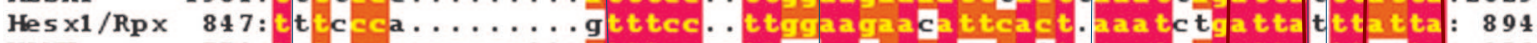

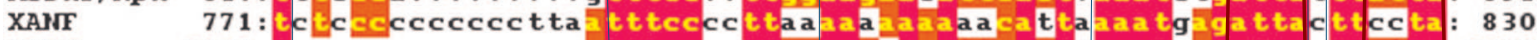

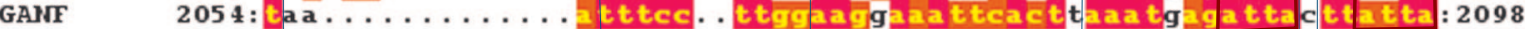

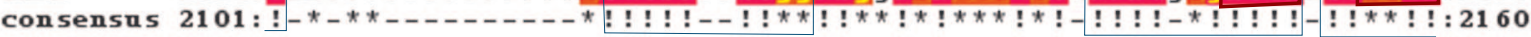

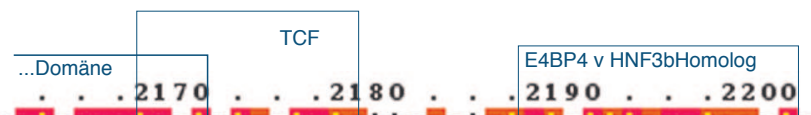

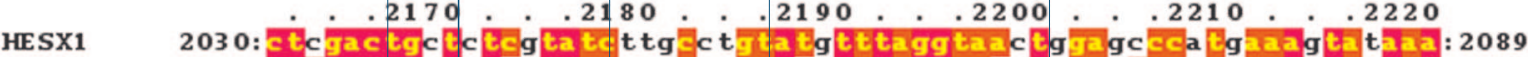
Hes $\times 1 / R p x$ 895:cttgactgctcttcta tccacsctgtacatteggtatctagaatcct tajaajtacaaa: 954

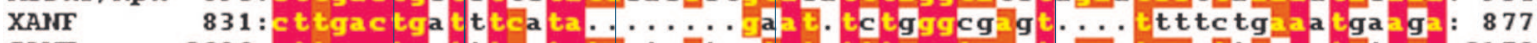

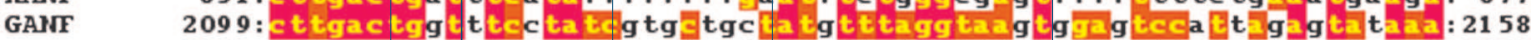

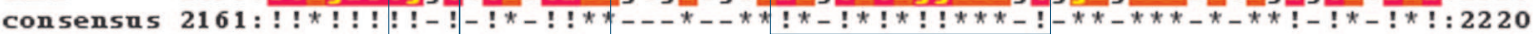

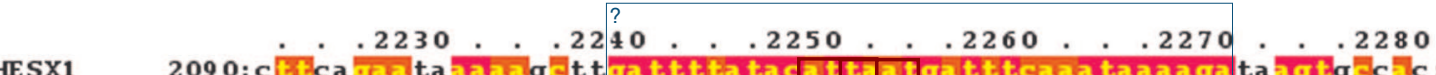

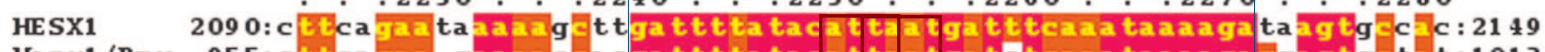

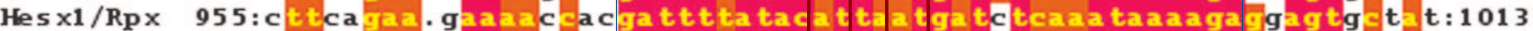
XANF $878:$ gga traa taagttgacgatttcatacgttggtggtttccataaagaggagttagtc: 937

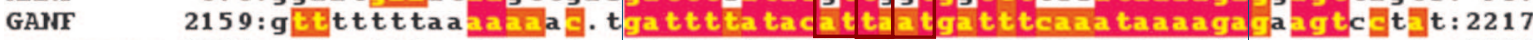
consensus $2221:-\star^{*}--\star_{*}-_{-} ! !^{*} *_{-}--! ! ! ! * ! ! ! ! * ! ! * * ! ! * ! * ! * * * ! ! ! ! ! ! ! ! *-! ! !-*-*-: 2280$

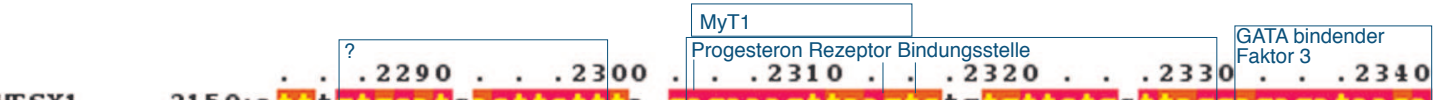
HESX1 $2150: a$ tet

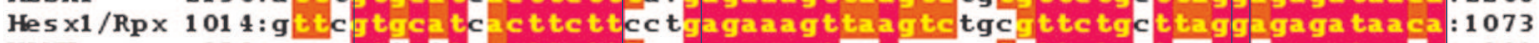
XAIF 938:ggcgottcttaicttcttta.gagaaagtaga.....tattctggtcgggggagataaga: 991

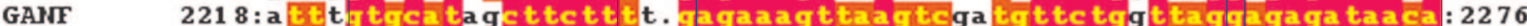

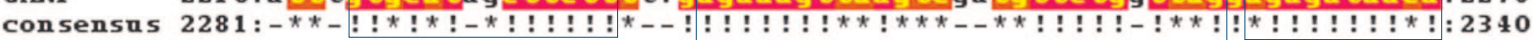

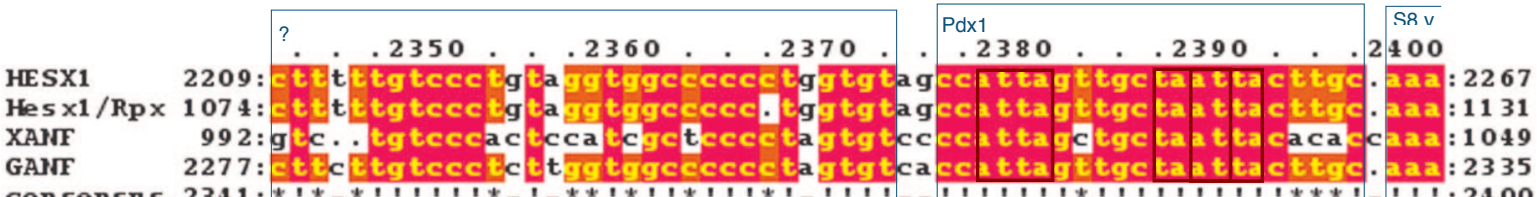

Fortsetzung nächste Seite 


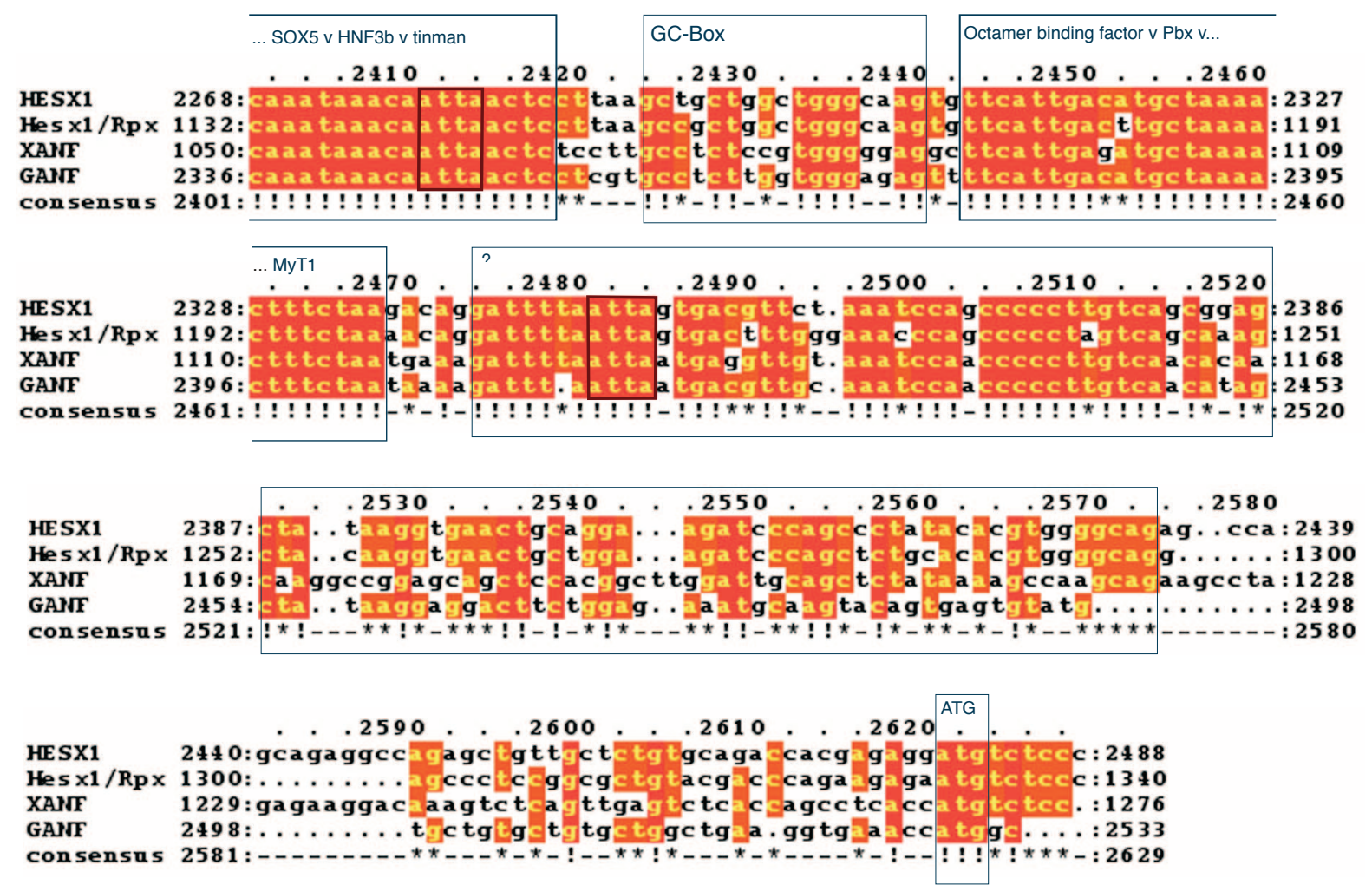

Abb. 17: Vergleich der stark konservierten Region der ANF-Homöobox-Genfamilie direkt in 5'-Richtung vor dem ATG. Vier Übereinstimmungen sind mit einem Ausrufezeichen, drei mit einem Stern unterlegt. Außerdem sind mögliche Bindungspartner, die GC-Box und das Startkodon angegeben.

Einem Großteil der konservierten Boxen wurden mögliche Bindungspartner zugeordnet. Grundlage dafür waren die Angaben der Sequenzen der transfac-Datenbank und der Sequenzen, die Originalarbeiten entnommen worden sind. Besonders interessant sind die folgenden Transkriptionsfaktoren, da ihre Expressionsdomänen mit der von GANF überlappen und für einen Teil von ihnen eine Rolle in der Morphogenese des Vorderhirns funktionell nachgewiesen worden ist: S8 (Jong de et al. 1993; Leussink et al. 1995; Norris und Kern 2001), HNF3及 (Perea-Gomez et al. 1999), Otx2 (Bally-Cuif et al. 1995), Pax6 und Tef (Mukhopadhyay et al. 2001).

Für die folgenden weiteren Homöobox-Gene sind bis jetzt keine Bindungssequenzen nachgewiesen worden. Doch die Ähnlichkeit bzw. Beziehung in ihrer Expression mit der von GANF legt allerdings ebenfalls eine mögliche Wechselwirkung mit dem Promotor von GANF nah: Vax (Hallonet et al. 1998; Hallonet et al. 1999), Irx3 (iroquois) (Kobayashi et al. 2002), Six3 (Kobayashi et al. 1998; Loosli et al. 1999), Rx (Andreazzoli et al. 1999; Casarosa et al. 1997).

\section{3 Übersicht über die klonierten Reporterkonstrukte}

Das Startkodon von GANF ist von den Basen umgeben, die zu einer Schnittstelle von NcoI führen 
(siehe Abbildungen 12 und 18, Seite 23 bzw. 50). Um diese Schnittstelle zur direkten Klonierung des 5'-Elementes nutzen zu können, wurde in das Startkodon des lacZ des Reporterplasmids eine NcoISchnittstelle eingefügt. In Abbildung 18 sind die schließlich klonierten Reporterkonstrukte (RK1-RK6) dargestellt. Die jeweiligen Schritte aller Klonierungen sind im Detail in 3.6 beschrieben.

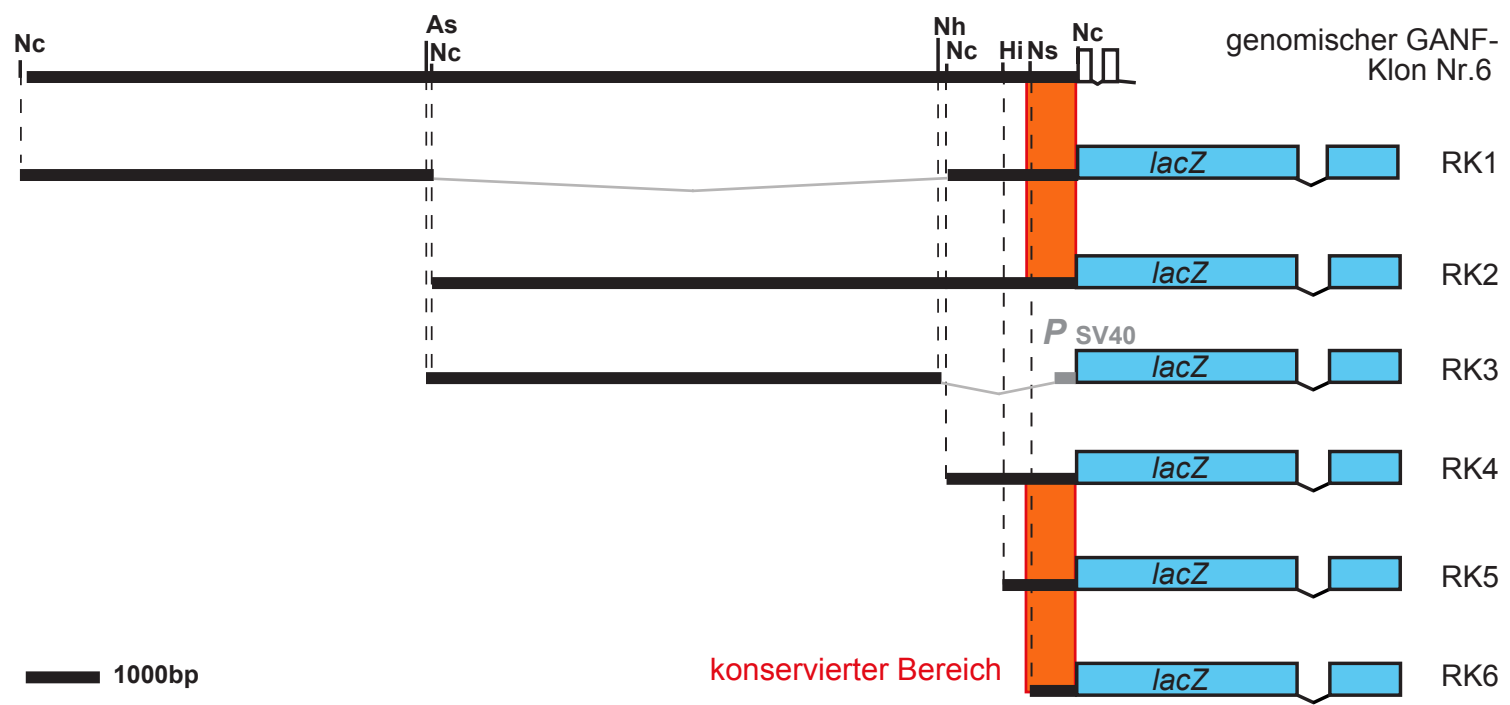

Abb. 18: Der genomische Klon Nummer 6 und die Reporterkonstrukte. ( $P$ SV40: SV40 basaler Promotor; Nc=NcoI, $\mathrm{Nh}=$ NheI, As=Asp718I, Hi=HindIII, Ns=NsiI, RK: Reporterkonstrukt.)

\subsection{Untersuchung der Reporterkonstrukte}

Mittels der Reporterkonstrukte wurde der Teil der Sequenz des genomischen Klons gesucht, der für die spezifische Expression des Homöobox-Genes GANF verantwortlich ist. Die Reporterkonstrukte wurden im Huhn, im Zebrafisch und in der Maus untersucht. Im Folgenden werden die jeweiligen Ergebnisse vorgestellt.

\subsubsection{Reporterkonstrukte RK2 und RK4 zeigen anteriore Expression im Huhn}

$\mathrm{Zu}$ Beginn der Arbeit wurden verschiedene Variationen der Elektroporation ausprobiert. Mit der unter 3.9.2 dargestellten neu entwickelten Methode wurde schließlich ein Weg gefunden, der es ermöglichte, junge Embryonen mit hoher Effizienz zu elektroporieren. Mittels dieser Methode wurden Reporterkonstrukt RK 2 und RK4 im Rahmen dieser Arbeit getestet. In allen untersuchten Embryonen wurde die Xgal-Färbung immer innerhalb der größeren GFP-Expression gesehen (RK2: (n=5, 5/5); RK4: (n=7, 7/ 7)). Diese war in jüngeren Embryonen (um HH8, siehe Abbildung 19, Seite 51) auf die anterioren 

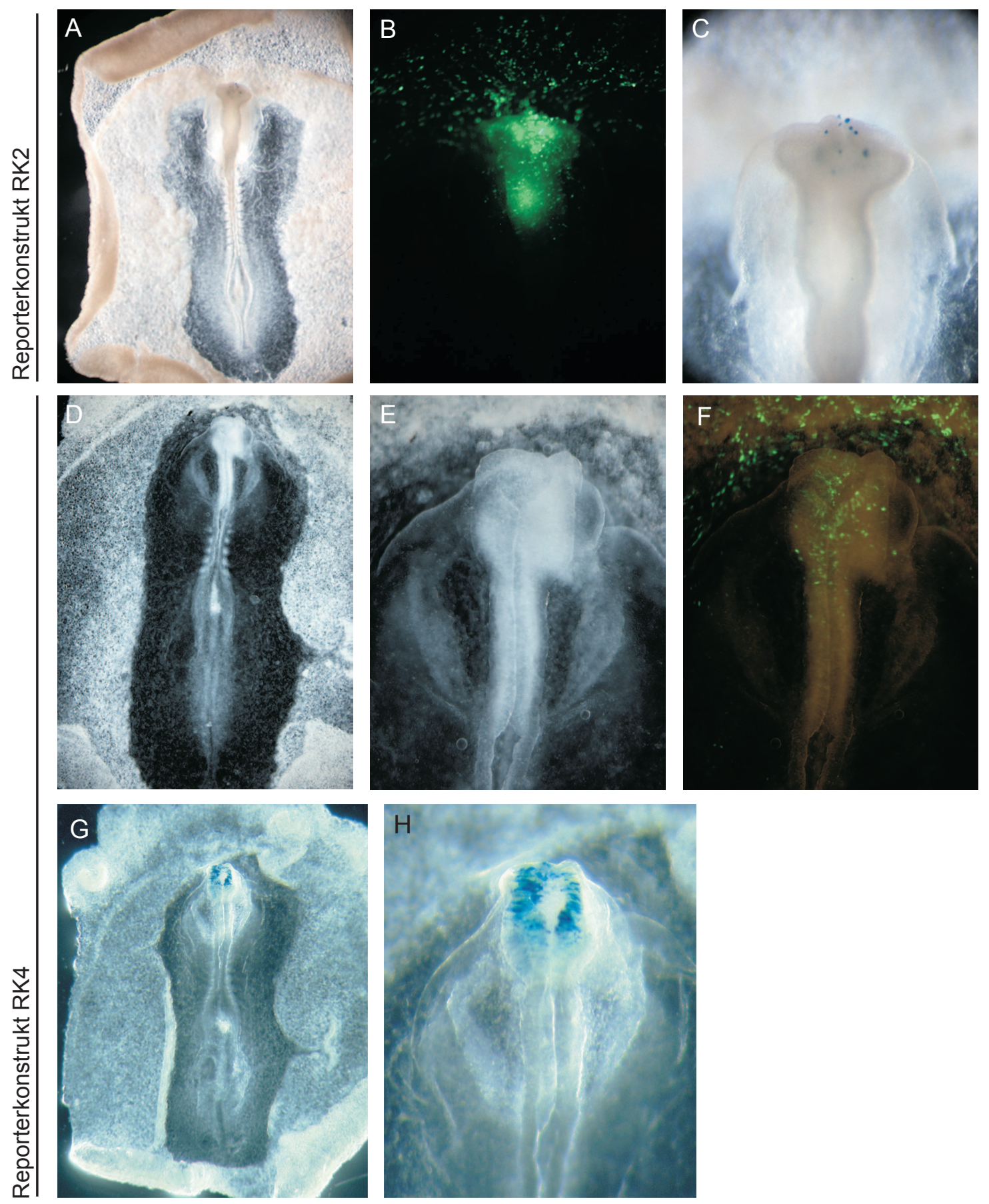

Abb. 19: Elektroporation der Reporterkonstrukte RK2 (A-C) und RK4 (D-H) in der ec-Kultur. (A) Übersicht. (B) GFP (Kontrolle). (C) X-gal-Färbung (Ausschnitt). (D) Übersicht. (E) Detailansicht. (F) GFP (Kontrolle). (G) Übersicht X-gal-Färbung. (H) X-gal-Färbung (Ausschnitt).

Neuralfalten beschränkt und weder posterior noch im extraembryonalen Gewebe zu finden. In älteren Embryonen (HH11, siehe Abbildung 19), bei denen sich schon die Augenanlage auf beiden Seiten ausgebildet hatte, war die X-gal-Färbung des Weiteren nicht in den lateralen Teilen des Embryos zu finden, sondern nur auf die Mitte beschränkt. Es wurde noch kein Experiment durchgeführt, in dem der 
weitere Verlauf der X-gal-Färbung verfolgt wurde, nachdem die endogene Expression aufgehört hat. Bei einer Kontrolle, in der nur posterior elektroporiert wurde, wurde keine Blaufärbung bei guter GFPExpression gesehen ( $\mathrm{n}=10,10 / 10$; Daten nicht gezeigt). Die Ergebnisse sind in Abbildung 19 (Seite 51) dargestellt.

Die Region, die für die Expression von GANF, für die Expression im prospektiven Prosenzephalon, verantwortlich ist, konnte somit auf 1800 bp eingegrenzt werden. Dieser Bereich umfasst den in 4.2.4 dargestellten konservierten Bereich.

\subsubsection{Reporterkonstrukt RK2 und Reporterkonstrukt RK6 zeigen X-gal-Färbung im prospektiven Prosenzephalon des Zebrafisches, während Reporterkonstrukt RK3 gar keine X-gal-Färbung zeigt}

Um eine mögliche Konservierung der Promotorregion innerhalb der ANF-Genfamilie zu überprüfen, wurden die Reporterkonstrukte RK2, RK6 und RK3 in Zebrafischembryonen injiziert. Die Injektion fand nach der Befruchtung im Einzellstadium statt, die Fixierung und X-gal-Färbung erfolgte im 1-3 Somitenstadium nach ungefähr 11-13 h. Da in diesem Stadium die unterschiedlichen Regionen des Gehirns morphologisch noch nicht unterschieden werden können, schloss sich eine WMISH (Krox20) der X-gal-Färbung an.

Die Injektion in Zebrafischembryonen kann in unterschiedlicher Ausprägung zu einer fehlerhaften Entwicklung führen. Dabei ist die Injektion von $D N A$ (anstelle von $R N A$ ), die Nadel, die Art des injizierten Plasmids sowie die Qualität/Beschaffenheit der Embryonen für den Erfolg des Experimentes entscheidend. Von einer verlangsamten Entwicklung bis zu einem frühen Sterben überdurchschnittlich vieler Embryonen im Laufe der Entwicklung reichen diese Fehlentwicklungen. Die morphologischen Unterschiede spiegeln sich bei der Krox20-Färbung in einer völlig ausgebliebenen, einer fehlerhaften Krox20-Färbung bzw. der einer Wildtypfärbung vergleichbaren Färbung wieder.

Der Prozentsatz der nicht auswertbaren Embryonen variierte zwischen den experimentellen Serien und wird in Tabelle 14 (Seite 53) jeweils angegeben. Die Zahl der ausgewerteten Embryonen wird ebenfalls dort angegeben und gilt als Bezugspunkt für die Aussagen.

Die Injektion von Reporterkonstrukt RK2 verlief technisch am besten (siehe Tabelle 14, Seite 53). Die Embryonen zeigten eine eindeutige Färbung des anterioren Endes des Embryos (siehe Abbildung 20, Seite 54). Insgesamt 78,1 \% aller Embryonen zeigten ausschließlich in der Region des prospektiven Prosenzephalons des Embryos eine Färbung. 20,9 \% zeigten lacZ-Aktivität im prospektiven Prosenzephalon mit vereinzelt woanders liegenden blauen Zellen, die dann zum Beispiel am Eidotter oder hinter der Krox20-Färbung zu finden waren. Keine Färbung war bei $1 \%$ der Embryonen zu sehen. Bei keinen Embryonen war eine andere Expressionsdomäne zu finden, sowohl in Bezug auf die Größe als auch in Bezug auf den Ort. 


\begin{tabular}{|c|c|c|c|c|}
\hline & $\underset{(9000 \text { bp 5') }}{\mathbf{R K 2}}$ & $\begin{array}{c}\text { RK6 } \\
(500 \text { bp 5') }\end{array}$ & $\begin{array}{l}\mathbf{R K 3} \\
(7200 \text { bp 5 } \\
+ \text { PSV40) }\end{array}$ & CMV-lacz \\
\hline Embryonen nach WMISH & $101(100 \%)$ & $59(100 \%)$ & $7(100 \%)$ & $80(100 \%)$ \\
\hline auswertbare Embryonen (siehe unten): & $96(95 \%)$ & $16(27,1 \%)$ & $4(57,1 \%)$ & $28(35 \%)$ \\
\hline $\begin{array}{l}\text { nicht auswertbare Embryonen (nicht Wildtyp- } \\
\text { Krox20 WMISH oder zerstört): }\end{array}$ & $5(5 \%)$ & $43(72,9 \%)$ & $3(42,9 \%)$ & $52(65 \%)$ \\
\hline a) durch den WMISH zerstörte Embryonen: & $5(5 \%)$ & $3(5,1 \%)$ & $0(0 \%)$ & $4(5 \%)$ \\
\hline b) keine Krox20-Färbung: & $0(0 \%)$ & $15(25,4 \%)$ & $2(28,6 \%)$ & $17(21,3 \%)$ \\
\hline $\begin{array}{l}\text { c) fehlerhafte Krox } 20 \text {-Färbung (nicht vergleichbar } \\
\text { mit Wildtyp-WMISH): }\end{array}$ & $0(0 \%)$ & $25(42,4 \%)$ & $1(14,3 \%)$ & $31(38,8 \%)$ \\
\hline $\begin{array}{l}\text { d) große Regionen lacZ-Expression zusammen mit } \\
\text { in a), b) bzw. c) beschriebenen Zuständen }\end{array}$ & $0(0 \%)$ & $0(0 \%)$ & $0(0 \%)$ & $37(46,3 \%)$ \\
\hline auswertbare Embryonen (korrekte WMISH) & $96(100 \%)$ & $16(100 \%)$ & $4(100 \%)$ & $28(100 \%)$ \\
\hline a) lacZ-negativ & $1(1 \%)$ & $2(12,5 \%)$ & $4(100 \%)$ & $11(39,3 \%)$ \\
\hline b) lacZ-positiv: & $95(99 \%)$ & $14(87,5 \%)$ & $0(0 \%)$ & $17(60,7 \%)$ \\
\hline c) lacZ nur im prospektiven Prosenzephalon: & $75(78,1 \%)$ & $12(75 \%)$ & $0(0 \%)$ & $0(0 \%)$ \\
\hline $\begin{array}{l}\text { d) lacZ im prospektiven Prosenzephalon mit verein- } \\
\text { zelt woanders liegenden blauen Zellen: }\end{array}$ & $20(20,8 \%)$ & $2(12,5 \%)$ & $0(0 \%)$ & $0(0 \%)$ \\
\hline $\begin{array}{l}\text { e) lacZ nicht aussschließlich im prospektiven } \\
\text { Prosenzephalon, sondern über den ganzen Embryo } \\
\text { entweder punktförmig oder flächig verteilt (z.B. } \\
\text { Dotter oder posterior von Krox20) }\end{array}$ & $0(0 \%)$ & $0(0 \%)$ & $0(0 \%)$ & $17(60,7 \%)$ \\
\hline $\begin{array}{l}\text { f) lacZ überall, nur nicht im Bereich anterior von } \\
\text { Krox } 20\end{array}$ & $0(0 \%)$ & $0(0 \%)$ & $0(0 \%)$ & $1(3,6 \%)$ \\
\hline
\end{tabular}

Tabelle 14: Zusammenfassung der Ergebnisse der Injektionen der Reporterkonstrukte RK2, RK6 und RK3 sowie des Kontrollvektors CMV-lacZ im Zebrafisch.

Das Reporterkonstrukt RK3 beinhaltet nicht die ersten 1800 bp 5'. Diese sind durch den basalen Promotor von SV40 ersetzt. Somit konnte überprüft werden, inwieweit die Sequenz von RK2 über den konservierten Teil hinaus zur Kontrolle der Transkription beiträgt. $100 \%$ aller untersuchten Embryonen waren lacZ-negativ, was den Schluss zulässt, dass die 1800 bp 5' ausreichend für die Kontrolle der GANF-Expression sind. Da die Ergebnisse von Reporterkonstrukt RK2 und RK6 in Bezug auf die Lokalisation vergleichbar sind, lässt sich also die Promotorregion von GANF auf 600 bp direkt von dem Startkodon eingrenzen. Allerdings erschien die durchschnittliche Intensität geringer (siehe Abbildung 20, Seite 54). Weitere Angaben zu den Versuchsreihen finden sich in Tabelle 14.

Als Kontrolle wurde ein durch den CMV-Promotor gesteuerter lacZ-Vektor benutzt. Die so behandelten Embryonen überlebten bzw. entwickelten sich während der Inkubation sehr schlecht, nur $37 \%$ 
waren auswertbar. Es war kein einziger Embryo dabei, der ein vergleichbares lacZ-Muster hatte wie die, die mit RK2 und RK6 injiziert waren.

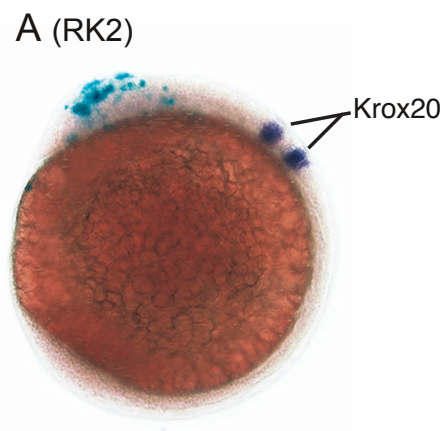

B (RK6)

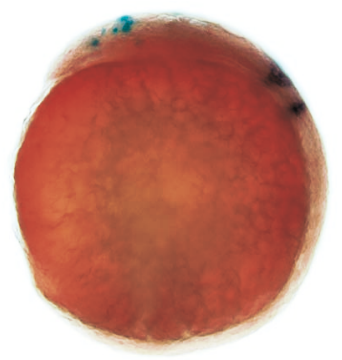

C (RK6)

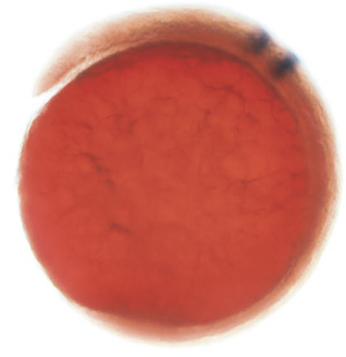

D (CMV-lacZ)

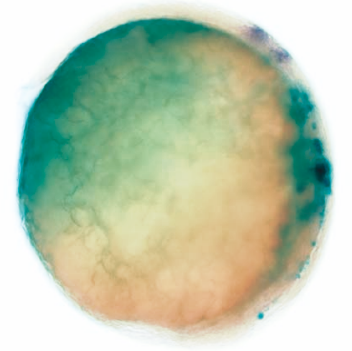

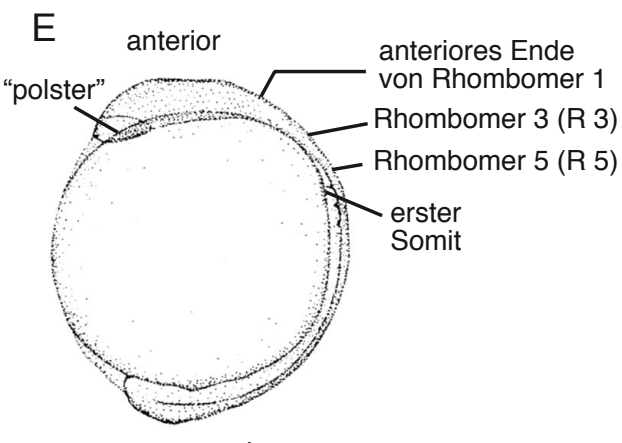

posterior

$\mathrm{F}$

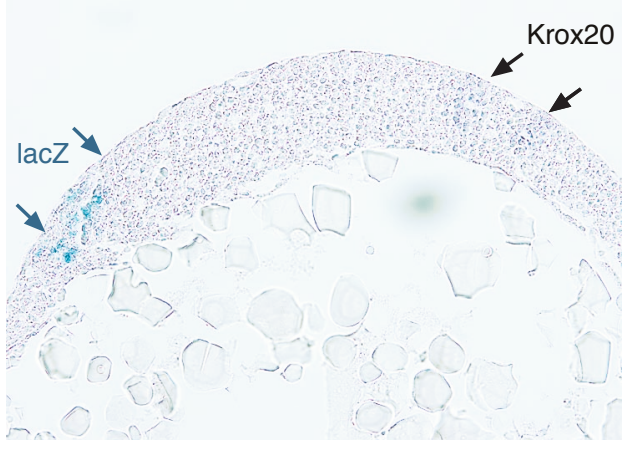

G $\operatorname{lacZ}$

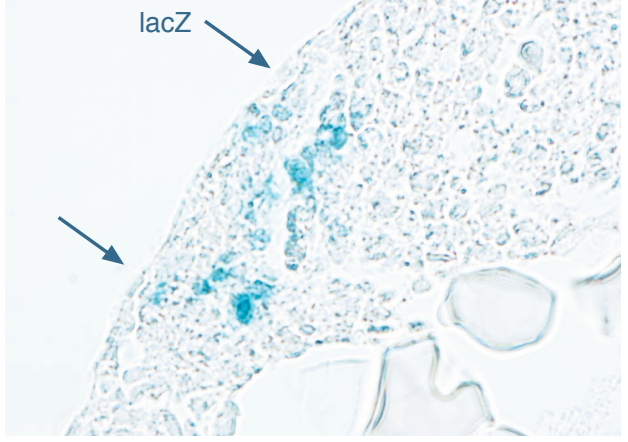

Abb. 20: Injektionen in Zebrafischembryonen. (E) zeigt ein Schema eines $11 \mathrm{~h}$ alten Zebrafisches. (A-D) Repräsentative Embryonen der Injektionen. (A) RK2, (B) RK6, (C) RK 3 und (D) CMV-lacZ. Schema entnommen aus Kimmel et al. (1995, Seite 257). (F und G) zeigen Sagittalschnit von Embryo (A). 


\subsubsection{Die Reporterkonstrukte RK2 und RK4 zeigen keine X-gal-Färbung in der Maus}

Um auch in Bezug auf die Säugetiere eine mögliche Konservierung der Promotorregion innerhalb der ANF-Genfamilie zu überprüfen, wurden die Reporterkonstrukte RK2 und RK4 in die Pronuklei von fertilisierten Oozyten der Maus injiziert. In Bezug auf das Reporterkonstrukt RK2 wurden 17 schwangere Mäuse untersucht. Die entnommenen Embryonen wurden in den Stadien e7.5 bis e.8.5 mittels der X-gal-Färbung gefärbt. Von diesen war bei keinem Embryo eine Blaufärbung zu erkennen. Die Effizienz der Injektion wurde im Anschluss bei 74 Embryonen mittels PCR überprüft. Als Ausgangsmaterial wurden dafür die ganzen Embryonen nach der X-gal-Färbung verwendet. Es zeigten 15 eine sehr starke, 8 eine starke und 17 eine schwache Bande (siehe Abbildung 21).

Die untersuchte Sequenz ist somit nicht ausreichend für die Expression der ANF-Genfamilie in der Maus. Die mit Reporterkonstrukt RK4 injizierten Embryonen waren ebenfalls nicht gefärbt. Die lacZPCR wurde hierbei als Überprüfung der Effizienz der Injektion nicht durchgeführt.

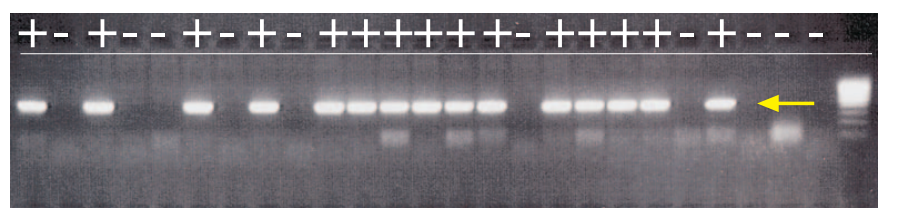

Abb. 21.: Kontrolle der Effizienz der Injektion: lacZ-PCR-Produkte. Erwartete Bande ist mit Pfeil gekennzeichnet.

\subsection{Potenzielle Bindungspartner des GANF-Promotors}

Mit dem Ziel, in dem konservierten Sequenzteil gefundene Bindungssequenzen näher zu charakterisieren, wurden insgesamt vier solche "Boxen" näher mittels EMSA charakterisiert. Dabei handelt es sich zweimal um eine potenzielle Bindungsstelle von Otx2 und jeweils einmal um eine potenzielle Bindungsstelle von GANF bzw. Pax6. Die Lage dieser Bindungsstellen relativ zum Startkodon ist in Abbildung 22 dargestellt.

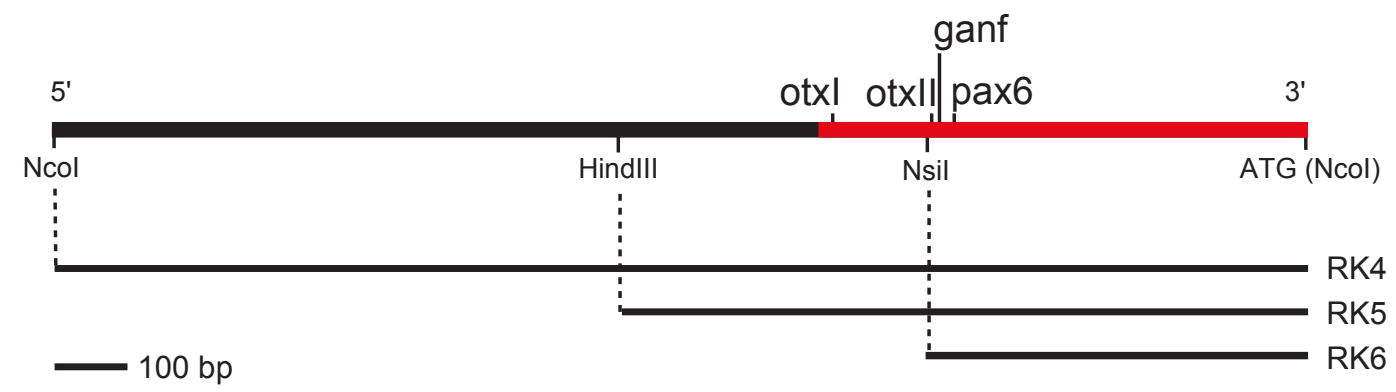

Abb. 22: Übersicht über die Lage der untersuchten Bindungsstellen in der 5'-Region von GANF zusammen mit den Reporterkonstrukten. Der konservierte Teil ist rot markiert. Zur besseren Unterscheidung sind die potenziellen Bindungsstellen kleingedruckt vermerkt. 


\subsubsection{Das Homöobox-Gen Otx2 bindet an zwei Stellen des GANF-Promotors}

Für die Untersuchung der zwei Otx2-Bindestellen (Sequenz: CCTAAT (White 2001)) wurden das invitro hergestellte Otx2 sowie HPLC-gereinigte Oligonukleotide (siehe 3.7.4.4) verwendet. Die beobachteten Shifts sind in Abbildung 23 gezeigt. Sie zeigten für beide Bindungsstellen eine DNA-ProteinBindung (Spur 4 und 9). Diese Bindungen konnten mit einem Antikörper gegen Otx2 aufgehoben werden, wurden aber nicht durch einen Pax2-Antikörper beeinflusst (Spur 5 und 6 sowie 10 und 11). Die Inkubation ohne Otx2, aber mit dem Retikulozytenextrakt zeigte in beiden Fällen keine spezifische Bindung (Spur 7 und 12). Die veränderten Nukleotide im mutierten Oligonukleotid bsotxIMUT (siehe 3.7.4.4) hoben die Bindung komplett auf, die veränderten Nukleotide im mutierten Oligonukleotid bsotxIIMUT (siehe 3.7.4.4) zeigten eine signifikante Reduktion der Bindung (Spur 8 und 13). In Spur 1-3 der Abbildung 23 ist die Kontrolle gezeigt (ots; Briata et al. 1999). Das Homöobox-Gen Otx2 bindet somit an zwei Stellen des GANF-Promotors.

A

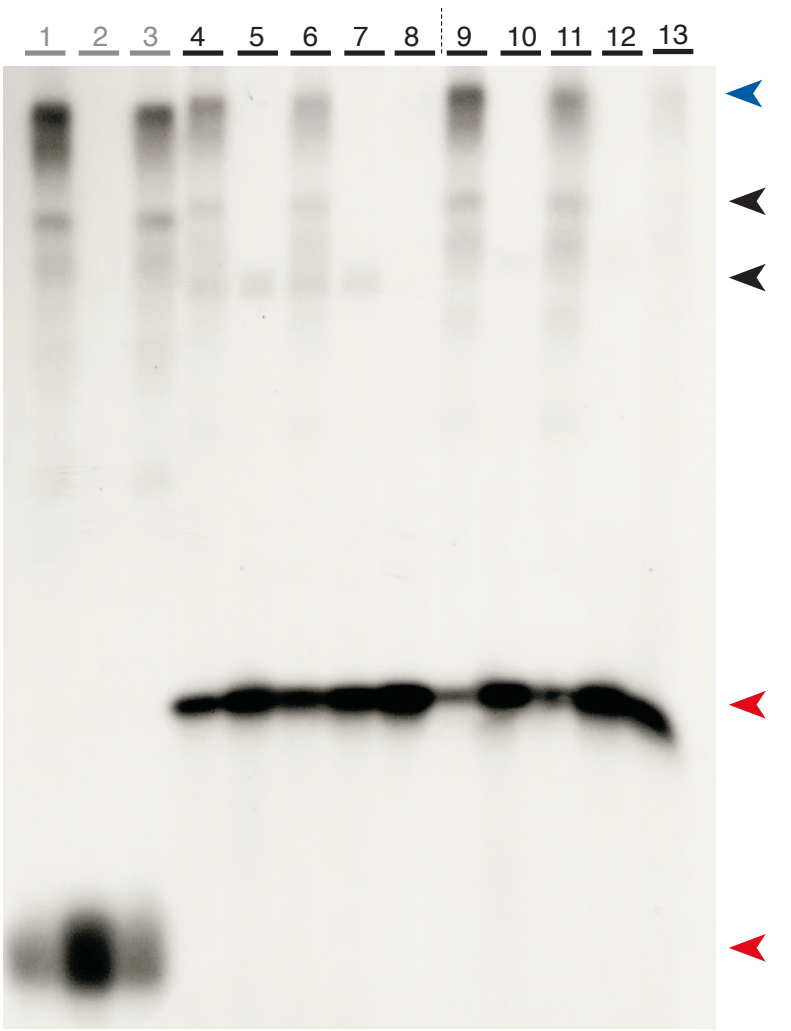

B

\begin{tabular}{llll} 
Bahn Oligonukleotid & Protein & Antikörper(AB) \\
1 & ots Control & Otx2 & \\
2 & ots Control & Otx2 & Otx2-AB \\
3 & ots Control & Otx2 & Pax2-AB \\
4 & otxl & Otx2 & \\
5 & otxl & Otx2 & Otx2-AB \\
6 & otxl & Otx2 & Pax2-AB \\
7 & otxl & & \\
8 & otxIMUT & Otx2 & \\
\hdashline 9 & otxII & Otx2 & \\
10 & otxll & Otx2 & Otx2-AB \\
11 & otxll & Otx2 & Pax2-AB \\
12 & otxII & & \\
13 & otxIIMUT & Otx2 &
\end{tabular}

Abb. 23: Potenzielle Bindungsstellen für Otx2. (A) EMSA für die Otx2-Bindestellen. (B) Legende für den EMSA, dargestellt in (A). Rote Pfeilspitzen zeigen das freie Oligonukleotid. Blaue Pfeilspitze zeigt den langsamer durch das Gel wandernden Komplex aus Protein und Oligonukleotid (und evtl. Antikörper). Schwarze Pfeilspitzen zeigen unspezifische Bindungen.

\subsubsection{Eine nahe liegende Bindungssequenz für GANF wird von GANF nicht spezifisch gebunden}

Für Hesx1 ist gezeigt worden, dass es an DNA-Sequenzen bindet, die die Basenabfolge TAATXY- 
ZATTA haben (Sornson et al. 1996; siehe unter 3.7.4.4: bs001(P3)). Eine solche Sequenz findet sich in der Promotorsequenz von GANF. Die untersuchte Sequenz wurde von GANF gebunden. Jedoch zeigte auch das mutierte Oligonukleotid weiterhin eine Bindung. Es liegt somit keine spezifische Bindung vor, die mit dem bisherigen Wissen über die Bindung von Homöobox-Genen vereinbar ist (Daten nicht gezeigt).

\subsubsection{Das Paired-Homöobox-Gen Pax6 bindet an den GANF-Promotor}

Für die Untersuchung der Pax6-Bindungsstelle wurde das murine Pax6 verwendet (komplette cDNA), da die Aminosäuresequenz des murinen Pax6 zu 99,3 \% mit dem Ortholog des Huhnes identisch ist und der murine Klon im Labor vorlag. Abbildung 24 (C) zeigt die Übereinstimmung der potenziellen Bindungssequenz sowohl der Paired- als auch der Homöobox-Domäne im GANF-Promotor mit der Konsensussequenz von Pax6 (unterstrichene Nukleotide); des Weiteren sind die in den vier verglichenen Spezies konservierten Nukleotide dick gedruckt und grau hinterlegt. Teil A und B von Abbildung 24 zeigt das Ergebnis der EMSA-Untersuchung (entsprechende Oligonukleotide siehe 3.7.4.4). Beide Kontroll-Oligonukleotide sind der Arbeit von Andrejewski (2002) entnommen.

A

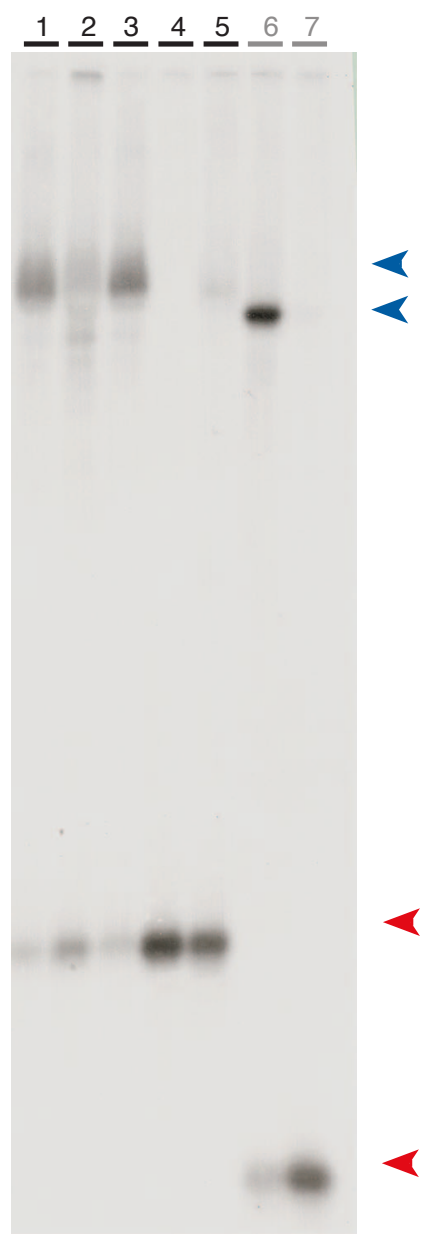

B

$\begin{array}{llll}\text { Bahn } \text { Oligonukleotid } & \text { Protein } & \text { Antikörper(AB) } \\ 1 & \text { Pax6bs } & \text { Pax6 } & \\ 2 & \text { Pax6b } & \text { Pax6 } & \text { Pax6-AB } \\ 3 & \text { Pax6bs } & \text { Pax6 } & \text { Pax2-AB } \\ 4 & \text { Pax6bs } & & \\ 5 & \text { Pax6bsMUT } & \text { Pax6 } & \\ 6 & \text { pax6ControlOligo } & \text { Pax6 } & \\ 7 & \text { pax6ControlOligoMUT } & \text { Pax6 } & \end{array}$

C
Abb.24: Potenzielle Bindungsstelle für Pax6. (A) EMSA für die Pax6Bindestelle. (B) Legende für den EMSA, dargestellt in (A). (C) Konsensussequenz von Pax6. Die ersten vier Zeilen zeigen die homologen Sequenzen aus Abb. 16. Die Konsensussequenz ist entnommen aus Czerny und Busslinger (1995). Die letzte Zeile zeigt das mutierte Oligonukleotid. Unterstrichen sind die Nukleotide bzw. Nukleotidstellen, die die Konsensussequenz angibt. Dickgedruckt und ausserdem grau unterlegt sind die in allen vier verglichenen Organismen konservierten Nukleotide. Die veränderten Nukleotide in bspax6MUT sind in Rot dargestellt. Die Zahlen unter den Nukleotiden der Konsensussequenz geben die Häufigkeit in Prozent an. Rote Pfeilspitzen zeigen das freie Oligonukleotid. Blaue Pfeilspitzen zeigen den langsamer durch das Gel wandernden Komplex aus Protein und Oligonukleotid. 
Das Oligonukleotid wurde von dem in-vitro translatierten Pax6 gebunden (Bahn 1). Ein Antikörper gegen Pax6 verminderte eindeutig die Bindung (Bahn 2). Ein nicht spezifischer Antikörper zeigt keine Reduktion der Bindung (Antikörper gegen Pax 2, Bahn 3). Keinen Bandshift zeigt der Ansatz, in dem das Oligonukleotid nur mit dem Retikulozytenextrakt ohne Pax6 inkubiert wurde (Bahn 4). Das mutierte Oligonukleotid zeigt eine signifikante Reduktion der Bindung im Vergleich zu der Originalsequenz (bspax6MUTR, Bahn 5) (Czerny und Busslinger 1995). Bahn 5 und 6 zeigen zum einen ein Kontroll-Oligonukleotid, für das bereits eine Bindung gezeigt wurde, zum anderen dessen mutierte Version. Das Homöobox-Gen Pax6 bindet somit an eine Stelle des GANF-Promotors.

\subsection{Molekulare Untersuchung von Patienten mit der Septo-optischen Dysplasie}

Da bei vielen Patienten, die an dem Syndrom der Septo-optischen Dysplasie (SOD) erkrankt sind, Mutationen im menschlichen GANF-Orthologen HESX1 gefunden worden sind und durch den Vergleich mit dem Phänotyp der murinen Verlustmutante von Hesx1 ein wesentlicher Grund für das Zustandekommen der Erkrankung in diesem Gen vermutet wird, habe ich mit der Unterstützung einiger Ärzte der Augenklinik, der Neuropädiatrie bzw. der Kinderpoliklinik der Universität Göttingen begonnen, Patienten auf eine Mutation hin zu untersuchen. Von den wenigen an SOD leidenden Patienten, die von Abteilungen der Universitätsklinik Göttingen betreut werden, wurde bis jetzt ein Patient im Rahmen der jährlichen Kontrolluntersuchung untersucht. Im Folgenden werden die Kasuistik sowie die Ergebnisse der Sequenzierung vorgestellt.

\subsubsection{Kasuistik}

Der Patient ist das erste Kind gesunder russischer Eltern. Nach einer unkomplizierten Schwangerschaft erfolgte die Geburt in der 40. SSW (Schädellage, Geburtsgewicht: ca. 3000 g, Länge 51 cm, Kopfumfang: $36 \mathrm{~cm}$ ).

Im Alter von 6 Jahren wurde ein Somatropin/GH-Mangel diagnostiziert und eine Substitutionstherapie $\left(\right.$ Genotropin $^{\mathrm{TM}}$ ) eingeleitet. Im Alter von 8 Jahren erfolgte die Diagnose eines Diabetes insipidus, woraufhin eine Minirin ${ }^{\mathrm{TM}}$-Therapie (Desmopressin) begonnen wurde. Seit dem 10. Lebensjahr erfolgt eine Hydrocortison-Substitution bei sekundärer Nebenniereninsuffizienz. Neben einem regelrechten vorderen Augenabschnitt zeigt der hintere Augenabschnitt beider Augen temporal beidseits sehr helle und kleine Papillen mit nasaler Supertraktion, d. h. hypoplastische bzw. atrophe Papillen (siehe Abbildung 25 (C und D), Seite 59). Seit Geburt wird ein Pendelnystagmus beobachtet, der in seitlichen Blickfeldbereichen zunimmt. Aufblick führt zu einem Up-Beat-Nystagmus; Abblick führt zu einem 

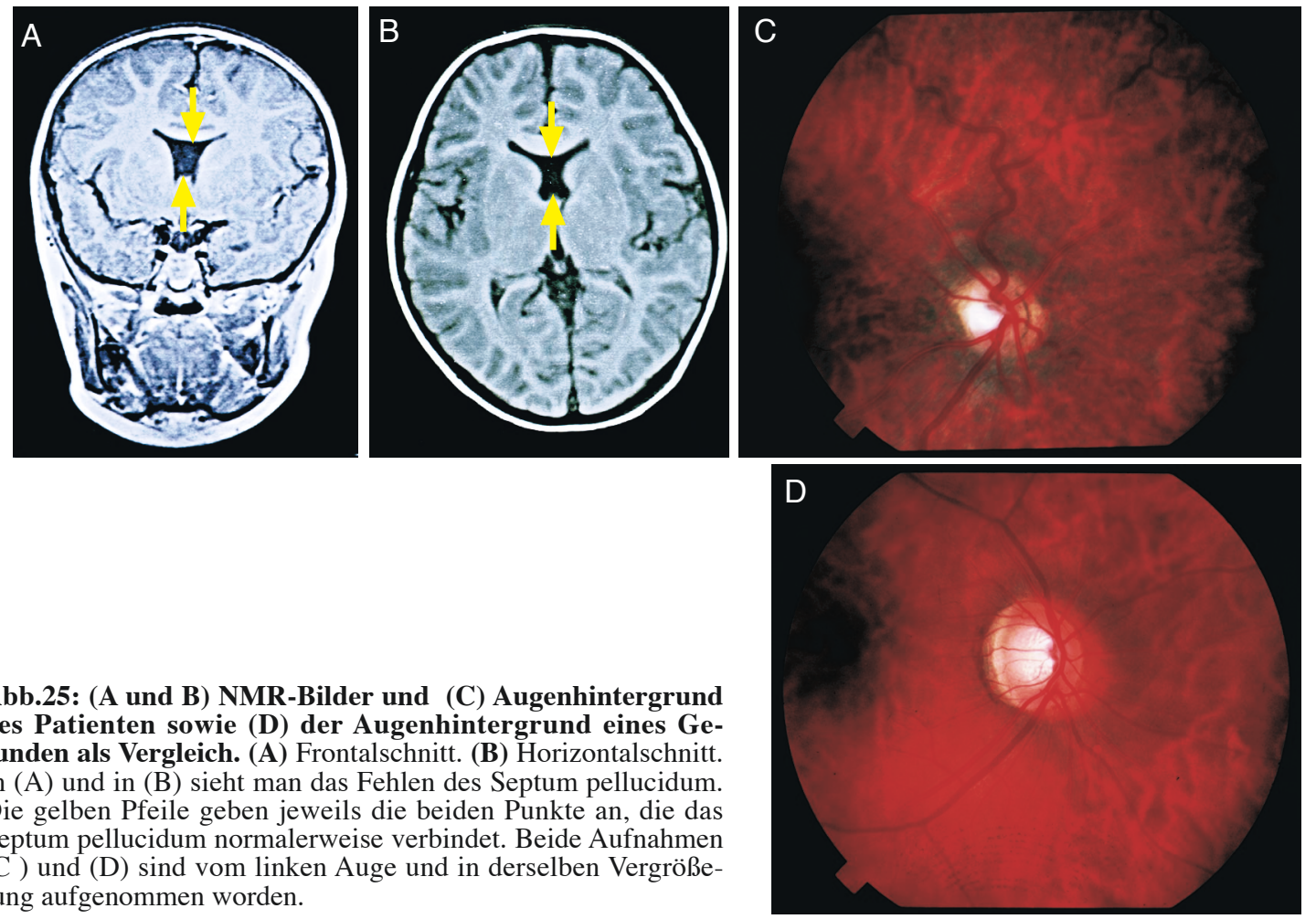

Abb.25: (A und B) NMR-Bilder und (C) Augenhintergrund des Patienten sowie (D) der Augenhintergrund eines Gesunden als Vergleich. (A) Frontalschnitt. (B) Horizontalschnitt. In (A) und in (B) sieht man das Fehlen des Septum pellucidum. Die gelben Pfeile geben jeweils die beiden Punkte an, die das Septum pellucidum normalerweise verbindet. Beide Aufnahmen (C ) und (D) sind vom linken Auge und in derselben Vergrößerung aufgenommen worden.

Down-Beat-Nystagmus. Zusätzlich ist eine rotatorische Komponente dieses Nystagmus zu beobachten. Bei Prüfung mit Ishihara-Sehtafeln liegt kein Hinweis auf eine Farbsinnstörung vor. Schielen ist der Mutter zufolge erst später aufgetreten. Dieser schwachen Esotropie wurde mit einer Operation entgegengewirkt. Im weiteren Verlauf folgten drei Operationen nach Kerstenbaum. Ein im Rahmen der Diagnostik angefertigtes NMR zeigt die Agenesie des Septum pellucidum. Einen Vergleich des Augenhintergrundes des Patienten mit dem Augenhintergrund eines Gesunden zeigt Abbildung 25. Beide Aufnahmen sind vom linken Auge und in derselben Vergrößerung aufgenommen worden. Der Augenhintergrund ist von einem älteren Menschen. Ein direkter Vergleich ist deshalb möglich, da das Auge im Alter von vier Jahren aufhört zu wachsen und somit Bilder von Augenhintergründen von Menschen mit unterschiedlichem Alter nach dem vierten Lebensjahr miteinander verglichen werden können.

\subsubsection{Sequenzierung}

Die Exons, die Introns und ein Fragment mit der Länge 500 bp vor dem ATG wurden zweimal in jede Richtung sequenziert. Es wurde dabei weder eine bekannte noch eine neue Mutation gefunden. 


\section{Diskussion}

\subsection{TATA-Box, CpG-Insel und Kozak-Sequenz}

Die für den Vergleich zugezogenen Konsensussequenzen sind im Internet veröffentlicht und werden ständig erweitert (Praz et al. 2002; http://www.epd.isb-sib.ch/promotor_elements/). Für die TATA-Box umfasst die Konsensussequenz Daten von 900 nicht miteinander verwandten Promotoren. Mit Ausnahme der drei letzten Basenpaare ist die potenzielle TATA-Box von GANF zu $100 \%$ mit dieser Konsensussequenz identisch, wobei alle Basenpaare vorhanden sind, mit denen die Aminosäuren des TBP eine Verbindung eingehen (Branden und Tooze 1999). Darüber hinaus ist bekannt, dass in einer kleinen Gruppe ein GC-Nukleotidpaar zu finden ist (Lewin 2000). Da in dem in Frage kommenden Gebiet keine alternativen TATA-Boxen zu finden sind, handelt es sich mit großer Wahrscheinlichkeit um die funktionelle TATA-Box des Homöobox-Genes GANF.

Die Lage nicht methylierter CpG-Inseln (Cytosin-Phosphat-Guanin) kann mit dem 5'-Ende von exprimierten Genen korrespondieren (Passarge 1994). Eine CpG-Insel besteht aus einem etwa 1-2 kb langen Abschnitt von CG-Nukleotiden. Wie bei den oben dargestellten konservierten Elementen bestätigt diese CpG-Insel, dass es sich bei der vorliegenden Sequenz um eine Promotorsequenz handelt. Viele methylierte CpG-Inseln findet man im Genom an Stellen, die nicht transkribiert werden (White 2001). Da GANF nur während der frühen Entwicklung des Organismus physiologisch von Bedeutung ist, kann eine mögliche Funktion der CpG-Insel in der klonierten Sequenz plausibel erklärt werden.

Von Marilyn Kozak wurde die Umgebung des Startkodons auf die für die Translation wichtigen Nukleotide hin untersucht (Kozak 1989; Kozak 1997). Sie fand die in Abbildung 16 (Seite 46) dargestellten Nukleotide, wobei dem Adenin an Position -3 und dem Guanin an Position +4 die größte Bedeutung zukommt, da der Tausch in ein anderes Nukleotid den größten negativen Einfluss auf die Effizienz der Translation zur Folge hat. Von insgesamt zehn Basen der benachbarten Nukleotide des GANF-Startkodons sind acht mit der Kozak-Sequenz identisch, einschließlich der wesentlichen, oben genannten. Somit handelt es sich bei dem ATG mit großer Wahrscheinlichkeit um das funktionelle ATG, was auch durch den Vergleich der Homologien mit den anderen Mitgliedern der ANF-Homöobox-Genfamilie bestätigt wird (siehe Abbildung 17, Seite 47 ff.).

Diese Überlegungen waren für die Klonierung ausschlaggebend, da direkt an dieses ATG die verschiedenen Promotorbereiche kloniert wurde (siehe dazu 3.6 (Seite 32 ff.) und Abbildung 18, Seite 50). 


\subsection{Die Untersuchung der Reporterkonstrukte}

\subsubsection{Untersuchung der Reporterkonstrukte im Huhn mittels Elektroporation}

\subsubsection{Anwendungsbereich der neu entwickelten Variante der Elektroporation}

Die neu entwickelte Variante der Elektroporation stellt keine Alternative zur In-ovo-Elektroporation dar, sondern ist als Erweiterung des Anwendungsbereiches der Elektroporation zu verstehen. Wegen der zum Neuralrohr parallel ausgerichteten Elektroden ist letztere nach wie vor die Methode der Wahl für Elektroporationen in das Neuralrohr (ab HH10). Des Weiteren ist die In-ovo-Elektroporation der ec-Elektroporation dann vorzuziehen, wenn die Versuchsdurchführung eine sehr lange Inkubation erfordert (ca. HH20, z.B.: Versuche im Rahmen der Extremitätenentwicklung). Sowohl der begrenzte Raum in der Kultur-Petrischale als auch die plane Inkubationsfläche sind hierbei die limitierenden Faktoren.

In Verbindung mit der Schnelligkeit der Erstellung und Handhabung der ec-Kultur (siehe 3.9.1) ermöglicht dagegen die neu entwickelte Variante der Elektroporation die Erzeugung transgener Zellen in jungen Hühnerembryonen des Stadiums HH4-HH6 (siehe Abbildung 19, Seite 51) sowie Embryonen um das Stadium HH10 (unter Berücksichtigung einer etwas höheren Voltzahl (12 V), siehe 3.9.2; siehe Abbildung 13, Seite 41) mit einer hohen Effizienz. Dies kann dazu dienen, sowohl Reporterkonstrukte auf ihre Funktion hin zu überprüfen (wie im Rahmen dieser Arbeit geschehen) als auch im Embryo mittels CMV-Vektoren Gene überzuexprimieren. In jedem Fall dient GFP (CMV-GFP) als Kontrolle für die Effektivität der Elektroporation, deren Dokumentation vor der weiteren Manipulation des Embryos (WMISH, X-gal-Färbung) erfolgen muss. Neben der Kontrolle durch GFP bietet sich im Rahmen der Promotoruntersuchung des Weiteren eine WMISH als Kontrolle an, welche aber im Rahmen dieser Arbeit noch nicht verwendet wurde.Eine gegenseitige Beeinflussung der benutzten Vektoren ist denkbar, wurde aber während dieser Arbeit nicht beobachtet. Gegenüber der In-ovo-Kultur besteht nicht die Gefahr, dass Embryonen während der Inkubation austrocknen. Ebenso ist das Wachstum jederzeit leicht durch den schnellen Zugriff auf die Kultur-Petrischalen zu überprüfen und gegebenenfalls abzustoppen.

Mit der neuen Variante der Elektroporation können vorzugsweise Zellen des Ektoderms, bei älteren Stadien auch Zellen des Mesoderms elektroporiert werden. Durch das Auswechseln der Polung und eine entsprechend andere DNA-Applikation ist aber auch eine Elektroporation des Endoderms denkbar. Die neu entwickelte Variante verbessert nicht nur die von Endo et al. (2002) beschriebene Methode dadurch, dass sie aufgrund der ec-Kulturtechnik (Chapman et al. 2001) leichter und zügiger durchzuführen ist, sondern erweitert außerdem ihren Anwendungsbereich auf Embryonen um das Stadium HH10. 


\subsubsection{Der konservierte Bereich und die Untersuchung der Reporterkonstrukte RK2 und RK4 legen die Begrenzung der Promotorregion von GANF auf ca. 600 bp nahe}

Die Elektroporationen der Reporterkonstrukte RK2 und RK4 zeigen, dass sowohl 9000 bp upstream als auch 1800 bp upstream ausreichend und notwendig für die Expression im anterioren Teil/im prospektiven Prosenzephalon des Embryos sind. Noch nicht dokumentierte Ergebnisse der Elektroporation von RK5 zeigen, dass auch 1000 bp (RK5) ausreichen. Diese Ergebnisse sowie auch die Konservierung der ersten 600 Basen direkt vor dem Startkodon lassen den Schluss zu, dass der Promotor/Enhancerbereich von GANF direkt vor der kodierenden Region des Genes liegt. Sie bestätigen damit die von Eroshkin et al. gefundenen Daten, die die Notwendigkeit dieser Region für die Kontrolle der Transkription belegen (Eroshkin et al. 2002). Eroshkin et al. untersuchten 5'-Elemente des XANF- Promotors in Xenopus laevis Embryonen durch Injektion von an Luciferase gekoppelten Promotorbereichen.

Im Rahmen der vorliegenden Arbeit konnte zum ersten Mal die Promotoraktivität dieser Region über den gezeigten quantitativen Aspekt hinaus im lebenden Embryo visualisiert werden. Darüber hinaus wurde in-vivo gezeigt, dass die Promotoraktivität innerhalb der ANF-Genfamilie - mit Ausnahme der Maus als Vertreter der Säugetiere - konserviert ist. Schließlich sind mögliche direkte Bindungspartner identifiziert worden, deren Interaktion mit GANF Gegenstand der weiteren In-vivo-Untersuchungen unter Verwendung der neu entwickelten Elektroporation sein werden (siehe 5.3).

\subsubsection{Die Injektionen der Reporterkonstrukte RK2, RK3 und RK6 in den Zebrafisch belegen in-vivo die Konservierung der Promotorregion der ANF-Homöobox-Genfamilie}

Wie in 4.4.2 des Ergebnisteiles (Seite 52) beschrieben wurde, kann die Injektion von DNA in Zebrafischembryonen aufgrund unterschiedlicher Faktoren in verschiedener Ausprägung zu einer fehlerhaften Entwicklung führen. Mit Ausnahme von nur einem Versuchsdurchgang (Reporterkonstrukt RK2) wird dies durch die hohen Prozentsätze der nicht auswertbaren Embryonen belegt (siehe Tabelle 14, Seite 53). Unter Berücksichtigung dieser Umstände ist das erzielte Ergebnis für das Reporterkonstrukt RK2 hervorragend und eindeutig. Im Gegensatz dazu spiegeln die Ergebnisse der übrigen Reporterkonstrukte den Verlauf eines normalen, durchschnittlichen Versuches wider.

Die Eingrenzung der GANF-Promotorregion auf ca. 600 bp wird im Rahmen der Injektionen in den Zebrafisch eindeutig bestätigt. Das Reporterkonstrukt RK2 zeigte eine eindeutige Färbung des prospektiven Prosenzephalons. Zwischen der anterior liegenden X-gal-Färbung und Krox20 war bei allen Embryonen ein Abstand zu beobachten. Reporterkonstrukt RK2 ist also notwendig und ausreichend für eine sehr spezifische Expression im anterioren ZNS des Zebrafisches. Bei keinem Embryo färbten sich ausschließlich posterior liegende Gebiete. Im Vergleich zu der durchgeführten Kontrolle (CMV-lacZ) war insofern ein klarer Unterschied zu erkennen (siehe Abbildung 20, Seite 54), als große und unter- 
schiedliche Gebiete der Embryonen blau angefärbt waren. Die Aktivierung innerhalb der ANF-Genfamilie bei Huhn und Fisch ist somit konserviert.

Im Rahmen der Untersuchung der Reporterkonstrukte im Zebrafisch wurde auch das Reporterkonstrukt RK6 (Abbildung 18, Seite 50) untersucht. Wenngleich die Lokalisation mit der übereinstimmt, die bei Reporterkonstrukt RK2 beobachtet wurde, scheint die Intensität der X-gal-Färbung reduziert zu sein (siehe Abbildung 20 (B), Seite 54). Bei gleicher Molarität (siehe 3.4.11, Seite 27) kann eine Bedeutung der fehlenden konservierten Region in Bezug auf die Transkriptionseffizienz vermutet werden. Abbildung 22 (Seite 55) zeigt diesen Bereich (5'-wärts von der NsiI-Schnittstelle liegender konservierter Teil). Für die weitere Analyse und Überprüfung dieser Beobachtung ist es von großem Interesse, ob eine gezielte Mutation der Otx2-Bindungsstelle, die in diesem Bereich liegt, zusammen mit der zweiten Bindungsstelle, die weiter 3'-wärts liegt (siehe Abbildungen 22 und 23, Seite 55 bzw. 56), eine Reduktion der Intensität der X-gal-Färbung hervorrufen kann.

Durch drei Überlegungen kann es erklärt werden, dass Zellen aus der endogenen Domäne herausfallen. Erstens könnte, wie es bei der Maus bekannt ist, eine Integration in eine Stelle der genomischen DNA erfolgt sein, die dazu führt, dass die $\beta$-Galactosidase unter der Kontrolle eines anderen starken Promotors steht. Zweitens besteht die Beobachtung, dass tote Zellen zu nicht physiologischer GFP-Expression beim Zebrafisch führen (persönliche Mitteilung von Dr. Marion Köpbrunner), so dass dies evtl. auch auf die $\beta$-Galactosidaseexpression/X-gal-Färbung zutrifft. Drittens können diese Zellen auf eine physiologische Expression der untersuchten DNA zurückzuführen sein. Unter Berücksichtigung der im Huhn durchgeführten Kontrolle - keine beobachtete X-gal-Färbung am posterioren Ende des Embryos (siehe 4.4.1, Seite 52 oben) - ist die zuletzt genannte alternative Erklärung äußerst unwahrscheinlich.

\subsubsection{Reporterkonstrukte RK2 und RK4 zeigen keine Färbung in der Maus}

Bei der X-gal-Färbung zeigte sich bei der Untersuchung von beiden Reporterkonstrukten RK2 und RK4 bei keinem Embryo eine positive blaue X-gal-Färbung. Gleichzeitig wurde mittels einer im Labor etablierten lacZ-Kontroll-PCR für das Reporterkonstrukt RK2 gezeigt, dass zu einem hohen Prozentsatz die Injektionen erfolgreich verlaufen waren. Die sehr hohe Effizienz der transgenen Embryonen ist dadurch zu erklären, dass es sich bei den untersuchten Embryonen um sehr junge Embyonen der Stadien e 7.5 bis e9.5 handelte und nicht um ältere Embryonen. Ein Fehler bei der Färbung ist aufgrund von positiven Färbungen im Rahmen der anderen Versuche auszuschließen. Das Resultat der lacZpositiven Embryonen ist nach Abwägung dieser Aspekte realistisch hoch. Insofern funktioniert das Reporterkonstrukt RK2 in der Maus nicht.

Das Ergebnis lässt den Schluss zu, dass das RK2 nicht die ausreichenden Bindungsstellen besitzt, um die Expression in der Maus zu steuern. Dieses Ergebnis korrespondiert mit den gefundenen Unterschieden zwischen GANF bzw. DANF und Hesx1, die in Tabelle 15 (Seite 64) zusammengefasst sind 
(Knoetgen et al. 1999a). Die gefundene Differenz ist somit ein weiterer Hinweis für einen unterschiedlichen Ablauf der Induktion von anteriorem neuralen Gewebe bei den Säugetieren bzw. Huhn und Fisch.

\begin{tabular}{l|c|c|c}
\hline & Zebrafisch & Huhn & $\begin{array}{c}\text { Säugetier (Maus, } \\
\text { Kaninchen) }\end{array}$ \\
\hline ANF-Expression vor Beginn der Gastrulation & - & - & + \\
\hline ANF-Induktion durch primitives Endoderm & $\begin{array}{c}\text { (noch nicht durch- } \\
\text { geführtes Experiment) }\end{array}$ & - & + \\
\hline Aktivität des Huhn-ANF-Promotors & + & + & - \\
\hline
\end{tabular}

Tabelle 15: Zusammenstellung der Unterschiede und Gemeinsamkeiten innerhalb der ANF-HomöoboxGenfamilie.

\subsection{Interaktionspartner mit dem GANF-Promotor: Otx2, GANF und Pax6}

\subsubsection{Das Homöobox-Gen Otx2 als für die Expression von GANF notwendiger Aktivator?}

Otx2 ist Mitglied einer stark konservierten Homöobox-Transkriptionsfaktorfamilie, die an der frühen Entwicklung des Gehirns beteiligt ist. Otx2 ist in allen dorsalen und fast allen ventralen Teilen des Telenzephalons, Mesenzephalons und Dienzephalons exprimiert (Simeone et al. 1992). Homozygote Verlustmutanten zeigen eine fehlende Ausbildung aller Strukturen rostral von Rhombomer 3 (Matsuo et al. 1995). Otx2 ist involviert in die AVE-Migration, die Führung von axonalem Wachstum, die Morphogenese des Gehirns und die Schaffung neuraler Identität (Boncinelli und Morgan 2001).

Mittlerweile sind eine Reihe von Zielgenen von Otx2 identifiziert worden. Diese gehören einer der folgenden Molekülklassen an: Aktin/Myosin-Bindungsproteine, extrazelluläre Adhäsionsmoleküle, Proteasen und deren Inhibitoren, RNA-Bindungsproteine, Transkriptionsfaktoren und sekretierte Proteine. Für die Funktionsweise von Otx2 sind sowohl eine direkte Beeinflussung dieser Zielgene als auch eine indirekte Beeinflussung dieser Gene durch zwischengeschaltete, weitere Transkriptionsfaktoren denkbar (Boncinelli und Morgan 2001). Als ein solches Zielgen ist der Transkiptionsfaktor GANF ein guter Kandidat. Im murinen Embryo im Stadium e8.5 ist gezeigt worden, dass Otx2 für die Hesx1-Expression in den Zellen des neuralen Ektoderms autonom notwendig ist (Rhinn et al. 1999). Somit sind die gefundenen und untersuchten Otx2-Bindungsstellen ein wichtiger Hinweis auf eine mögliche direkte 
Bindung von Otx2 an den GANF-Promotor. Die Expressionsdomäne von GANF liegt in der von Otx2. Damit ist eine alleinige Aktivierung von GANF durch Otx2 unwahrscheinlich. Allerdings sprechen diese Beobachtungen dafür, dass die GANF-Transkription von Otx2 abhängig ist. Ein Nichtbinden von Otx2 an der Promotorsequenz von GANF im Sinne einer indirekten Beeinflussung durch weitere zwischengeschaltete Transkriptionsfaktoren ist allerdings nicht auszuschließen.

\subsubsection{Kein Hinweis auf eine autoregulative Kontrolle von GANF}

In der Untersuchung der möglichen Bindungssequenz von GANF wurden in einem mutierten Oligonukleotid alle TAAT-Motive verändert. Trotzdem zeigte sich eine Bindung, die nicht von der des nicht mutierten Oligonukleotids zu unterscheiden war. Auch wenn weitere konservierte Nukleotide, die aufgrund der Konservierung offensichtlich wichtig sind, in dem mutierten Oligonukleotid erhalten blieben, ist die angenommene Spezifität nicht mehr gegeben gewesen. Da keine weiteren vergleichbaren Stellen gefunden worden sind, ist eine direkte autoregulative Kontrolle von GANF daher eher unwahrscheinlich.

\subsubsection{Das Homöobox-Gen Pax6 als möglicher Repressor von GANF?}

Pax6 gehört in die Paired-Homöobox-Genfamilie und ist das homologe Gegenstück des eyeless-Genes von Drosophila melanogaster bei Wirbeltieren. Die Bindung von Pax6 an das mutierte Oligonukleotid ist signifikant reduziert (siehe Abbildung 24, Seite 57), wenngleich kein Ergebnis erzielt wurde, bei dem die Bindung völlig aufgehoben worden ist. Neben neun veränderten Nukleotiden sind allerdings 15 weitere Nukleotide erhalten worden, denen entweder durch die Konsensussequenz (in Abbildung 24 unterstrichen, Seite 57) oder durch die Konservierung innerhalb der verglichenen Promotoren (in Abbildung 24 dick gedruckt und grau unterlegt) eine für die Protein-DNA-Bindung wichtige Bedeutung zukommt. Entsprechend der weiteren Kontrollen (Antikörper und Retikulozytenextrakt) ist die Bindung eindeutig auf das Pax6-Protein zurückzuführen.

Wie man in der Abbildung 7 (Seite 10) der Einleitung sehen kann, erstreckt sich die Expression von Pax6 über die ganze Neuralplatte (das prospektive Telenzephalon), wobei die Expression das ventrale mittige Vorderhirn ausspart - die Region, in der GANF exprimiert ist. Aus dieser Überlegung leitet sich die Hypothese ab, dass Pax6 ein Repressor von GANF sein könnte. Bei der weiteren Untersuchung dieser Bindungsstelle stehen somit folgende Schritte an: In-vivo-Untersuchung (Elektroporation, Injektion) eines an der Bindungsstelle mutierten Oligonukleotids und Doppelwholemount von GANF und Pax6 sowie die Elektroporation eines CMV-Pax6-Konstruktes im Hinblick auf eine Veränderung der endogenen GANF-Domäne. 


\subsection{Diskussion des Ergebnisses der Sequenzierung der Patienten-DNA}

Bei dem untersuchten Patienten wurde weder eine bekannte noch eine neue Mutation im HESX1 gefunden. Dafür gibt es wenigstens zwei alternative Erklärungsmöglichkeiten: Bei dem Vorliegen einer sehr genauen Übereinstimmung der Symptomatik mit der beschriebenen Trias der SOD ist eine Beteiligung von HESX1 nicht unwahrscheinlich. Ein Funktionsverlust in einem für die Transkription unbedingt notwendigen Enhancer kommt somit als erste Erklärung in Betracht. Wie in der Einleitung beschrieben worden ist, ist an der Morphogenese komplexer Strukturen, hier u. a. des Corpus callosum, eine ganze Reihe Gene beteiligt, so dass ein Funktionsverlust in einem dieser Gene für den oben beschriebenen Umstand als zweite Erklärungsmöglichkeit dienen kann (genetische Heterogenität; Gilbert 2000).

Im Rahmen dieser Arbeit ist damit begonnen worden, Patienten der Universitätsklinik Göttingen, die an der SOD erkrankt sind, auf eine Mutation im HESX1 zu untersuchen. Diese Untersuchungen werden bei weiteren Patienten fortgesetzt. 


\section{Zusammenfassung}

Die Mitglieder der ANF-Homöobox-Genfamilie gehören zu den frühesten Markern für das anteriore zentrale Nervensystem im Wirbeltierembryo. Bei einem Verlust ihrer Genaktivität in der Maus fallen morphologische Veränderungen im Bereich der Mittellinie des Gehirns auf (Septum pellucidum, kommissurale Axone und Hypophyse). Die vorliegende Arbeit beschäftigt sich mit Aspekten der Transkription der ANF-Homöobox-Gene. Im Mittelpunkt steht die Untersuchung des Promotors des orthologen Genes des Huhnes, GANF. Die GANF-Promotor-Region wurde im Rahmen dieser Arbeit auf 600 bp eingegrenzt, die ausreichend sind, um die Expression im Hühnerembryo zu kontrollieren. Diese Region ist konserviert in Maus, Mensch, Huhn und Frosch. Es konnte ferner gezeigt werden, dass dieser Bereich ebenfalls im Zebrafisch für die Steuerung der Expression ausreicht, nicht aber im Mausembryo. Dies korrespondiert mit bereits gefundenen Unterschieden zwischen GANF bzw. DANF auf der einen Seite und Hesx1 auf der anderen in Bezug auf die zusätzliche Expressionsdomäne von Hesx1 im anterioren viszeralen Endoderm (AVE) bzw. unterschiedliche Mechanismen der Induktion anteriorer neuraler Strukturen im Huhn bzw. Zebrafisch und den Säugetieren.

Mit dem Ziel, Interaktionspartner des GANF-Promotors zu finden, wurden Bindungsstellen aus dem gefundenen Promotorbereich näher untersucht. Für eine Bindestelle von Pax6 und zwei Bindestellen von Otx2 konnten sowohl die Bindungen als auch eine signifikant reduzierte Bindung an ein entsprechend mutiertes Oligonukleotid gezeigt werden. Für eine potenzielle Bindungssequenz von GANF konnte diese Spezifität nicht gezeigt werden.

Um die Reporterkonstrukte gemäß der frühen Expression von GANF auch in sehr jungen Embryonen zu untersuchen, wurde eine neue Elektroporationsvariante entwickelt und im Labor etabliert, die es im Gegensatz zur In-ovo-Elektroporation von Hühnerembryonen erlaubt, sehr junge Embryonen (HH4 HH 14) mit hoher Effizienz zu elektroporieren.

Im Rahmen dieser Arbeit wurde eine Untersuchung von an Septo-optischer Dysplasie (SOD) erkrankten Patienten der Universitätsklinik Göttingen auf Mutationen im menschlichen GANF-Ortholog HESX1 begonnnen. HESX1 ist an dem Zustandekommen der SOD beteiligt. Bei der Sequenzierung der DNA von bis jetzt einem Patienten wurden weder eine bekannte noch eine neue Mutation gefunden. Als Grund hierfür kommt eine mögliche genetische Heterogenität oder ein Funktionsverlust in einem noch nicht bekannten Enhancer in Frage. 


\section{Abkürzungen und Akronyme}

A, Adenin (Nukleotid)

A, Alanin (Aminosäure)

Abb., Abbildung

ACTH, adrenokortikotropes Hormon

ADH, anitdiuretisches Hormon

ANF, Homöobox-Genfamilie (engl.: anterior neural fold)

ANR, anteriorer neuraler Kamm (engl.: anterior neural ridge)

ATG, Startkodon

ATP, Adenosintriphosphat

AVE, anteriores viszerales Endoderm

bHLH, Akronym einer Transkriptionsfaktorfamilie (engl.: basic Helix Loop Helix (Domäne))

bHLHzip, Akronym einer Transkriptionsfaktorfamilie (engl.: basic Helix Loop Helix zip (Domäne))

BMP, Signalmolekülfamilie (engl.: bone morphogenic protein)

bp, Basenpaare

BSA, bovines Serum-Albumin

bzip, Akronym einer Transkriptionsfaktorfamilie (engl.: basic zip (Domäne))

C, Cystein (Aminosäure)

C, Cytosin (Nukleotid)

cDNA, komplementäre DNA

Ci, Curie

CMV, Zytomegalievirus (ubiquitär exprimierbarer viraler Promotor)

CpG, Cytosin-Phosphat-Guanin

cpm, Zerfälle pro Minute (engl.: counts per minute)

CT, Computer-Tomographie

d, Tag

dCTP, Desoxycytosintriphosphat

DNA, Desoxyribonukleinsäure

DMSO, Dimethyl-Sulfoxid

dNTP, Desoxynukleotidtrophosphat

DTT, Dithiothreitol

e, Stadien der Entwicklung des Mausembryos (embryonic day)

EDTA, Ethylendiamintetraazetat

EGFP, verstärkteVariante des grün fluoreszierenden Proteins

EMSA, elektrophoretischer Mobilitätstest (engl.: elektrophoretic mobility shift assay)

FCS, fötales Kälber-Serum 
FGF, Signalmolekülfamilie (engl.: fibroblast growth factor)

FSH, Follikel stimulierendes Hormon

G, Guanin

GANF, Ortholog des Huhns der ANF Homöobox-Genfamilie (lat.: Gallus gallus)

GFP, grün fluoreszierendes Protein

GH, Wachstumshormon (engl.: growth hormone)

GnRH, Gonadotropin Releasing Hormon

h, Stunde(n)

H, Histidin

HEPES, N-(2-Hydroxyethyl)Piperazin-N'-(2-Ethansulfonsäure)

HESX1/Hesx1, menschliches bzw. murines Ortholog der ANF-Homöobox-Genfamilie

HH, Stadien der Entwicklung des Hühnerembryos (Hamburger und Hamilton 1951)

HPLC, High Performance Liquid Chromatography

kb, Kilobasen

$\mathbf{k V}$, Kilovolt

L, Leucin

lacZ, $\beta$-Galactosidase

LB, Bakterienmedium (Luria Broth)

LH, Luteinisierendes Hormon

mA, elektrische Ladung in $10^{-3}$ Ampere

MAB(T), Inkubationspuffer für WMISH

MCS, Multiple Klonierungsstelle in Vektoren (engl.: multiple cloning site)

$\boldsymbol{\mu} \mathbf{F}$, Elektrische Kapazität in $10^{-6}$ Faraday

min, Minute(n)

mRNA, Boten-Ribonukleinsäure

$\mathbf{N}$, Asparagin

NBT/BCIP, Nitroblautetrazolium mit 5-Brom-4-chlor-3-indolylphosphat

NMR, Nuklear-Magnet-Resonanz-Tomographie

NTMT, Inkubationspuffer für WMISH

OD, optische Dichte

PBS, Phosphat-gepufferte Natriumchloridlösung

PBT, Phosphat-gepufferte Natriumchloridlösung mit Tween

PC, Pannett-Compton Salzlösung

PCR, Polymerasekettenreaktion (engl.: polymerase chain reaction) 
PFA, 4 \%iges Paraformaldehyd in PBS

PNK, Polynukleotidkinase

Q, Glutamin

R, Arginin

RNA, Ribonukleinsäure

rpm, Umdrehungen pro Minute (engl.: rotations per minute)

Rpx, Synonym für Hesx 1

RT, Raumtemperatur

RT-PCR, Reverse-Transkriptase-PCR

S, Serin

SDS, Natriumdodecylsulfat

SDS-PAGE, SDS-Polyacrylamidgelelektrophorese

SHH, Signalmolekül sonic hedgehog

SOC, Bakterienmedium

SOD, Septo-optische Dysplasie

sec, $\operatorname{Sekunde}(\mathrm{n})$

SSC, $\mathrm{NaCl} / \mathrm{Na}$-Citrat-Puffer

SSW, Schwangerschaftswoche

T, Threonin (Aminosäure)

T, Thymin (Nukleotid)

TBE, Tris-Borat-EDTA-Puffer

TBP, TATA-bindendes Protein

TEMED, Tetramethylethylendiamin

Tris, Tris-(hydroxymethyl)-aminomethan

TSH, Thyroidea stimulierendes Hormon

U, Einheiten (engl.: units)

UV, Ultraviolett

$\mathbf{V}$, Volt

WMISH, Whole-mount-in-situ-Hybridisierung

Wnt, Signalmolekülfamilie (Ihr Name basiert auf dem Segmentpolaritätsgen von Drosophila melanogaster 'wingless' und dem entsprechendenWirbeltierortholog 'int-1'.)

X-gal, 5-Bromo-4-Chloro-3-Indolyl- $\beta$-D-Glucuronid

ZNS, zentrales Nervensystem 


\section{Literaturverzeichnis}

Andersen B, Rosenfeld MG (2001): POU domain factors in the neuroendocrine system: lessons from developmental biology provide insights into human disease. Endocr Rev 22(1),2-35

Andreazzoli M, Gestri G, Angeloni D, Menna E, Barsacchi G (1999): Role of Xrx1 in Xenopus eye and anterior brain development. Development - Supplement 126(11),2451-60

Andrejewski N. Molekulargenetische Prozesse in der Augenentwicklung. Georg August Universität, Göttingen 2002

Ausubel FM, Brent R, Kingston RE, Moore DD, Seidman JG, Smith JA, Struhl K. Current Protocols in Molecular Biology. 1 ed. Whiley Interscience, Boston 1987

Baas D, Bumsted KM, Martinez JA, Vaccarino FM, Wikler KC, Barnstable CJ (2000): The subcellular localization of Otx2 is cell-type specific and developmentally regulated in the mouse retina. Proc Natl Acad Sci U S A $\underline{99}(5), 2907-11$

Bachiller D, Klingensmith J, Kemp C, Belo JA, Anderson RM, May SR, McMahon JA, McMahon AP, Harland RM, Rossant J et al. (2000): The organizer factors Chordin and Noggin are required for mouse forebrain development. Nature $\underline{403}(6770), 658-61$

Bally-Cuif L, Gulisano M, Broccoli V, Boncinelli E (1995): c-otx2 is expressed in two different phases of gastrulation and is sensitive to retinoic acid treatment in chick embryo. Mech Dev 49 (1-2), 49-63

Bateson W. Materials for the study of variation. London Macmillan and Co., London 1894

Beddington RS (1994): Induction of a second neural axis by the mouse node. Development - Supplement $\underline{120}(3), 613-20$

Blethen SL, Weldon VV (1985): Hypopituitarsm and Septooptic "Dysplasia" in First Cousins. Am J Med Genet 21, 123-9

Boettger T, Knoetgen H, Wittler L, Kessel M (2001): The avian organizer. Int J Dev Biol 4도 , 281-7

Boncinelli E, Morgan R (2001): Downstream of Otx2, or how to get a head. Trends Genet 17(11),633-6

Branden C, Tooze J. Introduction to Protein Structure. 2 ed. Garland Publishing, New York 1999

Briata P, Ilengo C, Bobola N, Corte G (1999): Binding properties of the human homeodomain protein OTX2 to a DNA target sequence. FEBS Lett $\underline{445}(1), 160-4$

Brickman JM, Clements M, Tyrell R, McNay D, Woods K, Warner J, Stewart A, Beddington RS, Dattani M (2001): Molecular effects of novel mutations in Hesx1/HESX1 associated with human pituitary disorders. Development - Supplement $\underline{128}(24), 5189-99$

Casarosa S, Andreazzoli M, Simeone A, Barsacchi G (1997): Xrx1, a novel Xenopus homeobox gene 
expressed during eye and pineal gland development. Mech Dev $\underline{61}(1-2), 187-98$

Chapman SC, Collignon J, Schoenwolf GC, Lumsden A (2001): Improved method for chick wholeembryo culture using a filter paper carrier. Dev Dyn $\underline{220}(3), 284-9$

Chow RL, Altmann CR, Lang RA, Hemmati-Brivanlou A (1999): Pax6 induces ectopic eyes in a vertebrate. Development - Supplement 126(19), 4213-22

Couly G, Le Douarin NM (1988): The fate map of the cephalic neural primordium at the presomitic to the 3-somite stage in the avian embryo. Development - Supplement 103(10), 101-13

Czerny T, Busslinger M (1995): DNA-binding and transactivation properties of Pax-6:three amino acids in the paired domain are responsible for the different sequence recognition of Pax-6 and BSAP (Pax-5). Mol Cell Biol 15(5), 2858-71

Dattani MT, Robinson IC (2000): The molecular basis for developmental disorders of the pituitary gland in man. Clin Gen $\underline{57}(5), 337-46$

Dattani MT, Matinez-Barbera J-P, Thomas PQ, Brickmann JM, Gupta R, Martensson I-L, Toresson H, Fox M, Wales JKH, Hindmarsh PC et al. (1998): Mutations in the homeobox gene HESX1/Hesx1 associated with septo-optic dysplasia in human an mouse. Nat Gen $\underline{19}(2), 125-33$

Dattani MT, Martinez-Barbera JP, Thomas PQ, Brickman JM, Gupta R, Wales JK, Hindmarsh PC, Beddington RS, Robinson IC (1999): HESX1: a novel gene implicated in a familial form of septooptic dysplasia. Acta Paediatr Suppl $\underline{88}(433), 49-54$

Dawid IB, Chitnis AB (2001): Lim homeobox genes and the CNS: a close relationship. Neuron $\underline{30}(2)$, $301-3$

Emerson BM (2002): Specificity of gene regulation. Cell 109(3), 267-70

Endo Y, Osumi N, Wakamatsu Y (2002): Bimodal functions of Notch-mediated signaling are involved in neural crest formation during avian ectoderm development. Development 129(4), 863-73

Ericson J, Rashbass P, Schedl A, Brenner-Morton S, Kawakami A, van Heyningen V, Jessell TM, Briscoe J (1997): Pax6 controls progenitor cell identity and neuronal fate in response to graded Shh signaling. Cell $\underline{90}(1), 169-80$

Eroshkin F, Kazanskaya O, Martynova N, Zaraisky A (2002): Characterization of cis-regulatory elements of the homeobox gene Xanf-1. Gene $\underline{285}(1-2), 279-86$

Ferre-D'Amare AR, Prendergast GC, Ziff EB, Burley SK (1993): Recognition by Max of its cognate DNA through a dimeric b/HLH/Z domain. Nature $\underline{363}(6424), 38-45$

Foley AC, Skromme I, Stern CD (2000): Reconcling different models of forebrain induction and patterning: a dual role for the hypoblast. Development $\underline{127(17), 3839-54}$ 
Galliot B, de Vargas C, Miller D (1999): Evolution of homeobox genes: Q50 Paired-like genes founded the Paired class. Dev Genes Evol 209(3), 186-97

Gehring WJ, Affolter M, Burglin T (1994a): Homeodomain proteins. Annu Rev Biochem $\underline{63}$, 487-526

Gehring WJ, Qian YQ, Billeter M, Furukubo-Tokunaga K, Schier AF, Resendez-Perez D, Affolter M, Otting G, Wuthrich K (1994b): Homeodomain-DNA recognition. Cell $\underline{78}$ (2), 211-23

Gilbert SF. Developmental Biology. 6 ed. Sinauer Associates Inc., Sunderland 2000

Hallonet M, Hollemann T, Wehr R, Jenkins NA, Copeland NG, Pieler T, Gruss P (1998): Vax1 is a novel homeobox-containing gene expressed in the developing anterior ventral forebrain. Development - Supplement $\underline{125}(14), 2599-610$

Hallonet M, Hollemann T, Pieler T, Gruss P (1999): Vax1, a novel homeobox-containing gene, directs development of the basal forebrain and visual system. Genes Dev 13(23), 3106-14

Hamburger V, Hamilton HL (1951): A series of normal stages in the development of the chick embryo. J Morphol $\underline{88}, 49-92$

Hanahan DJ.Techniques for transformation of E. coli. In: DM Glover, editor, translator and editor DNA Cloning. IRL Press, Oxford 1985, 109-35

Harland R, Gerhart J (1997): Formation and function of Spemann's organizer. Ann Rev Cell Dev Biol $\underline{13}, 611-67$

Heisenberg CP, Brand M, Jiang YJ, Warga RM, Beuchle D, van Eeden FJ, Furutani-Seiki M, Granato M, Haffter P, Hammerschmidt M et al. (1996): Genes involved in forebrain development in the zebrafish, Danio rerio. Development $\underline{123}, 191-203$

Heisenberg CP, Houart C, Take-Uchi M, Rauch GJ, Young N, Coutinho P, Masai I, Caneparo L, Concha ML, Geisler R et al. (2001): A mutation in the Gsk3-binding domain of zebrafish Masterblind/ Axin1 leads to a fate transformation of telencephalon and eyes to diencephalon. Genes Dev $\underline{15}(11)$, $1427-34$

Hensen (1876): Beobachtungen über die Befruchtung und Entwicklung des Kaninchens und Meerschweinchens. Z Anat Entwicklungsgesch 1, 353-423

Hermesz E, Mackem S, Mahon KA (1996): Rpx: a novel anterior-restricted homeobox gene progressively activated in the prechordal palte, anterior neural plate and Rathke's pouch of the mouse embryo. Development $\underline{122}, 41-52$

Hoyt WF, Kaplan SL, Grumbach MM, Glaser JS (1970): Septo-optic dysplasia and pituitary dwarfism. Lancet $\underline{1970,1}, 893-4$

Huseman CA, Kelch RP, Hopwood NJ, Zipf WB (1978): Sexual precocity in association with septo- 
optic dysplasia and hypothalamic hypopituitarism. J Pediatr 92(5), 748-53

Itasaki N, Bel-Vialar S, Krumlauf R (1999): 'Shocking' developments in chick embryology: electroporation and in ovo gene expression. Nat Cell Biol 1 (8), 203-7

Izenberg N, Rosenblum M, Parks JS (1984): The Endocrine Spectrum of Septo-Optic Dysplasia. Clin Pediatr (Phila) $\underline{23}(11), 632-6$

Jacobsen AG, Miyamoto DM, Mai S-H (1979): Rathke's Pouch morphogenesis in the chick embryo. J Exp Zool 207, 351-66

Jong de R, van der Heijden J, Meijlink F (1993): DNA-binding specificity of the S8 homeodomain. Nucleic Acids Res 21(20), 4711-20

Jowett T, Lettice L (1994): Whole-mount in situ hybridizations on zebrafish embryos using a mixture of digoxigenin- and fluorescein-labelled probes. Trends Genet $\underline{10}(3), 73-4$

Karlstrom RO, Talbot WS, Schier AF (1999): Comparative synteny cloning of zebrafish you-too: mutations in the Hedgehog target gli2 affect ventral forebrain patterning. Genes Dev $\underline{13}(4), 388-93$

Kawakami A, Kimura-Kawakami M, Nomura T, Fujisawa H (1997): Distributions of PAX6 and PAX7 proteins suggest their involvement in both early and late phases of chick brain development. Mech Dev $\underline{66}(1-2), 119-30$

Kazanskaya OV, Severtzova EA, Anukampa Barth K, Ermakova GV, Lukyanov SA, Benyumov AO, Pannese M, Boncinelli E, Wilson SW, Zaraisky AG (1997): Anf: a novel class of vertebrate homeobox genes expressed at the anterior and of the main embryonic axis. Gene $\underline{200}, 25-34$

Kessel M, Gruss P (1991): Homeotic transformations of murine vertebrae and concomitant alteration of Hox codes induced by retinoic acid. Cell $\underline{67}(1), 89-104$

Keynes R, Krumlauf R (1994): Hox genes and regionalization of the nervous system. Annu Rev Neu$\operatorname{rosci} \underline{17}(3), 109-32$

Kiecker C, Niehrs C (2001): A morphogen gradient of Wnt/beta-catenin signalling regulates anteroposterior neural patterning in Xenopus. Development - Supplement 128(21), 4189-201

Kimmel CB, Ballard WW, Kimmel SR, Ullmann B, Schilling TF (1995): Stages of embryonic development of the zebrafish. Dev Dyn 203(3), 253-310

Kissinger CR, Liu BS, Martin-Blanco E, Kornberg TB, Pabo CO (1990): Crystal structure of an engrailed homeodomain-DNA complex at 2.8 A resolution: a framework for understanding homeodomainDNA interactions. Cell $\underline{63}(3), 579-90$

Knoetgen H. Ektodermale Differenzierung im Wirbeltierembryo: Die Induktion der Vorderhirnanlage und der Neuralleiste. Universität Hannover, Hannover 2000 
Knoetgen H, Teichmann U, Kessel M (1999a): Head-organizing activities of endodermal tissues in vertebrates. Cell Mol Biol $\underline{45}(5), 481-92$

Knoetgen H, Viebahn C, Kessel M (1999b): Head induction in the chick by primitive endoderm of mammalian, but not avian origin. Development $\underline{126}, 815-25$

Knoetgen H, Teichmann U, Wittler L, Viebahn C, Kessel M (2000): Anterior Neural Induction by Nodes from Rabbits and Mice. Dev Biol 225, 370-80

Kobayashi M, Toyama R, Takeda H, Dawid IB, Kawakami K (1998): Overexpression of the forebrainspecific homeobox gene six3 induces rostral forebrain enlargement in zebrafish. Development - Supplement $\underline{125}(15), 2973-82$

Kobayashi D, Kobayashi M, Matsumoto K, Ogura T, Nakafuku M, Shimamura K (2002): Early subdivisions in the neural plate define distinct competence for inductive signals. Development - Supplement $\underline{129}(1), 83-93$

Koolman J, Röhm K-H. Taschenatlas der Biochemie. Georg Thieme Verlag, Stuttgart, New York 1994

Kozak M (1989): Context effects and inefficient initiation at non-AUG codons in eucaryotic cell-free translation systems. Mol Cell Biol 9 (11), 5073-80

Kozak M (1997): Recognition of AUG and alternative initiator codons is augmented by G in position +4 but is not generally affected by the nucleotides in positions +5 and +6 . EMBO J $\underline{16}(9), 2482-92$

Langman J. Medizinische Embryologie. 8 ed. Georg Thieme Verlag, Stuttgart, New York 1989

Leiper AD, Stanhope R, Preece MA, Grant DB, Chessells JM (1988): Precocious or early puberty and growth failure in girls treated for acute lymphoblastic leukaemia. Horm Res $\underline{30}(2-3), 72-6$

Leussink B, Brouwer A, el Khattabi M, Poelmann RE, Gittenberger-de Groot AC, Meijlink F (1995): Expression patterns of the paired-related homeobox genes MHox/Prx1 and S8/Prx2 suggest roles in development of the heart and the forebrain. Mech Dev $\underline{52}(1), 51-64$

Lewin B. Genes VII. 7 ed. Oxford University Press Inc., New York 2000

Li S, Crenshaw EB, 3rd, Rawson EJ, Simmons DM, Swanson LW, Rosenfeld MG (1990): Dwarf locus mutants lacking three pituitary cell types result from mutations in the POU-domain gene pit-1. Nature $\underline{347}(6293), 528-33$

Loosli F, Winkler S, Wittbrodt J (1999): Six3 overexpression initiates the formation of ectopic retina. Genes Dev $\underline{13}(6), 649-54$

Lu M, Gong ZY, Shen WF, Ho AD (1991): The tcl-3 proto-oncogene altered by chromosomal translocation in T-cell leukemia codes for a homeobox protein. EMBO J 10 (10), 2905-10 
Malandrini A, Mari F, Palmeri S, Gambelli S, Berti G, Bruttini M, Bardelli AM, Williamson K, van Heyningen V, Renieri A (2001): PAX6 mutation in a family with aniridia, congenital ptosis, and mental retardation. Clin Genet $\underline{60}(2), 151-4$

Mansouri A, Goudreau G, Gruss P (1999): Pax genes and their role in organogenesis. Cancer Res $\underline{59}(7), 1707-9$

Masai I, Heisenberg CP, Barth KA, Macdonald R, Adamek S, Wilson SW (1997): floating head and masterblind regulate neuronal patterning in the roof of the forebrain. Neuron $\underline{18}(1), 43-57$

Masera N, Graut DB, Stanhope R, Preece MA (1994): Diabetes insipidus with impaired osmotic regulation in septo-optic dysplasia and agenesis of the corpus callosum. Arch Dis Child $\underline{70}, 51-3$

Matsuo I, Kuratani S, Kimura C, Takeda N, Aizawa S (1995): Mouse Otx2 functions in the formation and patterning of rostral head. Genes Dev $\underline{9}(21), 2646-58$

Meyers EN, Lewandoski M, Martin GR (1998): An Fgf8 mutant allelic series generated by Cre- and Flp-mediated recombination. Nat Genet $\underline{18}(2), 136-41$

Morsier de G (1956): Agénésie du septum lucidum avec malformation du tractus optique. La dysplasie septo-optique. Schweiz Arch Neurol Psychiatrie 77, 267-92

Mukhopadhyay M, Shtrom S, Rodriguez-Esteban C, Chen L, Tsukui T, Gomer L, Dorward DW, Glinka A, Grinberg A, Huang SP et al. (2001): Dickkopf1 is required for embryonic head induction and limb morphogenesis in the mouse. Dev Cell $\underline{1}(3), 423-34$

Mülhardt C. Der Experimentator: Molekularbiologie. 1 ed. G. Fischer, Stuttgart, Jena, Lübeck, Ulm 1999

Muramatsu T, Nakamura A, Park HM (1998): In vivo electroporation: a powerful and convenient means of nonviral gene transfer to tissues of living animals (Review). Int J Mol Med 1 (1), 55-62

Nanduri VR, Stanhope R (1999): Why is the retention of gonadotrophin secretion common in children with panhypopituitarism due to septo-optic dysplasia? Eur J Endocrinol 140(1), 48-50

Nieuwkoop PD (1997): Short historical survey of pattern formation in the endo-mesoderm and the neural anlage in the vertebrates: the role of vertical and planar inductive actions. Cell Mol Life Sci $\underline{53}$, 305-18

Nieuwkoop PD, Boterenbrood EC, Kremer A, Bloesma FFSN, Hoessels ELMJ, Meyer G, Verheyen FJ (1952): Activation and organisation of the central nervous system in amphibians. J Exp Zool 120, 1108

Nikolov DB, Burley SK (1994): 2.1 A resolution refined structure of a TATA box-binding protein (TBP). Nat Struct Biol $\underline{1}(9), 621-37$ 
Norris RA, Kern MJ (2001): Identification of domains mediating transcription activation, repression, and inhibition in the paired-related homeobox protein, Prx2 (S8). DNA Cell Biol 20(2), 89-99

Oxtoby E, Jowett T (1993): Cloning of the zebrafish krox-20 gene (krx-20) and its expression during hindbrain development. Nucleic Acids Res 21 (5), 1087-95

Park HL, Bai C, Platt KA, Matise MP, Beeghly A, Hui CC, Nakashima M, Joyner AL (2000): Mouse Gli1 mutants are viable but have defects in SHH signaling in combination with a Gli2 mutation.

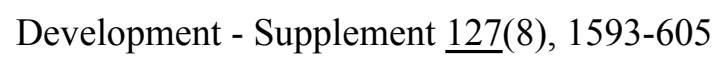

Passarge E. Humangenetik. 1 ed. Georg Thieme Verlag, Stuttgart, New York 1994

Perea-Gomez A, Shawlot W, Sasaki H, Behringer RR, Ang S (1999): HNF3beta and Lim1 interact in the visceral endoderm to regulate primitive streak formation and anterior-posterior polarity in the mouse embryo. Development - Supplement 126(20), 4499-511

Pikalow AS, Flynn ME, Searls RL (1994): Development of the cranial flexure and Rathke's Pouch in the chick embryo. Anat Rec $\underline{238}, 407-14$

Praz V, Perier R, Bonnard C, Bucher P (2002): The Eukaryotic Promoter Database, EPD: new entry types and links to gene expression data. Nucleic Acids Res 30(1), 322-4

Raleigh E, Wilson G (1986): Escherichia coli K-12 restricts DNA containing 5-methylcytosine. Proc Natl Acad Sci U S A $\underline{83}(23), 9070-4$

Reeves DL (1941): Congenital absence of the septum pellucidum. Bull Johns Hopkins Hosp $\underline{69}$, 61-71

Regulski M, Harding K, Kostriken R, Karch F, Levine M, McGinnis W (1985): Homeo box genes of the Antennapedia and bithorax complexes of Drosophila. Cell $\underline{43}(1), 71-80$

Rhinn M, Dierich A, Le Meur M, Ang S (1999): Cell autonomous and non-cell autonomous functions of Otx2 in patterning the rostral brain. Development - Supplement 126(19), 4295-304

Roessmann U (1989): Septo-optic Dysplasia (SOD) or DeMorsier Syndrome. J Clin Neuroophthal $\underline{9}(3), 156-9$

Romanoff AL: The Avian Embryo. The Macmillan Company; New York 1960

Saiki RK, Gelfand DH, Stoffel S, Scharf SJ, Higuchi R, Horn GT, Mullis KB, Erlich HA (1988): Primer-directed enzymatic amplification of DNA with a thermostable DNA polymerase. Science $\underline{239}(4839), 487-91$

Samakhvalov IM, Semanova NA, Nikolaev AI, Belyavskii AV (1993): Genomic structure of the homeobox-containing gene XANF1. Biochemistry (Mosc) 334(4), 552-25

Sambrook J, Russell DW. Molecular Cloning. 3 ed. Cold Spring Harbor Laboratory Press, New York 
2001.

Schoenwolf GC, Watterson RL: Laboratory Studies of Chick, Pig, and Frog Embryos. 6 ed. Macmillan Publishing Company, New York 1979

Schott JJ, Benson DW, Basson CT, Pease W, Silberbach GM, Moak JP, Maron BJ, Seidman CE, Seidman JG (1998): Congenital heart disease caused by mutations in the transcription factor NKX2-5. Science $\underline{281}(5373), 108-11$

Sheng HZ, Zhadanov AB, Mosinger B, Jr., Fujii T, Bertuzzi S, Grinberg A, Lee EJ, Huang SP, Mahon KA, Westphal H (1996): Specification of pituitary cell lineages by the LIM homeobox gene Lhx3. Science $\underline{272}(5264), 1004-7$

Shih J, Fraser SE (1996): Characterizing the zebrafish organizer: microsurgical analysis at the earlyshield stage. Development - Supplement 122(4), 1313-22

Shimamura K, Rubenstein JLR (1997): Inductive interactions direct early regionalization of the mouse forebrain. Development 124(14), 2709-18

Silbernagl S, Despopolus A. dtv-Atlas der Physiologie. 2 ed. Georg Thieme Verlag, Stuttgart, New York 1991

Simeone A, Acampora D, Gulisano M, Stornaiuolo A, Boncinelli E (1992): Nested expression domains of four homeobox genes in developing rostral brain. Nature $\underline{358}(6388), 687-90$

Smith ST, Jaynes JB (1996): A conserved region of engrailed, shared among all en-, gsc-, Nk1-, Nk2and msh-class homeoproteins, mediates active transcriptional repression in vivo. Development $\underline{122}(10), 3141-50$

Sornson MW, Wu W, Dasen JS, Flynn SE, Norman DJ, O'Connell SM, Gukovsky I, Carriere C, Ryan AK, Miller AP et al. (1996): Pituitary lineage determination by the Prophet of Pit-1 homeodomain factor defective in Ames dwarfism. Nature 384(6607), 327-33

Spemann H, Mangold H (1924): Über die Induktion von Embryoanlagen durch Implantation artfremder Organisatoren. Roux Archiv Entwicklungsmechanik 100, 599-638

Steitz TA (1990): Structural studies of protein-nucleic acid interaction: the sources of sequence-specific binding. Q Rev Biophys 23(3), 205-80

Thomas PQ, Johnson BV, Rathjen J, Rathjen PD (1995): Sequence, Genomic Organization, and Expression of the Novel Homeobox Gene Hesx1. J Biol Chem 270(8), 3869-75

Thomas PQ, Dattani MT, Brickman JM, McNay D, Warne G, Zacharin M, Cameron F, Hurst J, Woods K, Dunger D et al. (2001): Heterozygous HESX1 mutations associated with isolated congential pituitary hypoplasia and septo-optic dysplasia. Hum Mol Genet 10(1), 39-45 
Waddington $\mathrm{CH}$ (1932): Experiments on the development of chick and duck embryos, cultivated in vitro. Philos Trans R Soc London B Biol Sci $\underline{221}$, 179-230

Wales JKH, Quarrell OWJ (1996): Evidence for possible Mendelian inheritance of septo-optic dysplasia. Acta Paediatr $\underline{85}, 391-2$

White RJ. Gene Transcription. Blackwell Science Ltd., London, Edinburgh 2001

Wilson SW, Rubenstein JL (2000): Induction and dorsoventral patterning of the telencephalon. Neuron $\underline{28}(3), 641-51$

Wingender E, Chen X, Hehl R, Karas H, Liebich I, Matys V, Meinhardt T, Pruss M, Reuter I, Schacherer F (2000): TRANSFAC: an integrated system for gene expression regulation. Nucleic Acids Res $\underline{28}(1), 316-9$

Withington S, Beddington R, Cooke J (2001): Foregut endoderm is required at head process stages for anteriormost neural pattering in chick. Development $\underline{128}, 309-20$

Wolpert L, Beddington R, Brockers J, Jessell T, Lawrance P, Meyerowitz E. Entwicklungsbiologie. Spektrum Akademischer Verlag GmbH, Heidelberg, Berlin 1999

Wood W (1966): Host specificity of DNA produced by Escherichia coli. bacterial mutations affecting the restriction and modification of DNA. J Mol Biol 16 1 (1), 118-33

Zaias B, Becker D (1978): Septo-optic dysplasia: developmental or acquired abnormality? A case report. Trans Am Neurol Assoc $\underline{103}$, 273-7 


\section{Danksagungen}

Ich danke Herrn Professor Dr. Michael K e s s e 1, Leiter der Arbeitsgruppe Entwicklungsbiologie, Max-Planck-Institut für biophysikalische Chemie, Göttingen, herzlich für die Aufnahme in seine Arbeitsgruppe, für die inhaltliche Vorbereitung meines Laboraufenthaltes und für die Betreuung meiner Arbeit. Zahlreiche Anregungen und Gespräche mit ihm waren eine wesentliche Grundlage für meine hier vorliegende Dissertation. Herrn Professor Dr. Tomas P i e l e r, Abteilung Entwicklungsbiochemie im Biochemisches Institut der Universität Göttingen, möchte ich herzlich für die Übernahme der Betreuung im Rahmen des Promotionsverfahren danken. Für die Möglichkeit, in der Abteilung Molekulare Zellbiologie im Max-Planck-Institut für biophysikalische Chemie, Göttingen, zu arbeiten, danke ich herzlich Herrn Professor Dr. Peter G r u s s.

Bei allen Mitgliedern der Arbeitsgruppe um Professor Dr. Michael Kessel möchte ich mich herzlich für die Zusammenarbeit bedanken; in besonderer Weise bei Dr. Ulrike Teichmann für ihre grundlegenden Hilfen und Anleitungen zu Beginn meiner Laborarbeit beim Bakteriophagen-Screen; bei Dr. Hendrik Knötgen und Dr. Lars Wittler für ihre Bereitschaft, jederzeit meine molekularbiologischen, biochemischen oder embryologischen Fragen zu beantworten sowie für viele nützliche Hinweise von ihrer Seite; bei Michael Saborowski für seine Hilfen bei den In-situ-Hybridisierungen, bei Wiebke Behrens für ihren Einsatz bei der Erstellung der histologischen Schnitte sowie der New- und ec-Kulturen sowie bei Dr. Hyun-Jin Kim für ihre Freundlichkeit, ihre interessierten Fragen.

Wesentliche Hilfen in nahezu allen Gebieten meiner Arbeit habe ich von Dieter Treichel erhalten, dem ich dafür aufrichtig zu Dank verpflichtet bin. Dr. Nicole Bäumer ist für mich eine sehr wichtige und kritische Diskussionspartnerin geworden. Mit ihr zusammen sind die ersten schließlich erfolgreichen In-ovo-Elektroporationen zustande gekommen; ihre Einführung und ihr Engagement bei den EMSAExperimenten wurden eine Grundlage der in dieser Arbeit vorgestellten EMSA-Ergebnisse. Ich danke ihr für die freundschaftliche und produktive Zusammenarbeit. PD Dr. Ahmed Mansouri möchte ich für sein kontinuierliches Interesse an meiner Arbeit sowie verschiedene Hinweise im Bereich der molekularbiologischen Methoden danken.

Den folgenden Mitarbeitern der Abteilung Molekulare Zellbiologie um Professor Dr. Gruss möchte ich für Hilfen und Hinweise danken: Ralf Altschäffel, Wencke Armsen, Dr. Cornelius Bachmann, Martin Balastik, Dr. May-Britt Becker, Joachim Berger, Dr. Christopher Brink, Dr. Kamal Chowdury, Patrick Collombat, Silke Eckert, Dr. Bernd Föhring, Ullrich Franke, Sabine Geisendorf, Dr. Hans-Peter Geithe,

Dr. Guy Goudreau, Gundula Griesel, Sigurd Hille, Friederike Kirsch, Tobias Klöpper, Sven 
Mühlfriedel, Dr. Kay Nieselt-Struwe, Dr. Jan Schindehütte, Dr. Anastasia Stoykova, Dr. Tanja Vogel und Dr. Armin Zülich.

Gordon Dowe, Abteilung Molekulare Entwicklungsbiologie im Max-Planck-Institut für biophysikalische Chemie, Göttingen, hat es ermöglicht, den großen Klon Nummer 6 sehr schnell und in hervorragender Qualität zu sequenzieren. Thank you very, very much!

Aus der Arbeitsgruppe Keimzellentwicklung im Max-Planck-Institut für biophysikalische Chemie, Göttingen, möchte ich dem Leiter Dr. Erez Raz sowie Silke Eisenbeiss, Dr. Marion Köprunner, Stefan Rohr, Dr. Michal Reichmann-Fried und Dr. Gilbert Weidinger für ihre Hilfe und Mitarbeit im Rahmen der Injektionen der Reporterkonstrukte in die Zebrafischembryonen danken. In Zusammenarbeit mit Silke Eisenbeiss, Dr. Marion Köprunner und Dr. Michal Reichmann-Fried sind die in der Arbeit dargestellten Embryonen entstanden.

Die Einbeziehung des Syndroms der Septo-optischen Dysplasie in die vorliegende Arbeit wurde ermöglicht durch Förderung und Unterstützung von OÄ Dr. Hildegard Zappel, Dr. Clemens Freiberg (Kinderpoliklinik der Universität Göttingen), Professor Dr. Eckehard Wilichowski (Neuropädiatrie der Universität Göttingen), OA Dr. Christoph Müller-Löffelholz und Professor Dr. Hermann Mühlendyck (Augenklinik der Universität Göttingen, Abt. Neuroophthalmologie und Strabologie). Vielen Dank!

Hartmut Sebesse und Claus-Peter Adam, Mitarbeiter der Reprostelle des Max-Planck-Instituts für biophysikalische Chemie, Göttingen, haben mir bei der digitalen Umarbeitung der Entwürfe der Abbildungen dieser Arbeit sehr geholfen, wofür ich beiden herzlich danken möchte. Michael Zigan und Rainer Schürkötter (Werkstatt Feinmechanik F1 des Max-Planck-Instituts für biophysikalische Chemie, Göttingen) möchte ich für die schnelle und kompetente Umsetzung des Plans für die Elektroporationskammer danken, die die Grundlage für die von mir neu entwickelte Variante der Elektroporation geworden ist.

Mein Dank gilt der Studienstiftung des deutschen Volkes, in deren Förderung ich im Jahre 1999 aufgenommen wurde, gilt den Referenten der Studienstiftung in Bonn, Hella Kohrs und Heinz-Ulrich Nauels, sowie meinem Göttinger Vertrauensdozenten Professor Dr. Armin de Meijere für ihre nicht nur in Studienangelegenheiten beratende Tätigkeit wie auch für die mir gewährte finanzielle Unterstützung.

Von den Hochschullehrern der Universitäten Göttingen und Münster, an denen ich studiert habe, gebührt insbesondere Herrn Professor Dr. Erwin-Josef S p e c k m a n n, Institut für Physiologie, Westfälische Wilhelms-Universität Münster, mein besonderer Dank für studiumsbezogenen wie privaten Rat, den er mir in meinen ersten Semestern an der Universität zuteil werden ließ. 


\section{Förderungen}

1. Stipendium der Studienstiftung des deutschen Volkes seit April 1999.

2. Assoziierte Mitgliedschaft im Graduiertenkolleg "Molekulare Genetik der Entwicklung" der Medizinischen Fakultät der Universität Göttingen und des Max-Planck-Instituts für biophysikalische Chemie, Göttingen, seit August 2000 (Sprecher: Professor Dr. Tomas Pieler, Göttingen). 


\section{Lebenslauf}

Am 27. September 1975 bin ich als Sohn von Helga Spieler, geb. Stein, und Dr. phil. Karl-Heinz Spieler in Bremen geboren worden.

Nach einem Umzug meiner Eltern nach Hamburg im Jahre 1976 folgte 1980 der Umzug nach Essen, wo ich in den Jahren 1982 bis 1985 die Grundschule (Meisenburgschule in Essen-Bredeney) besuchte. Von 1986 bis 1995 besuchte ich das Gymnasium (Goetheschule, Essen-Bredeney) und legte dort im Juli 1995 meine Abiturprüfung ab. (Abiturfächer: Biologie und Geschichte als Leistungskurse, Latein und Kunst als Grundkurse.)

Vom September 1995 bis September 1996 leistete ich den Zivildienst auf der allgemeinen Chirurgiestation des Alfried-Krupp-Krankenhauses in Essen-Rüttenscheid ab.

Anschließend habe ich mich zum Wintersemester 1996/97 an der Westfälischen Wilhelms-Universität Münster für das Studienfach Humanmedizin immatrikuliert. Die ärztliche Vorprüfung (Physikum) habe ich im August 1998 in Münster abgelegt, den ersten Teil der ärztlichen Prüfung (erstes Staatsexamen) im August 1999, ebenfalls in Münster. In den Semesterferien dieser Zeit absolvierte ich zwei Laborpraktika in Münster: im Institut für Physiologie (Direktor: Herr Professor Dr. Erwin-Josef Speckmann) und in der der dermatologischen Universitätsklinik assoziierten Gruppe von Frau Professorin Dr. Leena Bruckner-Tudermann.

Seit dem Wintersemester 2000/2001 bin ich an der Georg-August-Universität Göttingen immatrikuliert. Sowohl in Münster als auch in Göttingen war ich studentische Hilfskraft im Rahmen von Kursen der Vorklinik (Kurs der makroskopischen Anatomie, "Anatomie am Lebenden", Kurs der Neurophysiologie). Während meines Studiums habe ich in Berlin, Göttingen und Köln in den Fächern Allgemeinmedizin, Innere Medizin, Kinderkardiologie und Neurochirurgie famuliert.

Im Februar 2000 habe ich meine Doktorarbeit im Labor von Herrn Professor Dr. Michael Kessel innerhalb der Abteilung Molekulare Zellbiologie des Max-Planck-Instituts für biophysikalische Chemie in Göttingen begonnen und - nach studienbedingter Unterbrechung der Laborarbeit im Wintersemester 2000/2001 und im Sommersemester 2001 - dann Ende 2002 abgeschlossen.

Göttingen, den 4.12.2002 